Pseudo Dynamic Testing and Seismic Rehabilitation of Iraqi Brick, Bearing and Shear Walls

Ghassan K. Al-Chaar, Steven C. Sweeney, Jonathan C. Trovillion, Orange S. Marshall, and Brendan Danielson

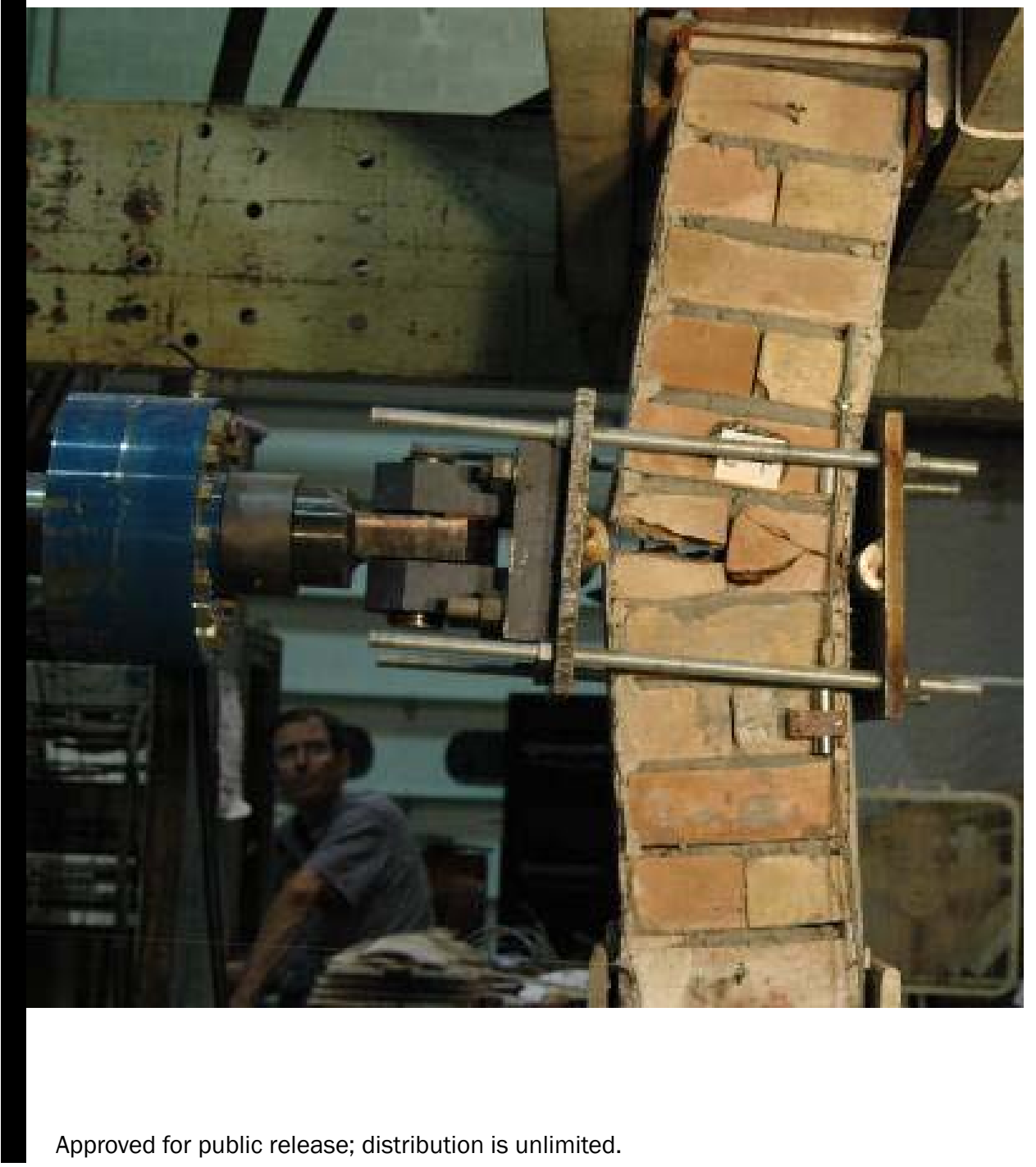




\section{Pseudo Dynamic Testing and Seismic Rehabilitation of Iraqi Brick, Bearing and Shear Walls}

Ghassan K. Al-Chaar, Steven C. Sweeney, Jonathan C. Trovillion, Orange S. Marshall, and Brendan Danielson

Construction Engineering Research Laboratory (CERL) U.S. Army Engineer Research and Development Center 2902 Newmark Dr.

Champaign, IL 61824

Final Report

Approved for public release; distribution is unlimited.

Prepared for U.S. Army Corps of Engineers

Washington, DC 20314-1000

Under Work Unit P2 140001 


\begin{abstract}
The Iraqi Village Project is a planned training center that will create a realistic training environment to simulate urban warfare in the Middle East. However, the materials, design, and construction methods typical in the Middle East do not provide adequate seismic protection. The Los Angeles District tasked the U.S. Army Engineer Research and Development Center, Construction Engineering Research Laboratory (ERDC-CERL) with developing alternative construction methods consistent with the overall project objectives and to test structural components to determine whether the alternative construction methods are adequate to withstand seismic design loads. ERDC-CERL conducted in-plane cyclic load tests on three double wythe panels and out-of-plane cyclic load tests on 24 double wythe wall strips of the same materials and construction to be used in the project. Unimproved walls and two alternative methods of strengthening were also tested. Elements to be addressed were the lack of adequate in-plane shear strength to resist lateral loads, and the lack of minimum reinforcement within the walls. Two surface applied overlay systems were considered as candidates for mitigating seismic risk. Results of the testing were analyzed and documented, and recommendations were made, including design detailing.
\end{abstract}

DISCLAIMER: The contents of this report are not to be used for advertising, publication, or promotional purposes. Citation of trade names does not constitute an official endorsement or approval of the use of such commercial products. All product names and trademarks cited are the property of their respective owners. The findings of this report are not to be construed as an official Department of the Army position unless so designated by other authorized documents. 


\section{Contents}

Figures and Tables.........................................................................................................................

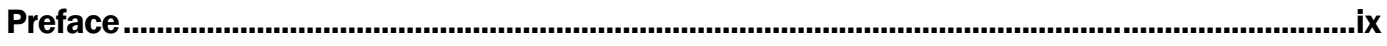

Unit Conversion Factors...........................................................................................................x

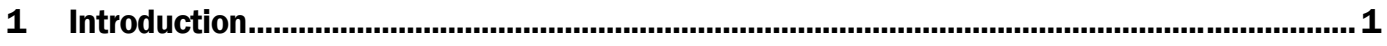

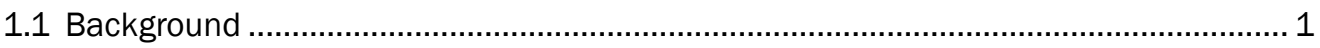

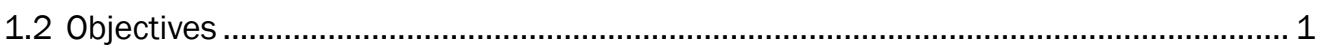

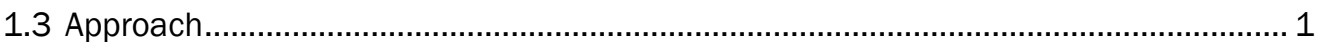

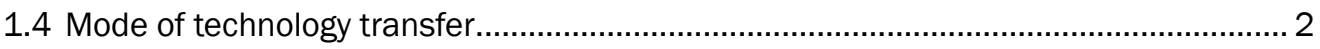

2 Literature Search....................................................................................................................... 3

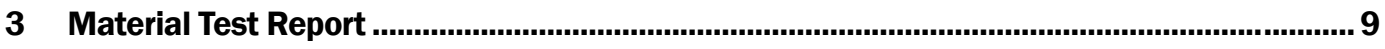

3.1 Compressive strength of brick units ................................................................... 9

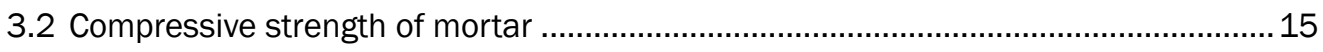

3.3 Compressive strength of masonry prisms ........................................................... 17

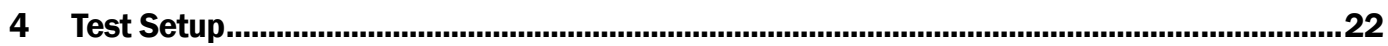

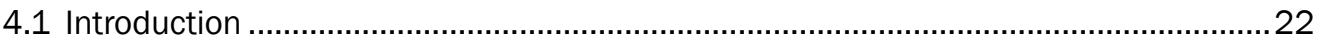

4.2 Description of the in-plane loading frame .............................................................. 24

4.3 Description of the out-of-plane loading frame........................................................... 25

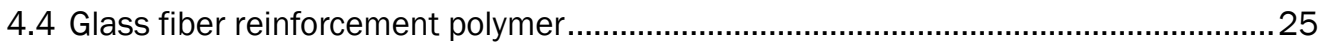

4.4.1 Procedure for applying the Sika Wrap Hex 100G 25

4.4.2 Procedure for applying the Saint Gobain Glass cement-base system 27

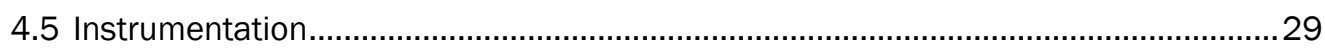

4.5.1 Instrumentation and data acquisition 29

4.5.2 Strain gauges $\quad 29$

4.5.3 Linear variable displacement transducers (LVDTs) 29

4.5.4 Absolute displacement transducers 30

4.5.5 Data acquisition and test control 30

4.6 Channels notation and description for the in-plane and out-of-plane testing............. 31

4.7 Selection of cyclic loading protocol for the masonry specimens..................................34

4.7.1 Investigation of existing cyclic loading methods 35

4.7.2 ACl method 36

4.7.3 ATC-24 method 36

$\begin{array}{lll}\text { 4.7.4 CUREe protocol } & 37\end{array}$

$\begin{array}{lll}\text { 4.7.5 SAC method } & 37\end{array}$

4.7.6 SEAOC method $\quad 38$

$\begin{array}{lll}\text { 4.7.7 Selection of loading history } & 38\end{array}$

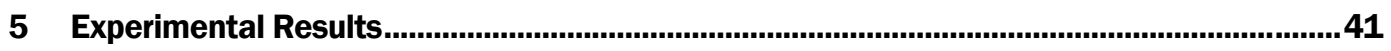

5.1 In-plane tests on wall specimens with and without FRP ........................................ 41

5.2 Modes of failure and experimental results for specimen IP-02 ................................ 41 
5.2.1 Specimen IP-C1 43

5.2.2 Specimen IP-G1 46

5.3 Experimental results for compression tests on wall strip specimens with and without FRP .50

5.3.1 Bare specimens $\quad 50$

5.3.2 Specimens with Saint Gobain cement-based GFRP 50

5.3.3 Specimens with Sika Wrap GFRP 52

5.4 Experimental results of the out-of-plane cyclic load on wall specimens with and

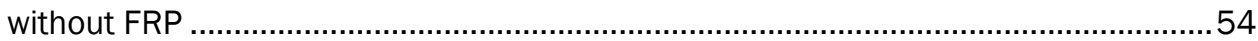

5.5 Out-of-plane tests of bare wall specimens .............................................................54

5.5.1 Specimen 04 (vertical load $=8.4 \%$ of $f^{\prime} \mathrm{m}$ ) 54

5.5.2 Specimen 06 (vertical load $=8.4 \%$ of $f^{\prime} \mathrm{m}$ ) 55

5.5.3 Specimen 07 (vertical load $=50 \%$ of $f^{\prime} \mathrm{m}$ ) 55

5.5.4 Specimen 09 (vertical load $=50 \%$ of $f^{\prime} m$ ) 56

5.5.5 Specimen 010 (vertical load $=25 \%$ of $f^{\prime} \mathrm{m}$ ) 56

5.5.6 Specimen 011 (vertical load $=75 \%$ of $f^{\prime} \mathrm{m}$ ) 56

5.5.7 Specimen 012 (vertical load $=75 \%$ of $f^{\prime} \mathrm{m}$ ) 56

5.6 Out-of-plane tests of wall specimens with saint gobain glass and cement based FRP. 58

5.6.1 Specimen C3 (vertical load $=6.3 \%$ of $f^{\prime} m$ ) $\quad 58$

5.6.2 Specimen C4 (vertical load $=6.3 \%$ of $f^{\prime} m$ ) $\quad 58$

5.6.3 Specimen C6 (vertical load $=25 \%$ of $f^{\prime} \mathrm{m}$ ) 58

5.6.4 Specimen C7 (vertical load $=25 \%$ of $f^{\prime} \mathrm{m}$ ) 59

5.6.5 Specimen C8 (vertical load $=50 \%$ of $f^{\prime} m$ ) 60

5.6.6 Specimen C5 (vertical load $=75 \%$ of $f^{\prime} \mathrm{m}$ ) 60

5.7 Out-of-plane tests of wall specimens with sika wrap FRP .........................................60

5.7.1 Specimen G3 (vertical load $=6.0 \%$ of $f^{\prime} m$ ) 60

5.7.2 Specimen G4 (vertical load $=6.0 \%$ of $f^{\prime} m$ ) 61

5.7.3 Specimen G6 (vertical load $=25 \%$ of $f^{\prime} \mathrm{m}$ ) 61

5.7.4 Specimen G5 (vertical load $=50 \%$ of $f^{\prime} m$ ) 61

5.7.5 Specimen G7 (vertical load $=50 \%$ of $f^{\prime} m$ ) 62

5.7.6 Specimen G8 (vertical load $=75 \%$ of $f^{\prime}{ }^{\prime}$ )

5.8 Summary of out-of-plane tests of wall specimens ..................................................63

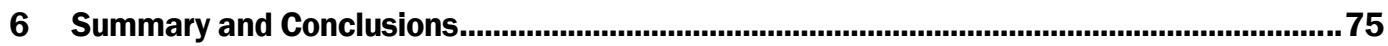

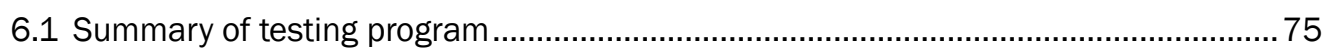

6.2 Conclusions relevant to design implications ...................................................... 78

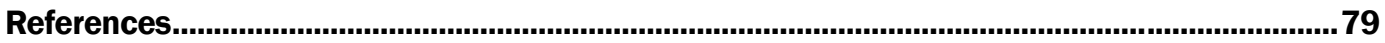

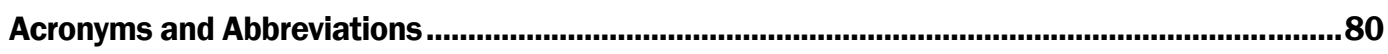

Report Documentation Page .................................................................................................................81 


\section{Figures and Tables}

\section{Figures}

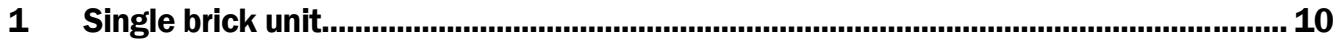

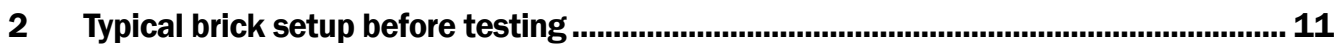

3 Typical failure of single brick unit under compressive load ...........................................11

4 Single brick from NNew 1, after testing ........................................................................... 12

5 Single brick from NOld 2, after testing .................................................................... 12

6 Single brick from NOld 1, after testing................................................................... 12

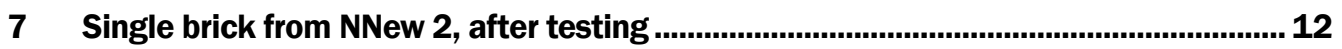

8 Single Brick from old batch \# 1, no fill, after testing................................................. 12

9 Single brick from new batch \#1, no fill, after testing ...................................................... 12

10 Single brick from old batch \#2, no fill, after testing ................................................. 13

11 Single brick from new batch \#2, no fill, after testing .................................................. 13

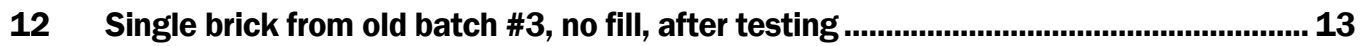

13 Single brick from new batch \#3, no fill, after testing .................................................... 13

14 Stress-strain curve for single brick from NOld 1..................................................... 13

15 Stress-strain curve for single brick from NNew 1 .................................................... 13

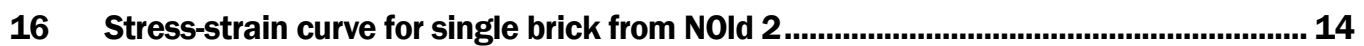

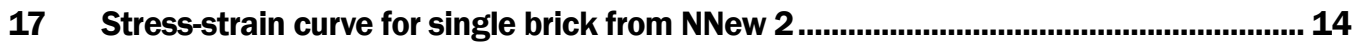

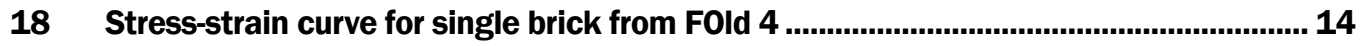

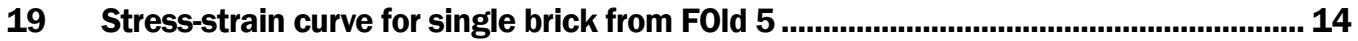

20 Stress-strain curve for single brick from FNew 5 ....................................................... 14

21 Stress-strain curve for single brick from FNew 6 ...................................................... 14

22 Mortar cube \#2 before testing …..................................................................................... 15

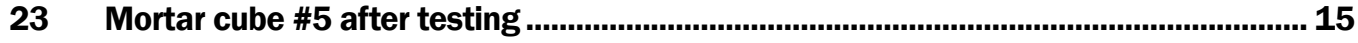

24 Stress-strain curves for Cube 2

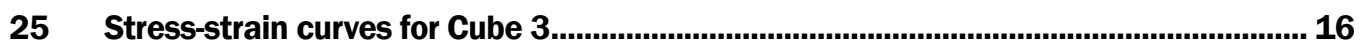

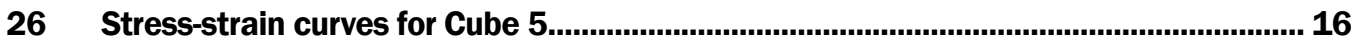

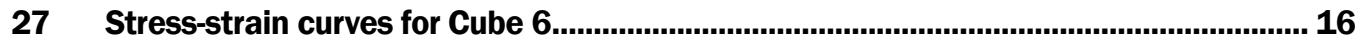

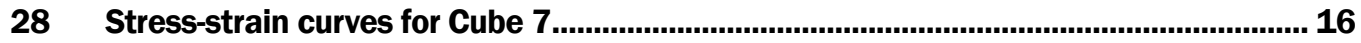

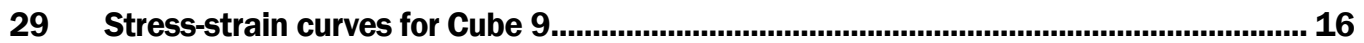

30 Prism from old batch \#2, before (left), after (right).................................................. 17

31 Prism from old batch \#2 after (left), after (right)........................................................... 17

32 Prism from new batch \#1, before (left) and after (right) .......................................... 18

33 Prism from new batch \#2 after (left), after (right).............................................................. 18 


\section{Figures}

34 Prism from new batch with cementitious reinforcement \#1, before (left), after (right)18

35 Prism from old batch with glass reinforcement, before (left), after (right) .................. 18

36 Prism from old batch with cementitious reinforcement, before (left), after (right)...... 19

37 Prism from new batch with cementitious reinforcement, after .................................... 19

38 Prism from new batch with glass reinforcement, before (left), after (right) ................. 19

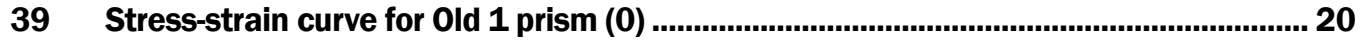

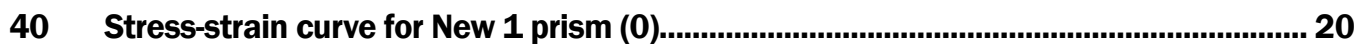

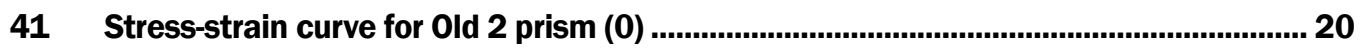

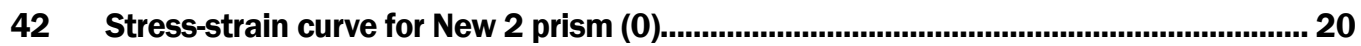

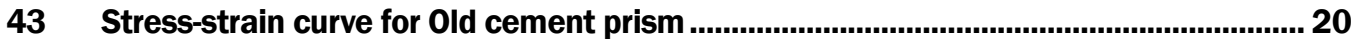

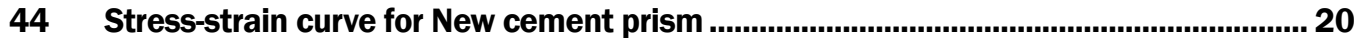

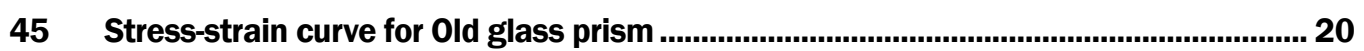

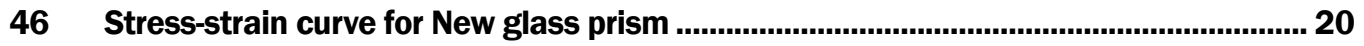

47 Bare wall (left), Saint Gobain cementitious FRP System (center), and SikaWrap FRP system (right) ..................................................................................................................... 22

48 Brick configuration as instructed by the sponsor ....................................................... 23

49 Representative specimens of all series tested under pure compression, bare specimen (left), Saint Gobain cementitious FRP system (center), and SikaWrap FRP system (right)

50 Representative specimens of all series tested under out-of-plane cyclic load combined with various levels of vertical loads, bare specimen (left), Saint Gobain cementitious FRP system (center), and SikaWrap FRP system (right)........................ 24

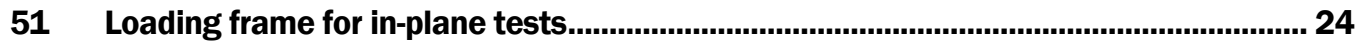

52 A sketch of the out-of-plane-test setup..................................................................... 25

53 SikaWrap fabric ......................................................................................................... 26

54 Coated Saint Gobain glass grid produced by Saint Gobain technical fabrics.............. 28

55 Functional block diagram of instrumentation, data acquisition, and test control systems....................................................................................................................... 31

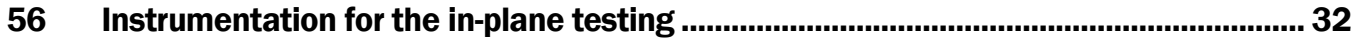

57 Instrumentation for the out-of-plane plane testing........................................................ 33

58 Test specimen notation ............................................................................................... 34

59 Modified CUREe loading history used for all lab specimens ...................................... 40

60 The modes of failure for IP-02 specimens.............................................................. 42

61 Specimen IP02 hysteresis curve for load versus displacement and backbone curves43

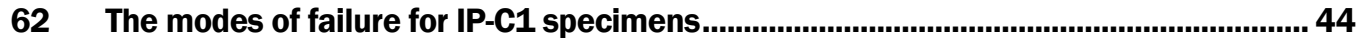

63 IPC1 pretest ................................................................................................................ 45

64 IPC1 cyclic with backbone curve ............................................................................. 46

65 The modes of failure for IP-C1 specimens................................................................. 46

66 The modes of failure for IP-G1 specimens....................................................................... 48 


\section{Figures}

67 IPG1 stress-displacement hysteresis with backbone .................................................... 49

68 IPG1 Stress-deformation under monotonic loading......................................................... 49

69 Two unprotected wall strip specimens tested under pure compression load............... 51

70 Two Saint Gobain GFRP protected wall strip specimens tested under pure compression load .................................................................................................................... 51

71 Two unprotected wall strip specimens tested under pure compression load................ 53

72 Deformation of specimens 04 and 06 under cyclic and low level vertical load ........... 55

73 Bare Specimen 010, before test (left) and after test (right) ........................................56

74 Deformation of specimens 07 and 09 under cyclic and low level vertical load........... 57

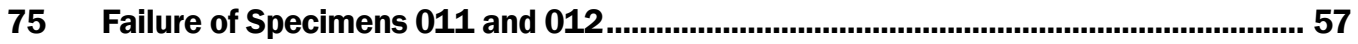

76 Deformation of specimens 04 and 06 under cyclic and low level vertical load ........... 58

77 Deformation of specimens $\mathbf{C 6}$ and $\mathrm{C7}$ under cyclic and low level vertical load ........... 59

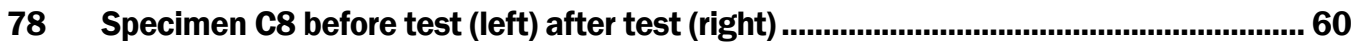

79 Saint Gobain Cement-Base Specimen C5, before test (left) after test (right) ..............60

80 Deformation of specimens 04 and 06 under cyclic and low level vertical load ...........61

81 Specimen G6 with SikaWrap Hex, before test (left) after test (right) ............................ 62

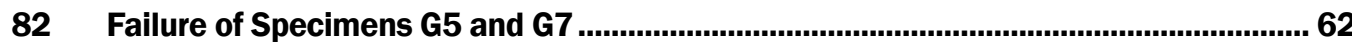

83 Specimen G8 with Sika Wrap Hex, before test (left), and sketch showing the point of

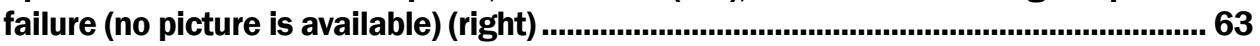

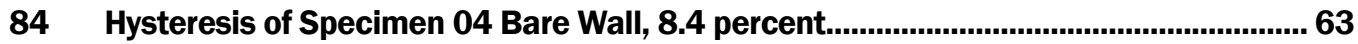

85 Hysteresis of Specimen 06 Bare Wall, 8.4 percent........................................................ 64

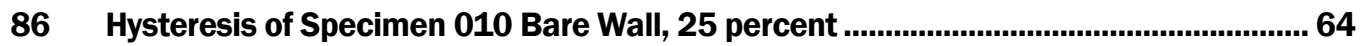

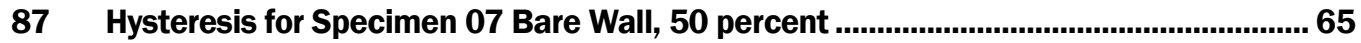

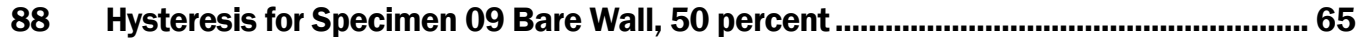

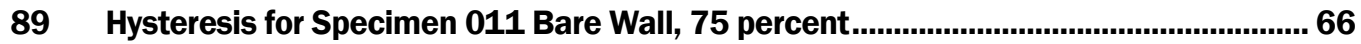

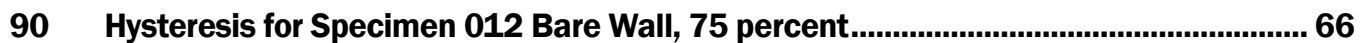

91 Hysteresis Specimen C3 Saint Gobain Glass with Cement Base FRP, 6.3 percent..... 67

92 Hysteresis of Specimen C4 Saint Gobain Glass with Cement Base FRP, 6.3 percent 67

93 Hysteresis of Specimen C6 Saint Gobain Glass with Cement Base FRP, 25 percent . 68

94 Hysteresis of Specimen C7 Saint Gobain Glass with Cement Base FRP, 25 percent . 68

95 Hysteresis for Specimen C8 Saint Gobain Glass with Cement Base FRP, 50 percent 69

96 Hysteresis for Specimen C5 Saint Gobain Glass with Cement Base FRP, 50 percent 69

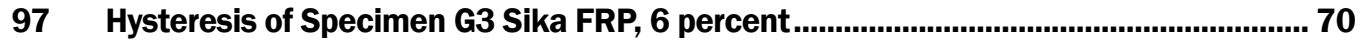

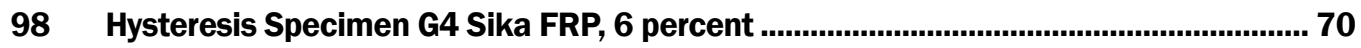

99 Hysteresis Specimen G6 Sika FRP, 25 percent.......................................................... 71

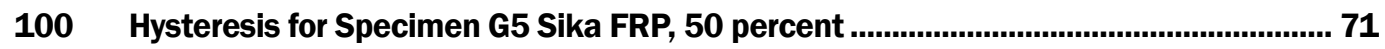

101 Hysteresis for Specimen G7 Sika FRP, 50 percent ...................................................... 72 


\section{Figures}

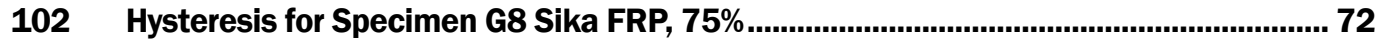

103 Axial stress v. maximum stress for each specimen type...........................................74

104 Proposed design section details in the construction................................................. 78

\section{Tables}

1 Summary of References and their relevant parameters ...................................................8

2 Average brick dimensions based on 10 randomly selected samples............................ 10

3 Summary of maximum compressive stress and corresponding strain of single

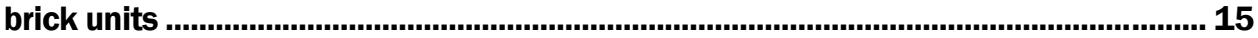

4 Summary of maximum compressive stress and corresponding strain of mortar cubes ................................................................................................................................... 16

5 Summary of maximum compressive stress and corresponding strain of prisms......... 21

6 Materials used for SikaWrap and their proportions.................................................... 26

7 Basic Material properties of 27 oz GFRP unidirectional glass with its epoxy matrix......................................................................................................................................... 26

8 Saint Gobain glass cement-base system ............................................................. 28

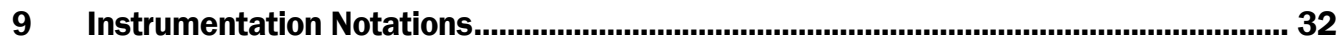

10 All tested specimens, dates, and vertical load control type ........................................ 33

11 ATC-24 Method type and number of cycles .......................................................... 36

12 SAC method description .............................................................................................37

13 Comparison of different cyclic loading methods......................................................... 39

14 Geometric properties of the walls and their design stress ......................................... 41

15 Summary of maximum stress and displacement............................................................ 50

16 Summary of pure compression tests forces and stresses ........................................... 53

17 Selected vertical loads for out-of-plane testing............................................................ 54

18 Summary of the maximum stresses and their corresponding displacements and maximum displacements and their corresponding stresses for all out-of-plane tests

19 Maximum shear stresses for all series under various vertical loading ..........................74

20 Summary of maximum stress and displacement............................................................76

21 Summary of Pure Compression Tests Forces and Stresses:............................................76

22 Summary of the maximum stresses and their corresponding displacements and maximum displacements and their corresponding stresses for all out-of-plane tests 


\section{Preface}

This reimbursable research project was conducted for Los Angeles District under Customer Order W81EYN70935664, 53211K Work Unit, P2 140001, "Structural Testing for Iraqi Village Project in Fort Irwin."

The work was performed by the Materials and Structures Branch (CF-M) of the Facilities Division (CF), Construction Engineering Research Laboratory (CERL). The CERL Principal Investigators were Dr. Ghassan Al-Chaar and Steven Sweeney. The CERL Program Manager was Kirk McGraw. Vicki L. VanBlaricum is Chief, CEERD-CF-M and L. Michael Golish is Chief, CEERD-CF. The Technical Director of the Facility Acquisition and Revitalization business area is Martin J. Savoie, CEERD-CV-ZT. The Director of CERL is Dr. Ilker Adiguzel.

CERL is an element of the U.S. Army Engineer Research and Development Center (ERDC), U.S. Army Corps of Engineers. The Commander and Executive Director of ERDC is COL Richard B. Jenkins, and the Director of ERDC is Dr. James R. Houston. 


\section{Unit Conversion Factors}

\begin{tabular}{|c|c|c|}
\hline Multiply & By & To Obtain \\
\hline cubic feet & 0.02831685 & cubic meters \\
\hline cubic inches & 1.6387064 E-05 & cubic meters \\
\hline cubic yards & 0.7645549 & cubic meters \\
\hline degrees (angle) & 0.01745329 & radians \\
\hline degrees Fahrenheit & $(F-32) / 1.8$ & degrees Celsius \\
\hline feet & 0.3048 & meters \\
\hline foot-pounds force & 1.355818 & joules \\
\hline gallons (U.S. liquid) & 3.785412 E-03 & cubic meters \\
\hline inches & 0.0254 & meters \\
\hline inch-pounds (force) & 0.1129848 & newton meters \\
\hline miles (U.S. statute) & $1,609.347$ & meters \\
\hline miles per hour & 0.44704 & meters per second \\
\hline square feet & 0.09290304 & square meters \\
\hline square inches & $6.4516 \mathrm{E}-04$ & square meters \\
\hline square feet & 0.09290304 & square meters \\
\hline square inches & $6.4516 \mathrm{E}-04$ & square meters \\
\hline square miles & $2.589998 E+06$ & square meters \\
\hline square yards & 0.8361274 & square meters \\
\hline tons (nuclear equivalent of TNT) & 4.184 E+09 & joules \\
\hline tons (2,000 pounds, mass) & 907.1847 & kilograms \\
\hline tons $(2,000$ pounds, mass) per square foot & $9,764.856$ & kilograms per square meter \\
\hline yards & 0.9144 & meters \\
\hline
\end{tabular}




\section{Introduction}

\subsection{Background}

The Iraqi Village Project, a planned training center for the U.S. Army soldiers, will be located in a high seismic zone in California. The intent of the project is to create a realistic training environment that represents urban warfare in the Middle East. The construction features, configuration, architecture, and material will represent a typical neighborhood in Iraq. One significant problem is that the materials, design, and construction methods typical in the Middle East do not provide adequate seismic protection. The Los Angeles District tasked the U.S. Army Engineer Research and Development Center, Construction Engineering Research Laboratory (ERDCCERL) with developing alternative construction methods consistent with the overall project objectives and to test structural components to determine whether the alternative construction methods are adequate to withstand seismic design loads. ERDC-CERL conducted in-plane cyclic load tests on three double wythe panels and out-of-plane cyclic load tests on 24 double wythe wall strips of the same materials and construction to be used in the project. Unimproved walls and two alternative methods of strengthening were also tested.

\subsection{Objectives}

The objective of this study was to evaluate the effectiveness of two types of composite reinforcement systems surface-applied to walls constructed of the materials to be used in the Iraqi Village Project, to improve seismic performance.

\subsection{Approach}

Researchers reviewed the initial design concepts for the Iraqi Village Project and commented on several design issues related to the seismic safety of the proposed project. The two key elements that needed to be addressed were the lack of adequate in-plane shear strength to resist lateral loads, and the lack of minimum reinforcement within the walls. Two surface applied overlay systems were considered as candidates for mitigating seismic risk.

A series of laboratory tests were conducted to evaluate the effectiveness of the two systems applied to the specific materials and construction meth- 
ods used in the Iraqi Village Project. In-plane cyclic load tests on three double wythe panels and out-of-plane cyclic load tests on 24 double wythe wall strips were conducted. A bare (unimproved) wall and strips and walls and strips strengthened with Glass Fiber Reinforced Polymer (GFRP) were tested. The two GFRP systems used were SikaWrap Hex 100G and Saint Gobain Tech-Feb Super FibaCrete (SFC). Additional testing was done to determine the basic material properties of the component materials.

Observations were recorded during testing. Results of the testing were analyzed and documented. Recommendations were made based on the test results and observations, including design detailing.

\subsection{Mode of technology transfer}

This report will be made accessible through the World Wide Web (WWW) at URL:

http://www.cecer.army.mil 


\section{Literature Search}

ElGawady constructed half-scale, single-wythe walls using half-scale hollow clay brick masonry units $(150 \times 75 \times 95 \mathrm{~mm})$. The specimens were built using weak type $\mathrm{M}$ mix mortar. He tested three reference specimens to failure (one with a moment/shear ratio of 0.67 and two with moment/shear ratios of 0.5), then repaired them by applying fiber-reinforced polymer (FRP). He also tested one specimen with a moment/shear ratio of 0.5, which had FRP applied directly after construction. In his investigation, ElGawady found that the increase of the ultimate in-plane lateral strength of each specimen was positively influenced by the axial rigidity of the FRP used. The ultimate strength increased from 141 to 590 percent when the FRP axial rigidity was increased from 0.05 to $0.28 \mathrm{GPa}$ in the specimens with moment/shear ratio of 0.7. In the specimens with moment/shear ratios of 0.5, the increase in ultimate lateral strength was proportional to the FRP axial rigidity (ElGawady, Pierino, and Badoux 2007).

Korany tested full-size wall panels under out-of-plane monotonically increasing uniform lateral pressure using an airbag. The walls were constructed in double-wythe using jumbo size brick units and type $\mathrm{O}$ mortar. The FRP used was a procured, $5 \mathrm{~mm}$-diameter carbon fiber composite cable (CFCC), which is fed into grooves cut into the wall and adhered using epoxy. Using minimal reinforcement to retrofit a wall resulted in a 25 percent increase in the ultimate capacity and three times the energy absorption. Horizontal and vertical intermittently bonded reinforcement permitted large rotations to take place and allowed energy dissipation through cracking, debonding of CFCC, and masonry deformations at high load levels. The wall failed in tension mode by rupture of the CFCC. The test results demonstrated the high efficiency of the proposed unobtrusive FRP rehabilitation techniques. Significant increases in ultimate capacity, energy absorption, and deformability were achieved for various reinforcing schemes compared to the behavior of the corresponding unreinforced walls. Despite the absence of a post-peak plateau in the load-displacement response, FRP reinforced walls showed significant capability to accommodate large displacements and absorb energy through elastic deformations before failure (Korany and Drysdale 2006). 
Velazquez constructed four half-scale slender masonry walls using solid clay bricks with dimensions of $49 \times 38 \times 102 \mathrm{~mm}$. The units were bonded with a low-strength capacity Type $\mathrm{N}$ mortar. Each specimen had a heightthickness ratio of 28 . Three of the walls were single wythe and the fourth was double wythe. Mortar joints were $1 / 4$ in. thick. The single-wythe specimens were retrofitted with three vertical strips of glass fabric bonded on two sides (six strips total). The double-wythe wall was strengthened on one side only. The composite strips were bonded with an epoxy resin using the wet layup procedure. The four walls were tested in a steel reaction frame, simply supported at the top and bottom edges. Cyclic out-of-plane loads were applied through an airbag system.

A single-wythe specimen was symmetrically strengthened with three vertical composite strips on both sides; it had a reinforcement ratio equivalent to the balanced condition. Fairly symmetrical behavior was observed for both wall faces. Rotations were observed on the vertical edges, indicating how the composite strips can transform a brittle wall into a flexible one. Failure load was nearly 13 times the weight of the wall, and maximum deflection was almost 4 percent of the span. Cracking occurred along the mortar joints and delamination occurred along around 75 percent of the area of the strips.

Another single-wythe specimen was fully covered on both sides with the same fabric, resulting in a reinforcement ratio equivalent to three times the balanced condition. Velazquez observed very stiff behavior. Failure occurred with shear failure of the brick. The wall supported lateral pressures equivalent to almost 24 times its own weight. The maximum deflection was $1 / 50$ the wall span, which was almost 13 times the allowable value without reinforcement. A third, single-wythe specimen with varying reinforcement on each side of the wall (half the balanced condition on south face and twice the balanced condition on the north face) had three modes of failure: tensile fracture of the composite strips on the south face, delamination on the north face, and crushing of masonry on the south face.

The wall supported pressures equivalent to 7 and 23 times its own weight for the south and north faces, respectively. Deflection capabilities were 18 and 30 times the maximum allowable deflection if unreinforced for the south and north faces, respectively. Better energy dissipation was developed on the north face. A fourth, double-wythe specimen, with a header course placed every six courses, was reinforced equivalent to the balanced condition on one face only. Bed joint cracks, delamination, splitting of the 
wythes, and sliding of the reinforced wythe along two bed-joint cracks caused failure. It was capable of deflecting a span drift of 17 times the allowable deflection if it was unreinforced. It supported pressures in excess of five times its weight.

Velazquez found that specimens with lower reinforcement ratios exhibited a more ductile behavior, and therefore, the reinforcement ratio should be limited to two times that of the balanced failure to avoid very stiff behavior and to improve hysteretic response. Strength and deformation capacity of the retrofitted walls were significantly enhanced; retrofitted walls resisted pressures ranging from 5 to 24 times the weight of the wall and deflected as much as 5 percent of the wall height. The described retrofitting technique is very efficient. The retrofitted walls failed by one of these five modes: tension in composite fabrics, compression in brick, excessive delamination of the fabric, horizontal shear failure of the brickwork, and in the case of the double-wythe wall, interface shear failure. In general, the load resisted by the specimens that caused the first bed-joint crack, first delamination and ultimate failure appeared to be directly proportional to the reinforcement ratio (Velazques-Dimas, Ehsani, and Saadatmanesh 2000).

Experimental investigations by Hamed and Rabinovitch (2007) showed that the use of externally bonded FRP laminates leads to an increase of up to 50 times in the strength of the masonry wall for out-of-plane tests. The bonded laminates also enhance the ductility of the strengthened masonry wall and provide it with the ability to dissipate energy by cracking of the joints. Along with the improved stiffness, strength, and ductility, the experimental studies also revealed a broad range of physical phenomena that characterize the behavior of the strengthened wall. These unique physical phenomena include rupture of the FRP strip or crushing of the masonry at the mortar joints; debonding of the FRP strip; sliding of the masonry units (mortar slip); flexural shear cracking near the corners of the masonry unit; and outward buckling/wrinkling of the compressed FRP strip.

Al-Chaar and Hasan constructed two unreinforced CMU wall panels on two reinforced concrete base beams. Each panel was $6 \mathrm{ft} \mathrm{high,} 9 \mathrm{ft} 3.5 \mathrm{in}$. long, and 8 in. thick and was built from $8 \times 8 \times 16$ in. standard CMU using an N-type mortar. Each reinforced-concrete $(\mathrm{R} / \mathrm{C})$ base beam was 8 in. high, $10 \mathrm{ft}$ long, and $2 \mathrm{ft}$ wide. Walls were spaced $8 \mathrm{ft}$ apart with a reinforced concrete slab $8 \mathrm{in}$. thick, $9 \mathrm{ft} 3.75 \mathrm{in}$. by $10 \mathrm{ft} 10 \mathrm{in}$. simply supported on the two walls. The North wall was reinforced after construction, 
and the South wall was initially unreinforced until cracking first appeared during testing, after which it was retrofitted. Each wall had only one side reinforced. The overlay material used was the Hexcel-Fyfe TYFO ${ }^{\mathrm{TM}}$ system, which consists of a fiberglass fabric combined with special epoxies to create a high-strength, lightweight structural laminate.

Al-Chaar found that applying composite overlay material to only one side of an unreinforced masonry wall can increase both the in-plane and outof-plane strength of the wall and can enhance its seismic resistance, due to the composite material's resistance to slippage in the cracks and its ability to increase arching action where cracks have formed, specifically:

- Overlay composite material controls crack size and out-of-plane slippage and improves the wall's deformation and tension capacity

- The overall load capacity of the walls increased significantly when rehabilitated or retrofitted

- Al-Chaar suggests that the connection of the walls to the roof and foundation is the weak link in existing unreinforced masonry structures. Enhancing seismic performance will not be achieved without the application of an appropriate connection anchoring system that would include extending or wrapping the overlay composite material between the wall and the foundation

The results found are applicable only to systems with two parallel walls connected by a rigid diaphragm (Al-Chaar and Hasan 2002).

Velazquez tested two half-scale single-wythe unreinforced masonry (URM) walls under out-of-plane cyclic loading. The small-scale bricks were cut from solid clay bricks and had dimensions of $102 \times 49 \times 38 \mathrm{~mm}$. Type $\mathrm{N}$ mortar was used. The walls were $1220 \mathrm{~mm}$ wide and $50 \mathrm{~mm}$ thick. The slender wall was $1420 \mathrm{~mm}$ high and the short one was $710 \mathrm{~mm}$ high. Unidirectional glass fabric weighing $18 \mathrm{oz}$ per square yard was used for retrofitting the walls. The slender specimen was strengthened with three symmetrically placed vertical strips on each face, an amount that would cause balanced failure of the wall. The wall strip specimen was strengthened in a nonsymmetric way by applying 75 percent of the material required for the balanced condition on the north face and 25 percent on the south face.

After testing, it was determined that strength and ductility of URM masonry walls can be substantially enhanced through retrofitting with glass fabric composite strips. The short and the slender wall supported lateral pressures equivalent to 31 and 13 times the weight of the wall, respectively. 
Deflection drifts of 4 percent and 2.5 percent were measured for the slender and the short wall, respectively. Despite the tension failure observed on the north face of the slender wall, delamination process appeared to control the behavior of both walls (Velazquez, Ehsani, and Saadatmanesh 1998).

Berman, Al-Chaar, and Dutta constructed 100 triplet samples using three standard brick units each, nominal dimensions $8 \times 2 \frac{1}{1 / 2} \times 4$ in. The bricks were connected using 3.8-in. joints of N-type mortar made of Portland cement, lime, and sand in proportions of 1:1:6 by volume, respectively. The middle brick in each triplet was offset 0.5 in. relative to the adjacent bricks to provide load transfer from exterior brick surfaces to the mortar joints during lateral (shear) loading. Some triplet samples were reinforced with FRP overlays, which consisted of glass/epoxy patches measuring $2 \times 7.5$ in. These patches were applied across all three brick courses to within $1 / 8$ in. of the surfaces designated to bear the comprehensive (normal) load.

The samples were organized into three test series, designated o, I, II. Series o had no FRP patches applied; Series I triplets had an FRP patch applied on one side only; Series II triplets had an FRP patch applied to both sides. The mortar was allowed to cure 30 days before application of the FRP and/or testing of the triplets. Prior to FRP application, all samples were thoroughly cleaned with a wire brush using at least 60 strokes on both sides of the triplet. The FRP consisted of plain weave E-glass fabric embedded in an epoxy resin. The epoxy used was a standard roomtemperature-cure bisphenol A epoxide with a polyamine curing agent. A thin layer of epoxy was used to prime either one side or both sides of the Series I or Series II triplets. FRP upgraded triplets were allowed to completely cure for 2 days.

With FRP applied to Series I and II, Series I loaded at 25 percent normal capacity, the shear capacity increased by a factor of 6.32 . For a Series I and II specimens loaded at 25 percent normal capacity, the shear capacity increased by factors of 2.60 and 2.66, respectively. Another observation also showed that under normal loading, the relative gain in shear capacity was lower for the FRP-upgraded specimens than for the Series o triplets. In a test looking for ultimate displacement increase while under normal load, Series o under a 25 percent normal load increased in ultimate displacement by a factor of 13.13 with respect to the pure shear case. Under the same normal load, the ultimate displacement of a Series I increased by a factor of only 6.77 and the Series II only increased by a factor of 4.47 under 
the same normal load. Under a pure normal load of 100 percent, the crushing strength Series I decreased in normal capacity by 9 percent and Series II remained constant (2 percent average increase).

In every test that included any normal load component, the application of FRP decreased shear capacity as compared with bare specimens. One commonality found in all three triplet series is that the presence of a normal load below 12.5 percent produces a general increase in shear capacity followed by a shear failure of the brick/mortar surface. The application of FRP increased the ultimate displacement for the pure shear loading case. However, when normal loads were introduced, no clear trend in ultimate displacement was evident (Berman, Al-Chaar, and Dutta 2002).

Table 1 lists literature cited in this report and relevant parameters.

Table 1. Summary of References and their relevant parameters

\begin{tabular}{|l|l|l|l|l|l|}
\hline References & Types of masonry & $\begin{array}{c}\text { Types of } \\
\text { Mortar }\end{array}$ & Type of Test & \multicolumn{1}{|c|}{ Wythe } & \multicolumn{1}{|c|}{$\begin{array}{c}\text { FRP Used } \\
\text { No. Sides }\end{array}$} \\
\hline $\begin{array}{l}\text { Al-Chaar } \\
(2002)\end{array}$ & CMU & N-Type & Dynamic & Single & $\begin{array}{l}\text { Hexcel-Fyfe } \\
\text { TYFOTM/one side }\end{array}$ \\
\hline $\begin{array}{l}\text { Berman } \\
(2002)\end{array}$ & Brick Prisms & N-Type & Monotonic & Single & $\begin{array}{l}\text { glass/epoxy } \\
\text { patches }\end{array}$ \\
\hline $\begin{array}{l}\text { ElGawady } \\
(2007)\end{array}$ & Hollow clay brick & M-type & In-plane & $\begin{array}{l}\text { Half-scale, } \\
\text { Single wythe }\end{array}$ & $\begin{array}{l}\text { GFRP, aramid fiber- } \\
\text { reinforced polymer } \\
\text { (AFRP) }\end{array}$ \\
\hline $\begin{array}{l}\text { Hamed } \\
(2006)\end{array}$ & N/A & N/A & Out-of-plane & N/A & N/A \\
\hline $\begin{array}{l}\text { Korany } \\
(2006)\end{array}$ & Brick & N/A & Out-of-plane & Double & $\begin{array}{l}\text { Carbon fiber com- } \\
\text { posite cable }\end{array}$ \\
\hline $\begin{array}{l}\text { Velazquez } \\
(1998)\end{array}$ & Solid clay brick & Type N & Out-of-plane & $\begin{array}{l}\text { Half-scale, } \\
\text { single wythe }\end{array}$ & $\begin{array}{l}\text { Unidirectional glass } \\
\text { fabric/ } \\
\text { \# sides varies }\end{array}$ \\
\hline $\begin{array}{l}\text { Velazquez } \\
(2000)\end{array}$ & Solid clay brick & Type N & $\begin{array}{l}\text { Cyclic out-of- } \\
\text { plane with } \\
\text { airbag }\end{array}$ & $\begin{array}{l}\text { Single and } \\
\text { double }\end{array}$ & $\begin{array}{l}\text { GFRP / Both sides } \\
\text { for single, one side } \\
\text { for double }\end{array}$ \\
\hline
\end{tabular}




\section{Material Test Report}

This chapter describes the basic mechanical properties of the materials used to construct the laboratory specimens.

\subsection{Compressive strength of brick units}

Specimens were built using brick provided by Los Angeles District. The brick was manufactured in Mexico and intended to have similar properties to that used in Iraq. Two batches of brick were received, referred to here as "old" and "new" batches. Figure 1 shows a single brick. The clay-fired unit consists of softer material than that used in the United States. The variation in brick dimensions is significant compared to U.S. materials. The average dimensions, based on 10 samples selected at random, were $8.78 \mathrm{in}$. long, $2.88 \mathrm{in}$. high and $4.41 \mathrm{in}$. wide. The bricks contained grooves on the top surface, measuring on the average $5.95 \mathrm{in}$. long, $2.25 \mathrm{in}$. wide, and $1 \mathrm{in}$. deep. Table 2 lists the dimensions of the 10 samples.

Compressive strength tests of the brick were performed according to the ASTM C67. The brick units have grooves, which is atypical of U.S. units, therefore they were tested both with and without mortar filling the grooved area. Compressive strength for the mortar-filled brick is calculated based on the cross-sectional area while the compressive strength of brick units with no mortar fill (equivalent to face shell bedding with concrete masonry units) was calculated based on net facial area around the grooves. Figure 2 shows a typical brick setup before testing and Figure 3 shows a typical failure of single brick unit under compressive load. Figures 4 through 13 show the different modes of failure of various specimens. Figures 14 through 21 show stress-strain curves for these tests. Table 3 lists maximum compressive stress and corresponding strain of single brick units. The average flat-wise compression stress for the units is 766 psi. 


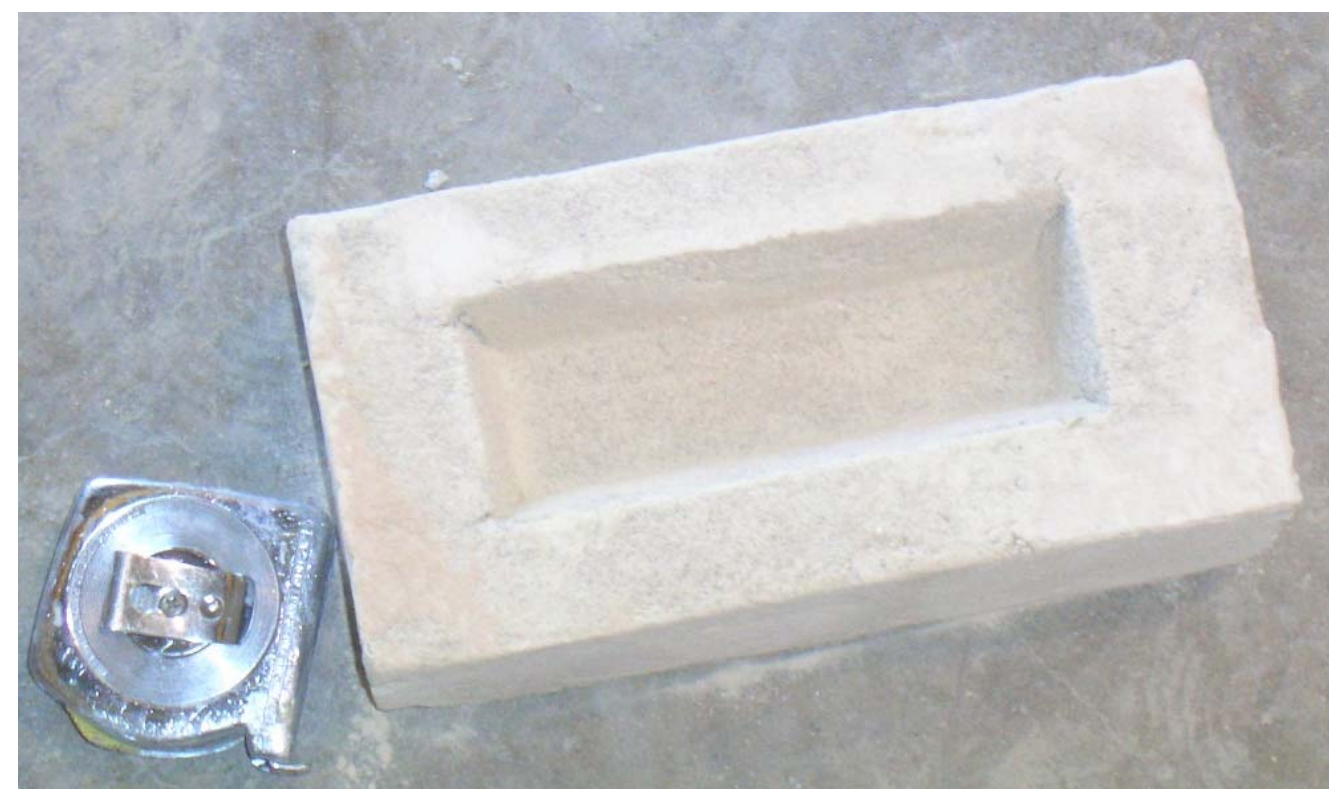

Figure 1. Single brick unit.

Table 2. Average brick dimensions based on 10 randomly selected samples.

\begin{tabular}{|l|l|l|c|c|c|c|c|c|}
\hline \multirow{2}{*}{ ID } & \multirow{2}{*}{ Height } & \multicolumn{3}{|c|}{ Perimeter } & \multicolumn{3}{c|}{ Groove } \\
\cline { 3 - 8 } & Length & Width & Area & Length & Width & Area & Net Area \\
\hline 1 & 2.88 & 8.88 & 4.38 & 38.83 & 6.00 & 2.13 & 12.75 & 26.08 \\
\hline 2 & 3.00 & 8.88 & 4.38 & 38.83 & 6.06 & 2.25 & 13.64 & 25.19 \\
\hline 3 & 2.75 & 8.75 & 4.50 & 39.38 & 5.94 & 2.38 & 14.10 & 25.27 \\
\hline 4 & 2.75 & 8.75 & 4.38 & 38.28 & 5.94 & 2.25 & 13.36 & 24.92 \\
\hline 5 & 2.88 & 8.75 & 4.31 & 37.73 & 5.88 & 2.13 & 12.48 & 25.25 \\
\hline 6 & 2.88 & 8.81 & 4.50 & 39.66 & 5.94 & 2.25 & 13.36 & 26.30 \\
\hline 7 & 2.88 & 8.75 & 4.38 & 38.28 & 5.88 & 2.25 & 13.22 & 25.06 \\
\hline 8 & 2.94 & 8.81 & 4.44 & 39.11 & 5.88 & 2.25 & 13.22 & 25.89 \\
\hline 9 & 2.88 & 8.69 & 4.38 & 38.01 & 6.00 & 2.25 & 13.50 & 24.51 \\
\hline 10 & 2.94 & 8.75 & 4.44 & 38.83 & 6.00 & 2.25 & 13.50 & 25.33 \\
\hline Average & 2.88 & 8.78 & 4.41 & 38.69 & 5.95 & 2.24 & 13.31 & 25.38 \\
\hline
\end{tabular}




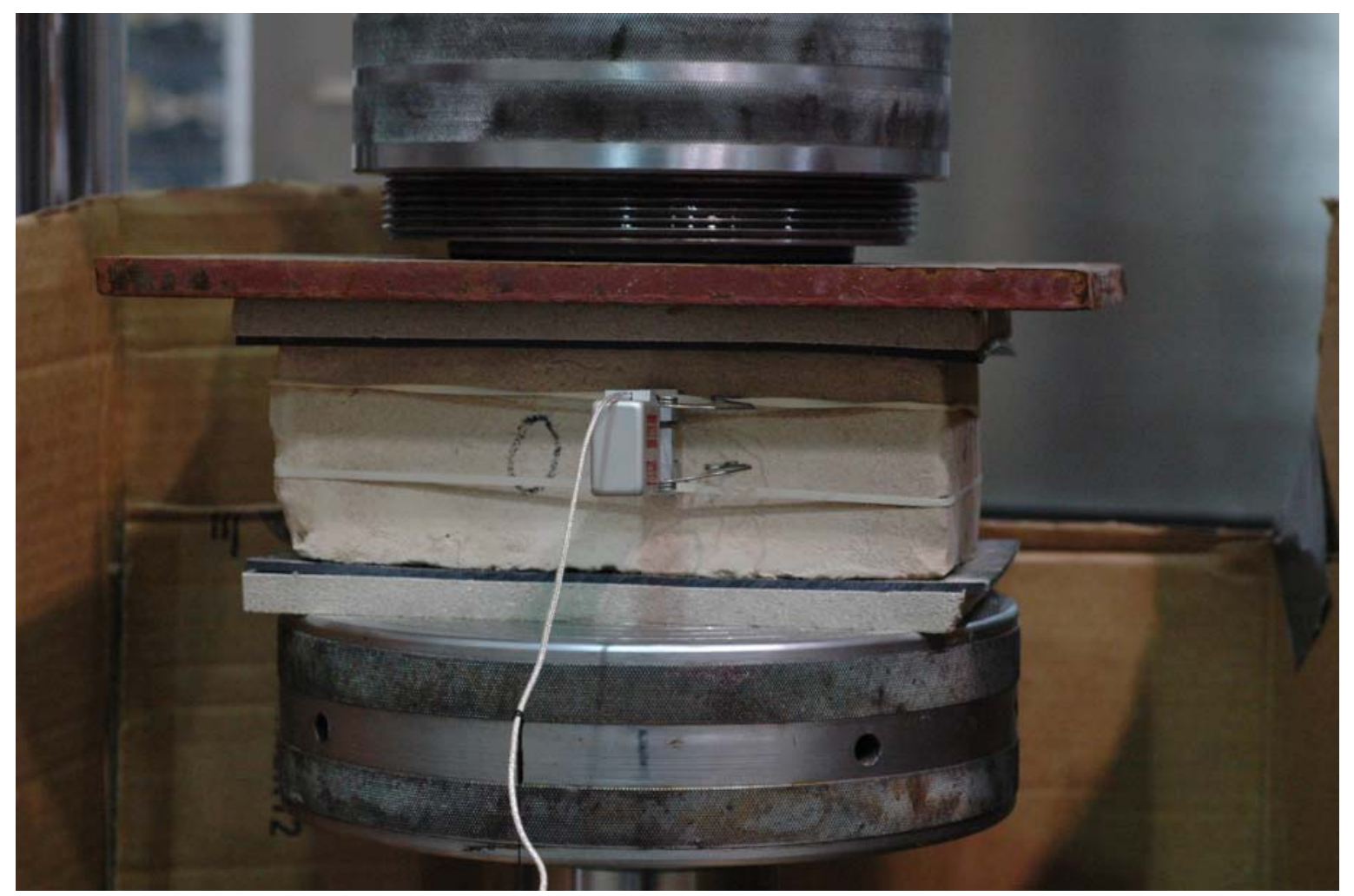

Figure 2. Typical brick setup before testing.

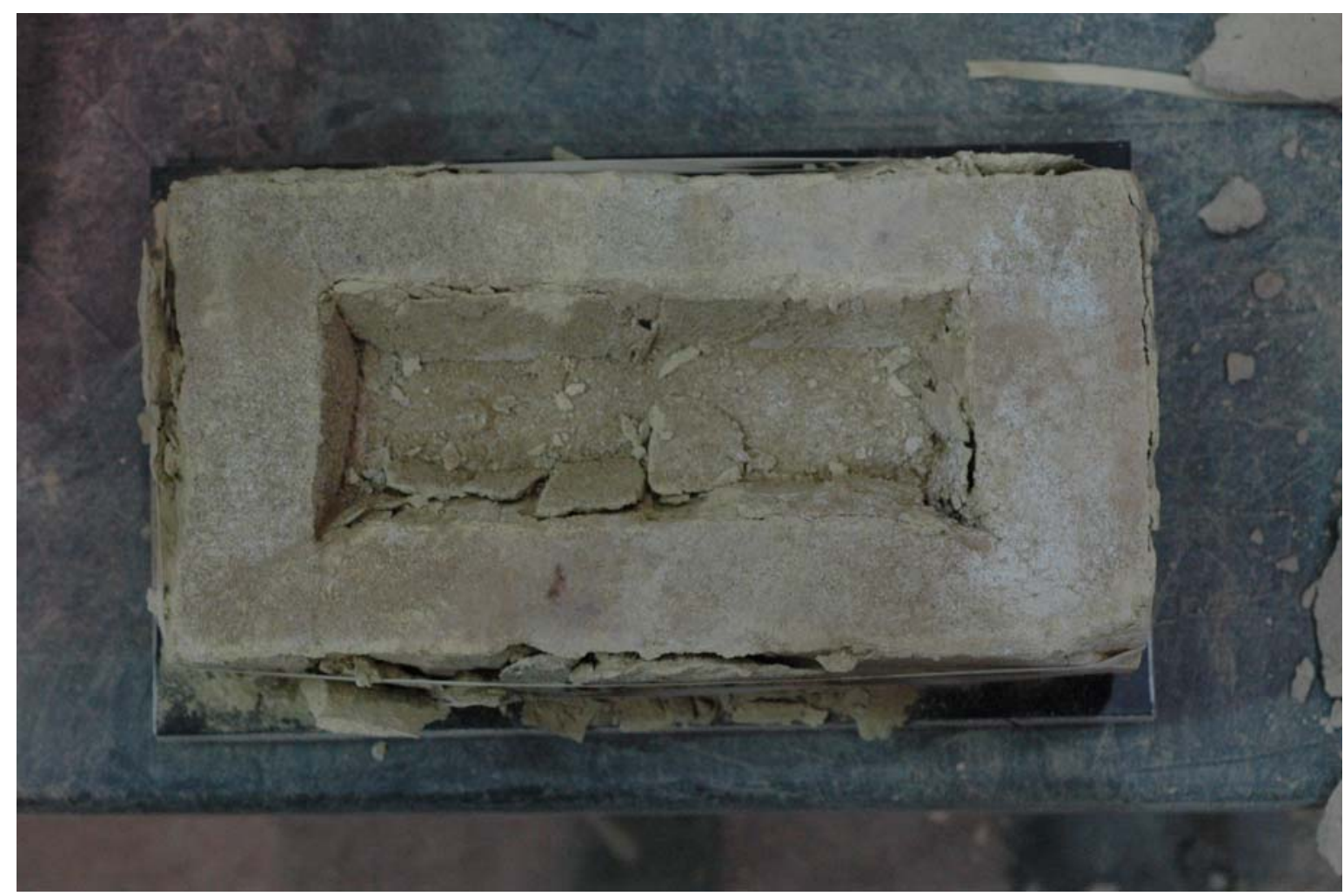

Figure 3. Typical failure of single brick unit under compressive load. 


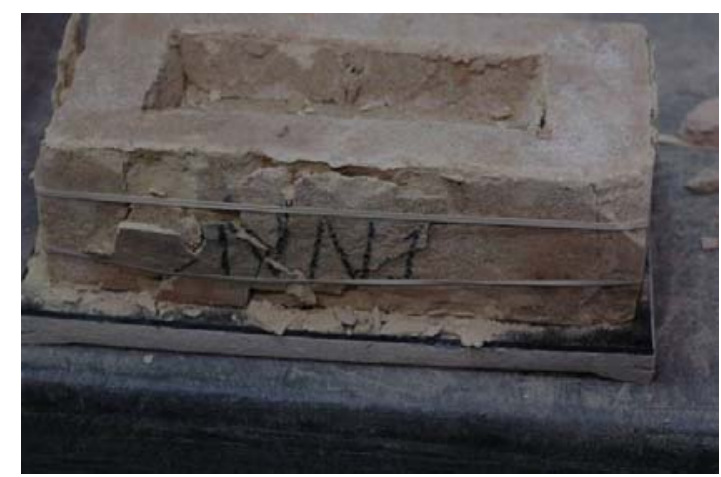

Figure 4. Single brick from NNew 1 , after testing.

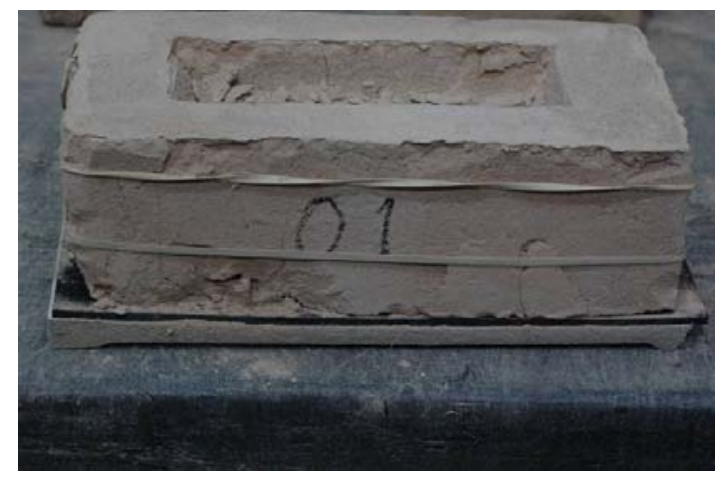

Figure 6. Single brick from NOld 1, after testing.

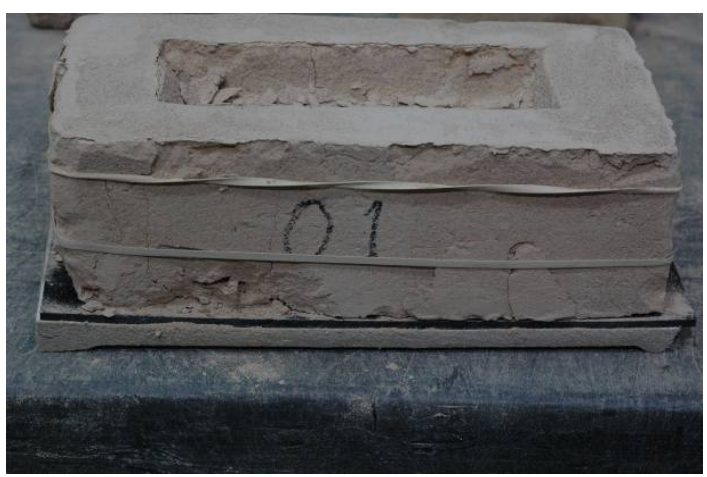

Figure 8. Single Brick from old batch \# 1, no fill, after testing.

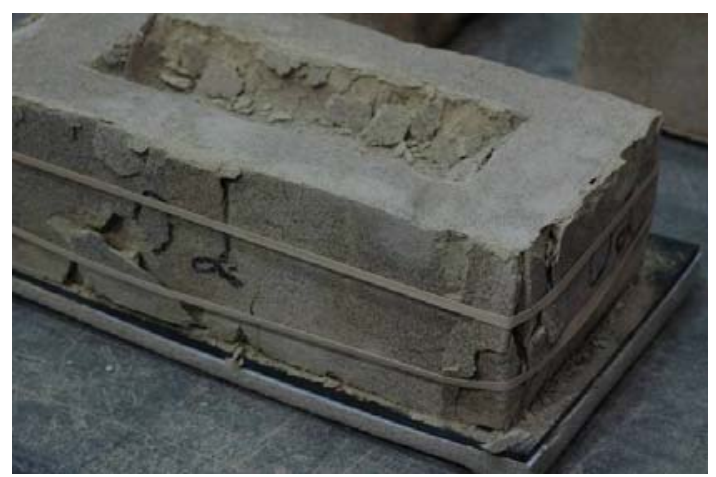

Figure 5. Single brick from NOld 2, after testing.

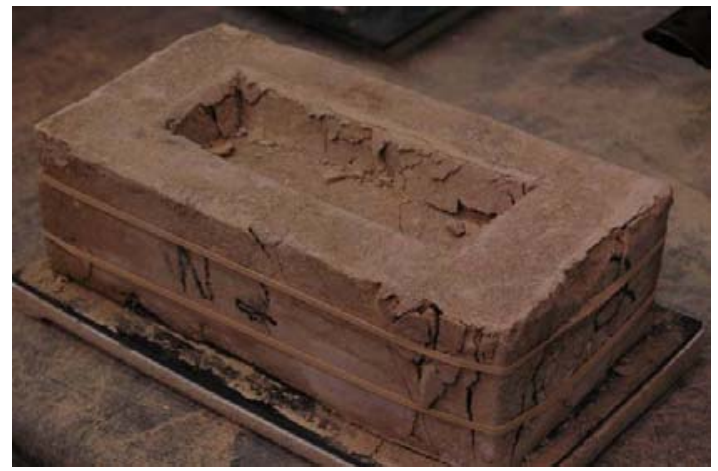

Figure 7. Single brick from NNew 2, after testing.

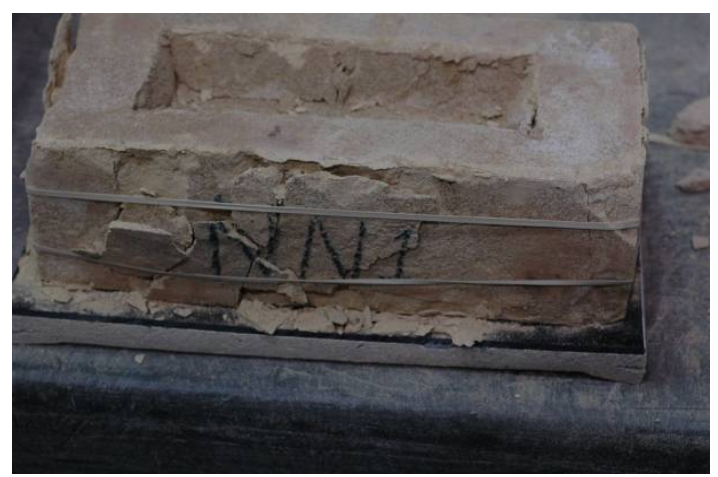

Figure 9. Single brick from new batch \#1, no fill, after testing. 


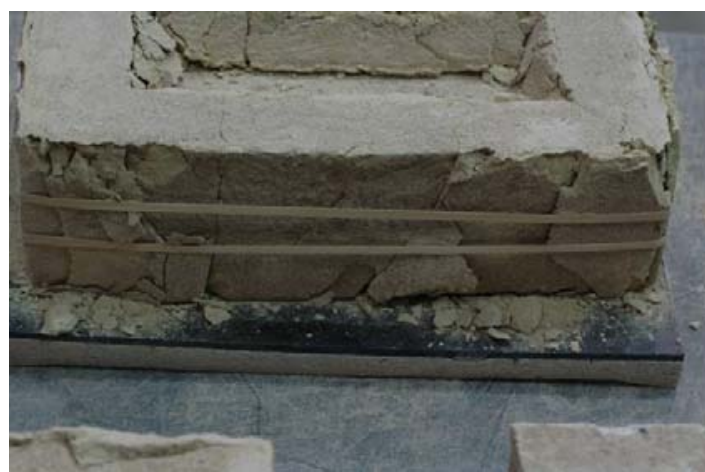

Figure 10. Single brick from old batch \#2, no fill, after testing.

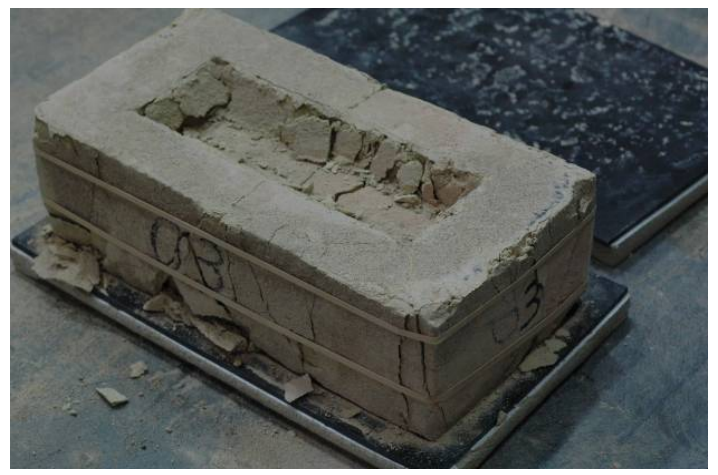

Figure 12. Single brick from old batch \#3, no fill, after testing.

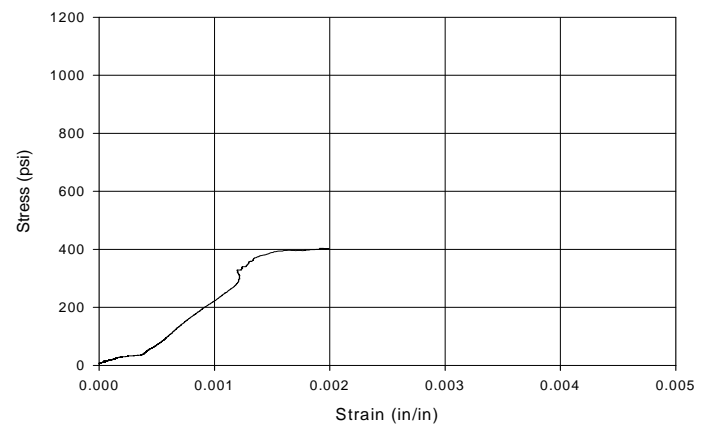

Figure 14. Stress-strain curve for single brick from NOld 1.

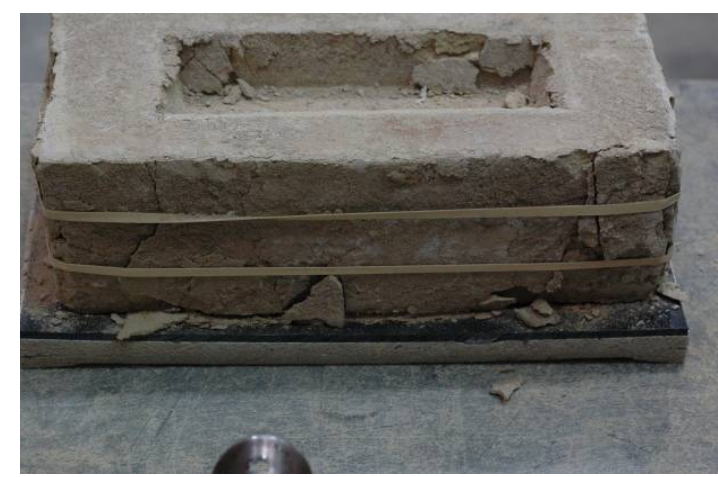

Figure 11. Single brick from new batch \#2, no fill, after testing.

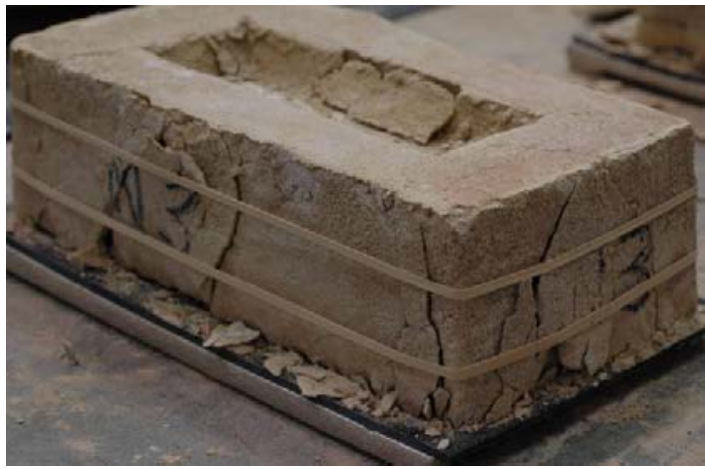

Figure 13. Single brick from new batch \#3, no fill, after testing.

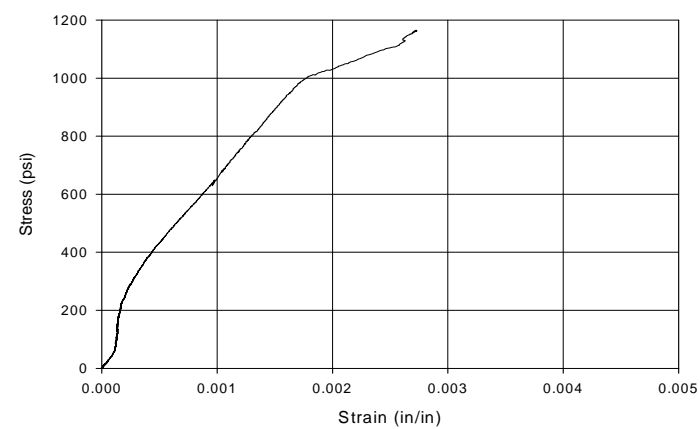

Figure 15. Stress-strain curve for single brick from NNew 1. 


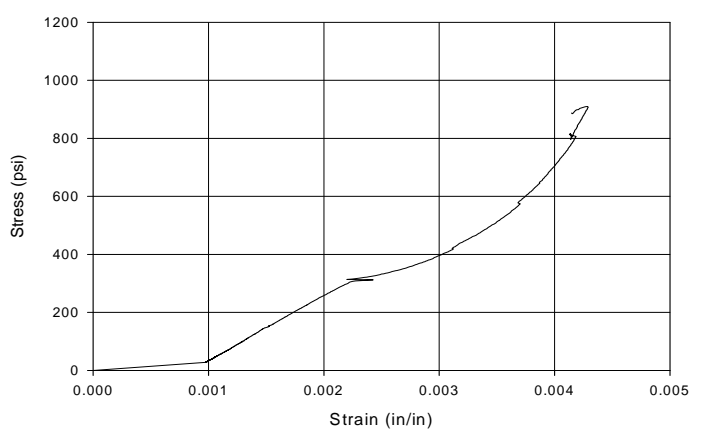

Figure 16. Stress-strain curve for single brick from NOld 2.

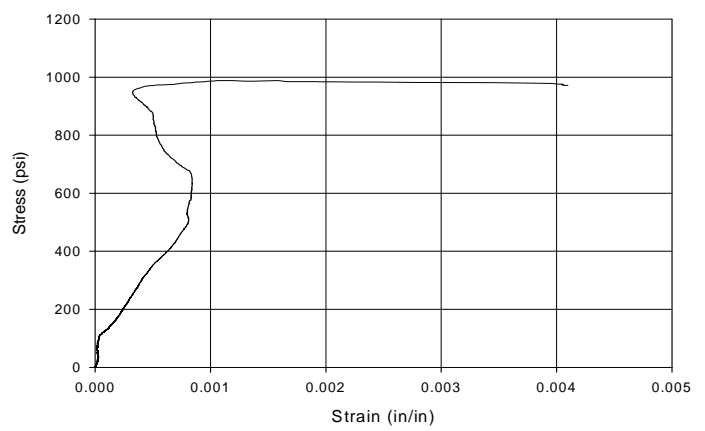

Figure 18. Stress-strain curve for single brick from FOld 4.

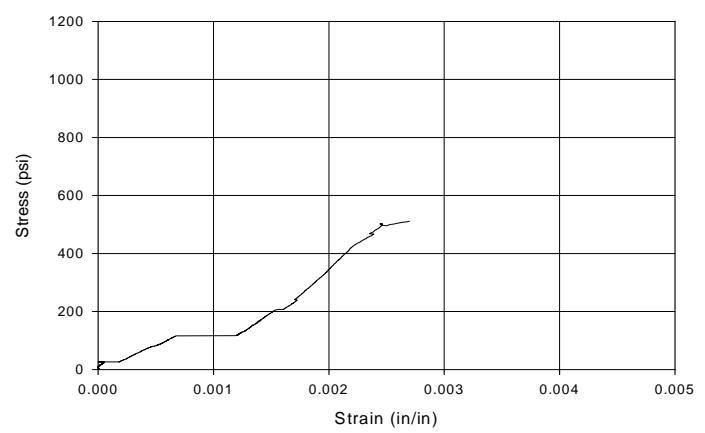

Figure 20. Stress-strain curve for single brick from FNew 5.

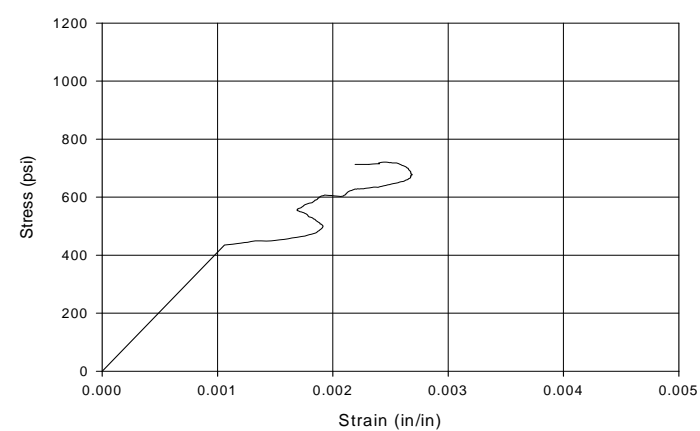

Figure 17. Stress-strain curve for single brick from NNew 2.

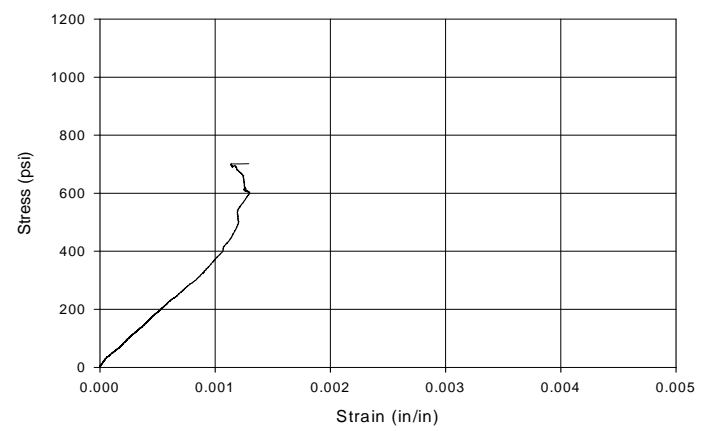

Figure 19. Stress-strain curve for single brick from FOld 5.

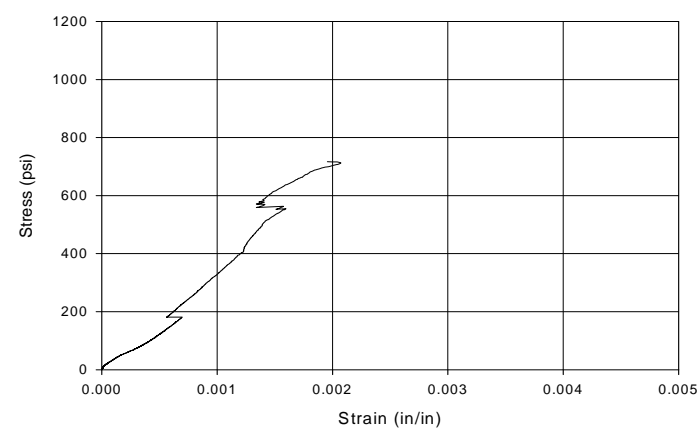

Figure 21. Stress-strain curve for single brick from FNew 6. 
Table 3. Summary of maximum compressive stress and corresponding strain of single brick units

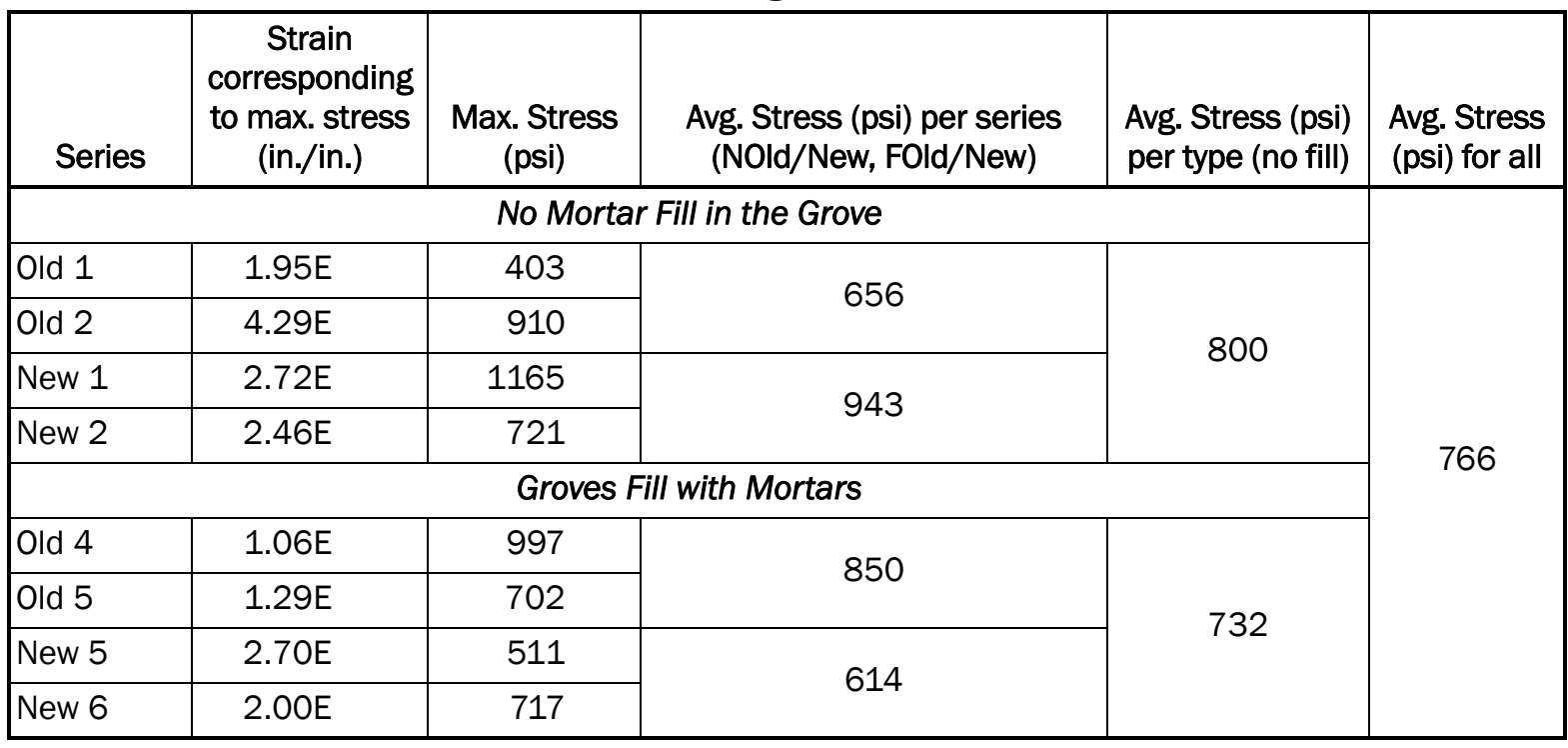

\subsection{Compressive strength of mortar}

S-type mortar without the lime was used. It had a mix ratio of one part Type I Portland Cement to four parts sand as an aggregate, and as much water as deemed necessary by the mason to keep a proper consistency. Compressive strength tests of six mortar cubes were performed according to ASTM C109. Cubes were made from different batches of mortar while laying the masonry. Figure 22 shows the setup for a typical cube before testing and Figure 23 shows a typical cube failure under compressive load. Figures 24 through 29 show stress-strain curves for cubes 2 through 9. Table 4 lists maximum compressive stress and corresponding strain of mortar cubes. The average mortar cube compression stress is $3617 \mathrm{psi}$.

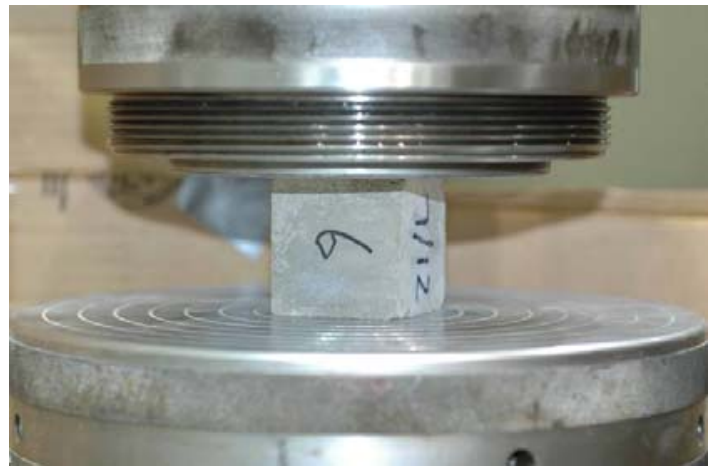

Figure 22. Mortar cube \#2 before testing.

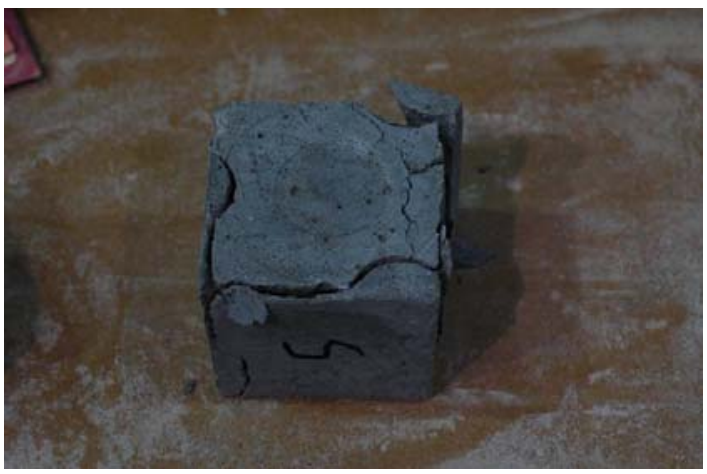

Figure 23. Mortar cube \#5 after testing. 


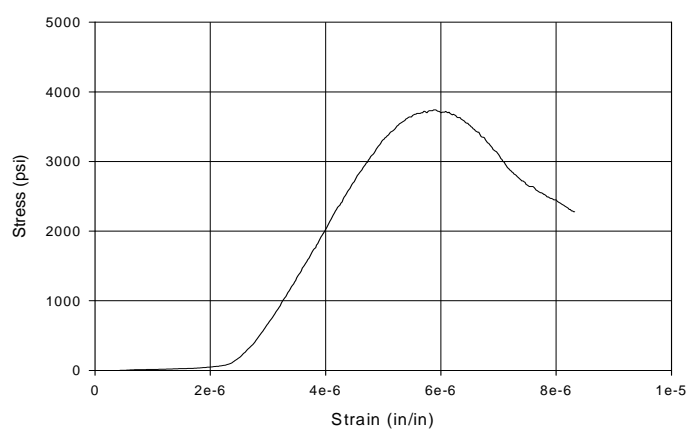

Figure 24. Stress-strain curves for Cube 2.

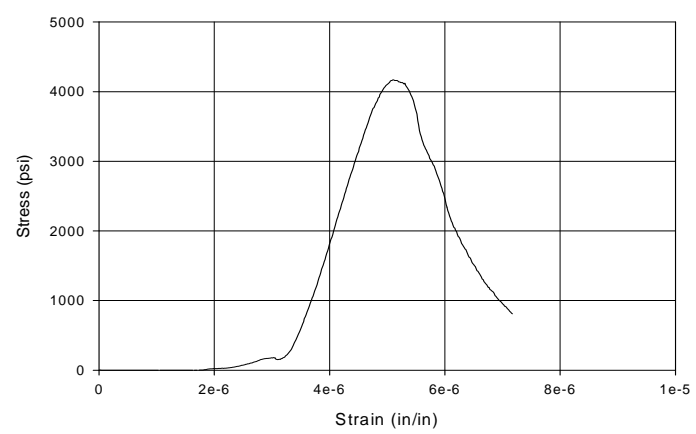

Figure 26. Stress-strain curves for Cube 5.

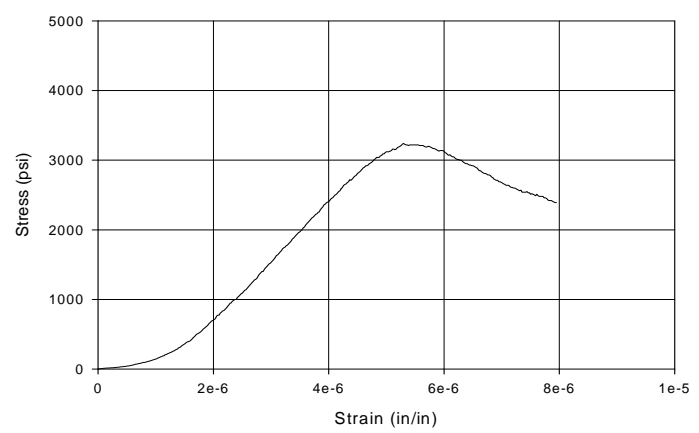

Figure 28. Stress-strain curves for Cube 7.

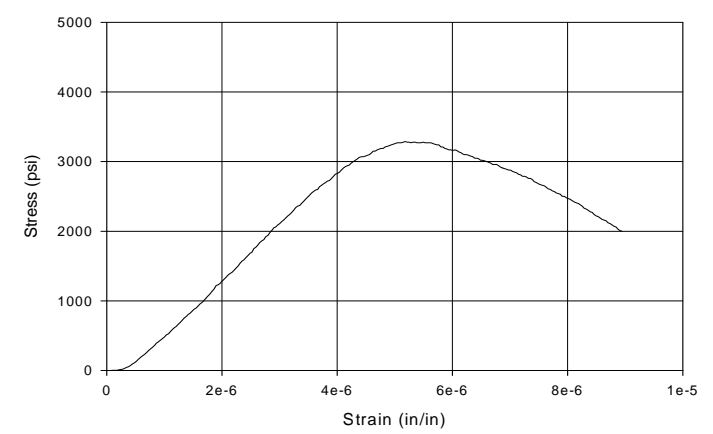

Figure 25. Stress-strain curves for Cube 3.

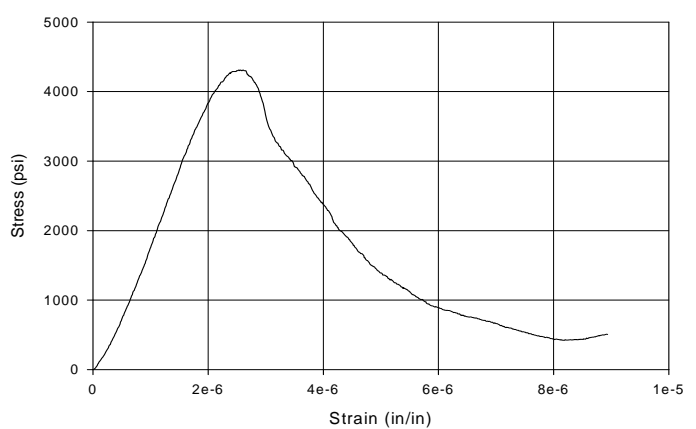

Figure 27. Stress-strain curves for Cube 6.

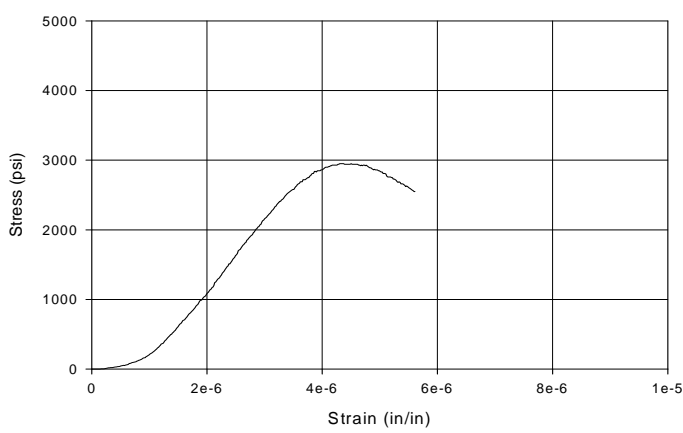

Figure 29. Stress-strain curves for Cube 9.

Table 4. Summary of maximum compressive stress and corresponding strain of mortar cubes

\begin{tabular}{|c|c|c|c|}
\hline Mortar Cubes ID & $\begin{array}{c}\text { Strain Corresponding to } \\
\text { Max. Stress (in./in.) }\end{array}$ & $\begin{array}{c}\text { Max. Stress } \\
\text { (psi) }\end{array}$ & $\begin{array}{c}\text { Average of Maximum } \\
\text { Stress (psi) }\end{array}$ \\
\hline 2 & $5.893 \mathrm{E}-06$ & 3743 & \\
\hline 3 & $5.181 \mathrm{E}-06$ & 3286 & \\
\hline 5 & $5.099 \mathrm{E}-06$ & 4166 & \multirow{2}{*}{3617} \\
\hline 6 & $2.570 \mathrm{E}-06$ & 4313 & \\
\hline 7 & $5.299 \mathrm{E}-06$ & 3238 & \\
\hline 9 & $4.341 \mathrm{E}-06$ & 2954 & \\
\hline
\end{tabular}




\subsection{Compressive strength of masonry prisms}

Compressive strength tests for prism samples were performed according to ASTM E447-84. For these tests, the grooves were filled with mortar and the compressive strengths were calculated based on the gross crosssectional area. Bare (unreinforced) prisms, prisms reinforced with Saint Gobain Cement, and prisms reinforced with Sika Wrap were all tested to obtain the composite section mechanical properties of each case.

The nature of failures in the brick prisms varied. Splitting, cone shapes within the units, and crushing were all observed. Figures 30 through 38 show the typical prism setup and samples of their modes of failures. Per ASTM, to obtain the maximum compressive strength factor $\mathrm{f}^{\prime} \mathrm{m}$ a correction factor of 1.07 for a three brick prism is required. Figures 39 through 46 show the stress strain curves for the tested prisms. Table 5 lists the maximum compressive stress and corresponding strain of all the tested prisms. The average $f^{\prime} m$ values for the bare prisms, prisms with Saint Gobain Cement, and prisms with Sika Wrap were 488 psi, 462 psi, and 737 psi, respectively.
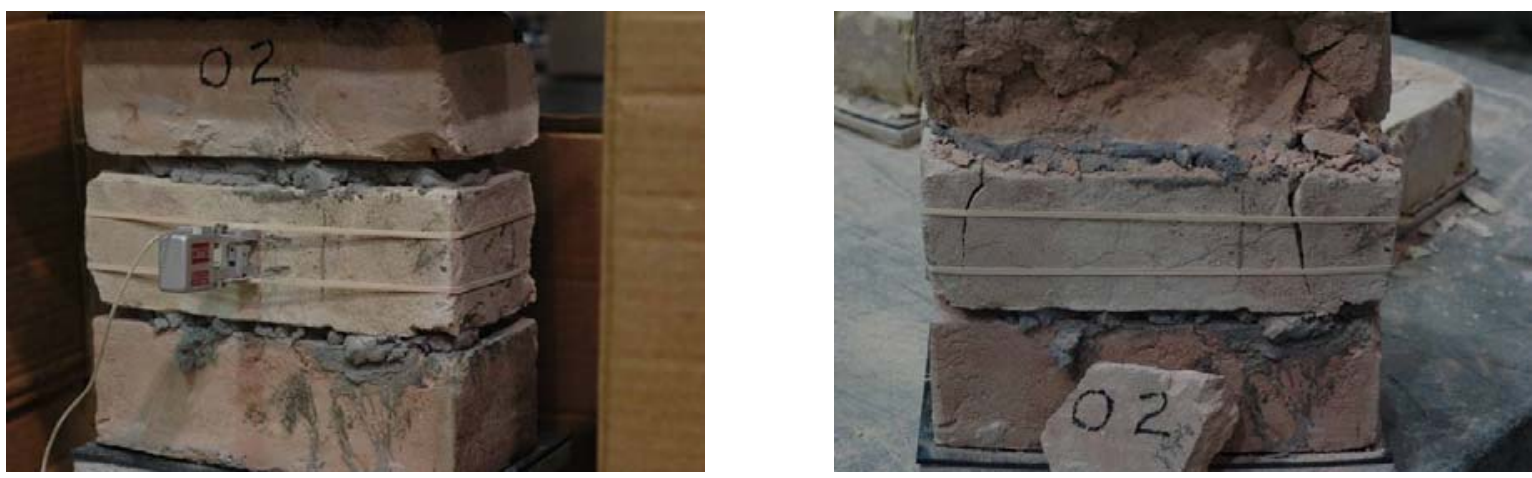

Figure 30. Prism from old batch \#2, before (left), after (right).
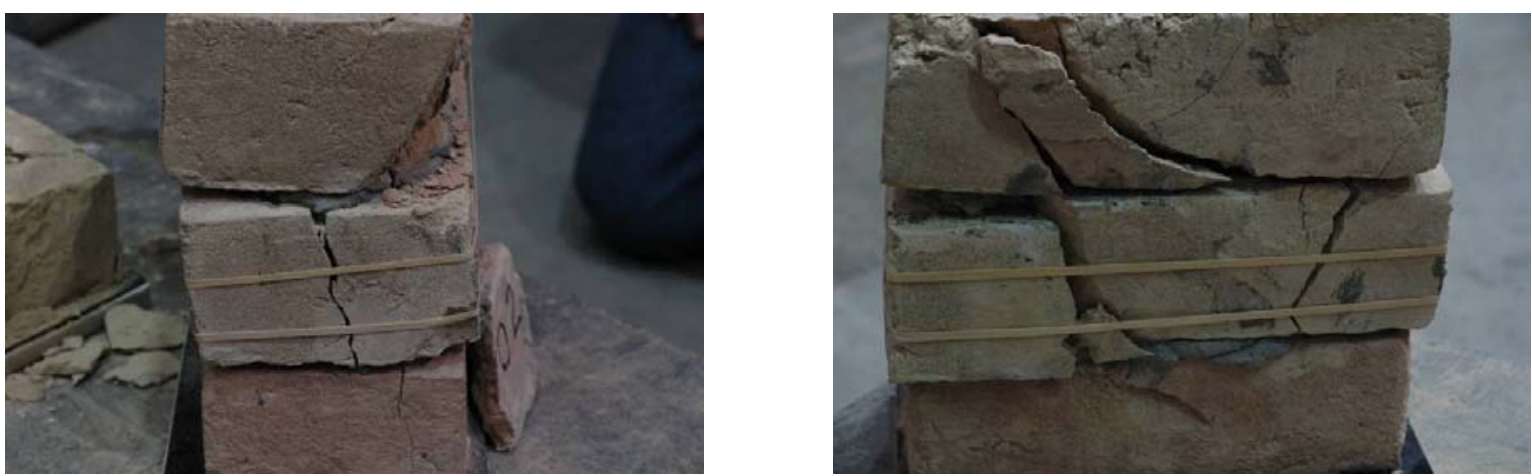

Figure 31. Prism from old batch \#2 after (left), after (right). 

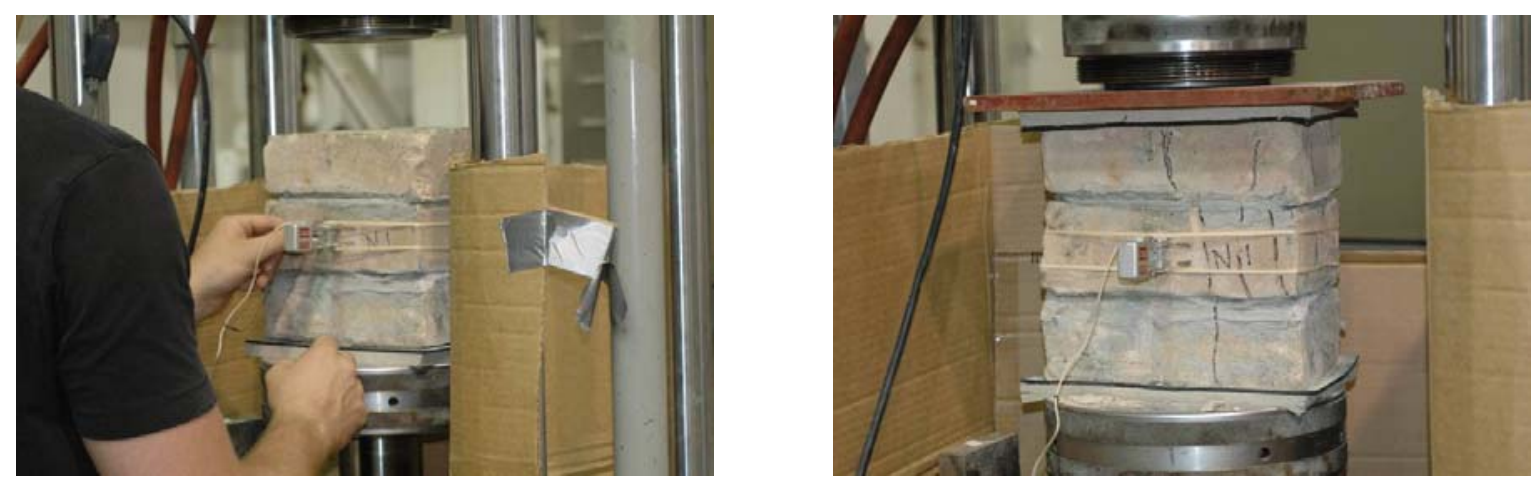

Figure 32. Prism from new batch \#1, before (left) and after (right).
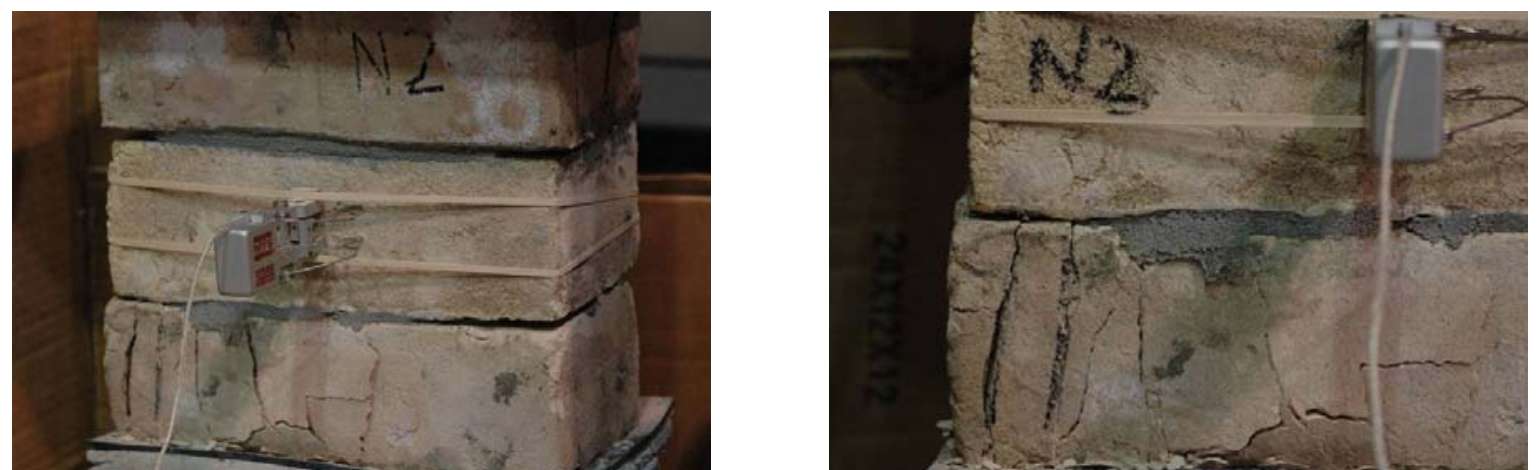

Figure 33. Prism from new batch \#2 after (left), after (right).
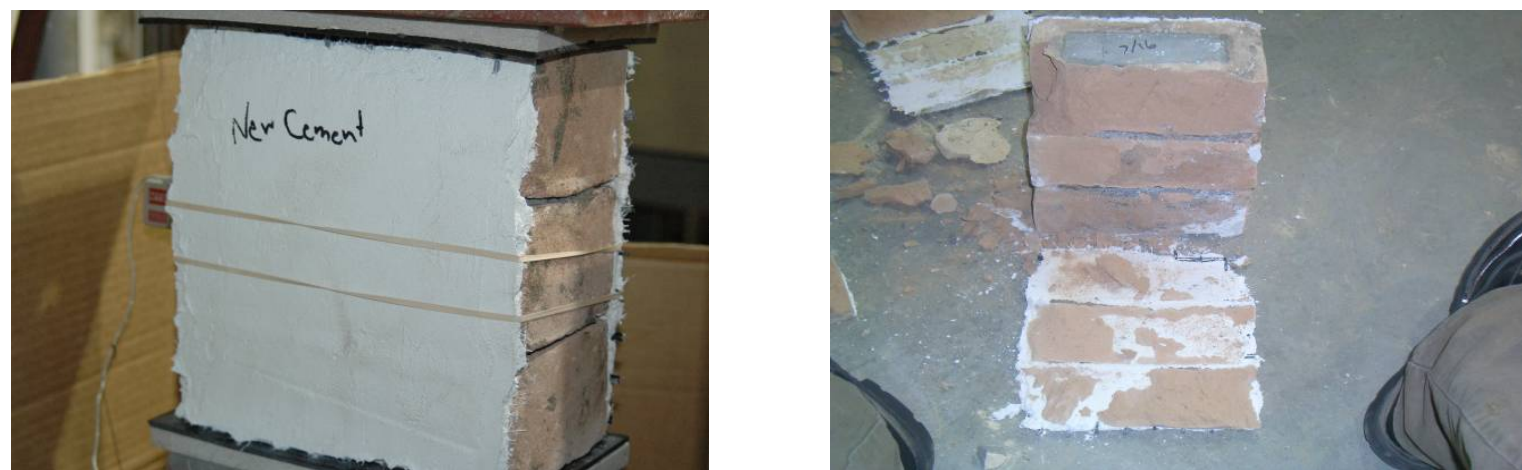

Figure 34. Prism from new batch with cementitious reinforcement \#1, before (left), after (right).
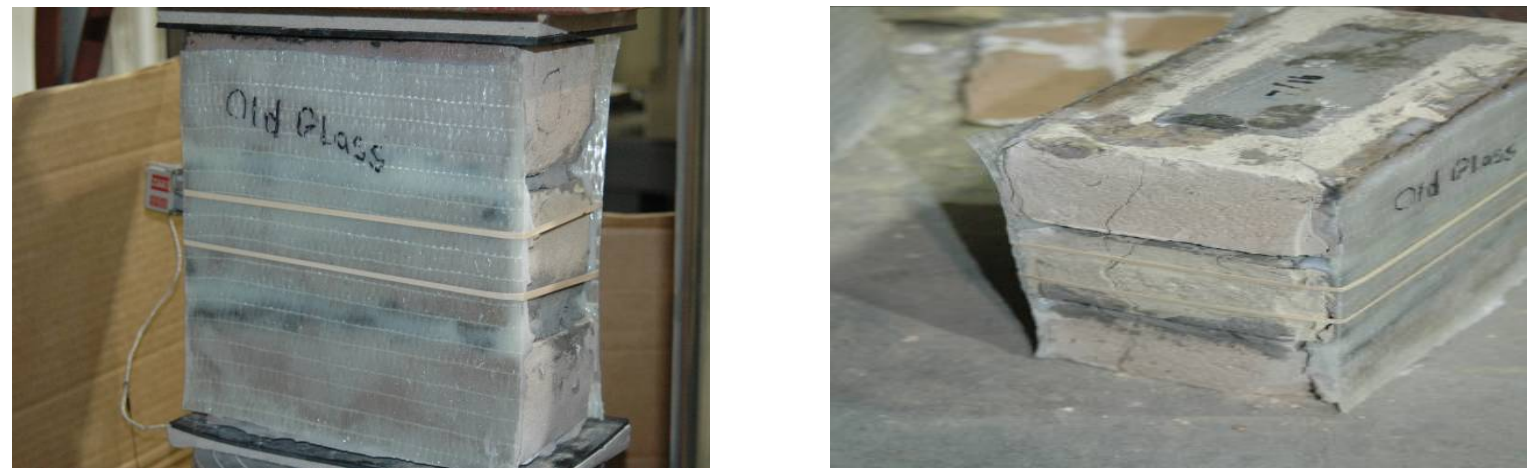

Figure 35. Prism from old batch with glass reinforcement, before (left), after (right). 

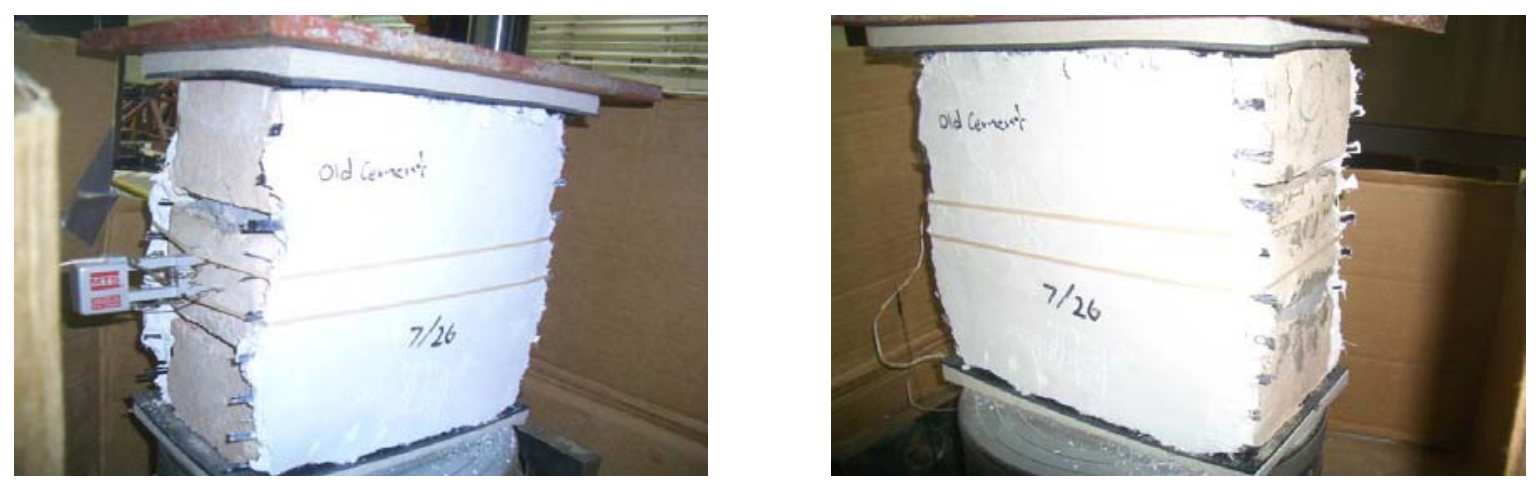

Figure 36. Prism from old batch with cementitious reinforcement, before (left), after (right).

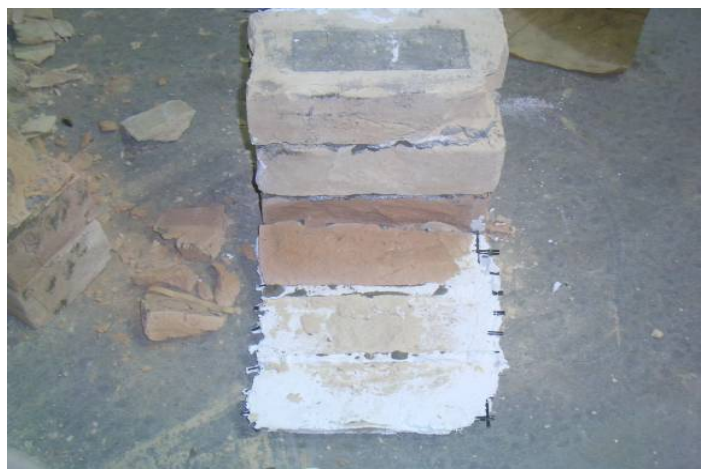

Figure 37. Prism from new batch with cementitious reinforcement, after.
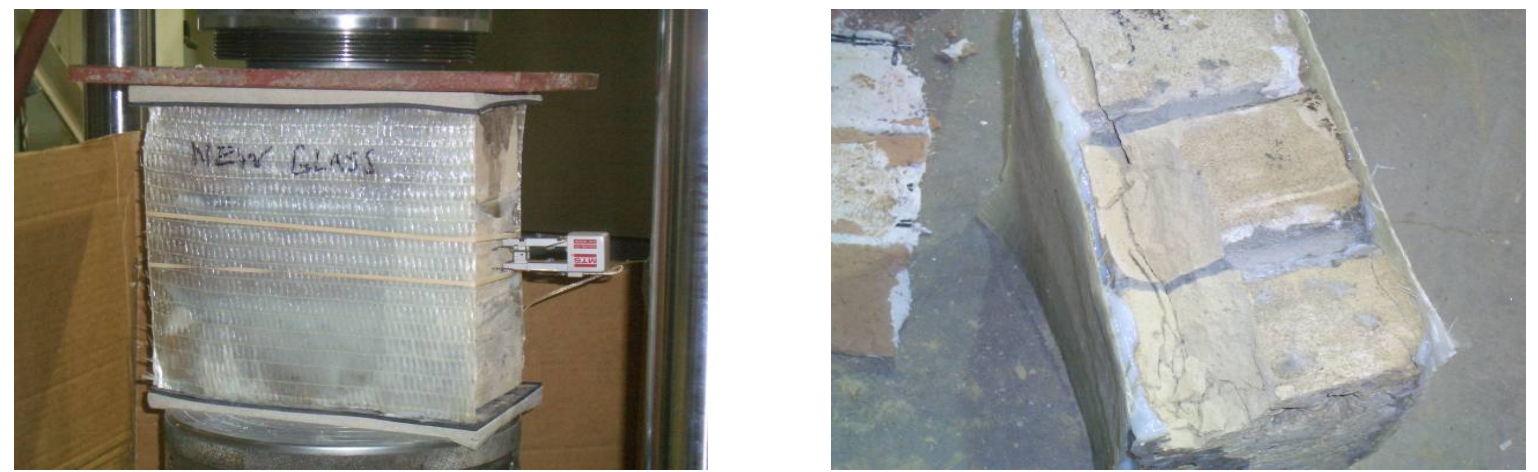

Figure 38. Prism from new batch with glass reinforcement, before (left), after (right). 


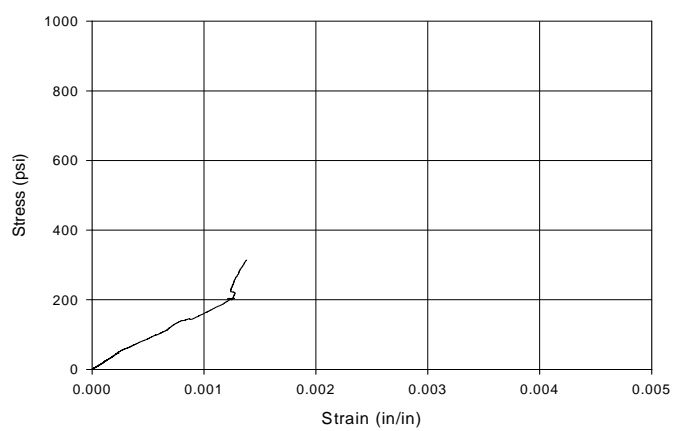

Figure 39. Stress-strain curve for Old 1 prism (0).

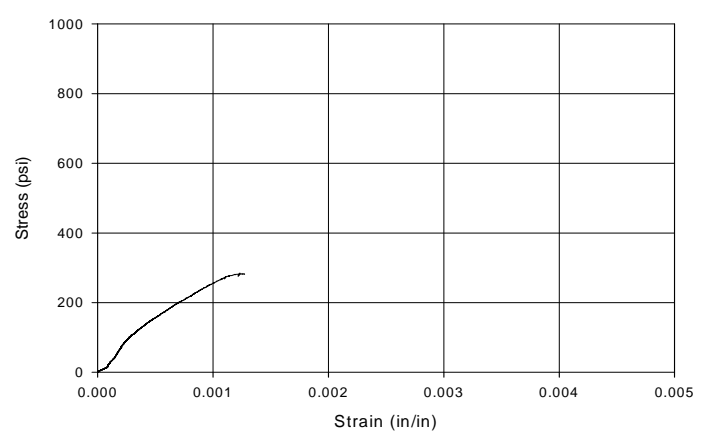

Figure 41. Stress-strain curve for Old 2 prism (0).

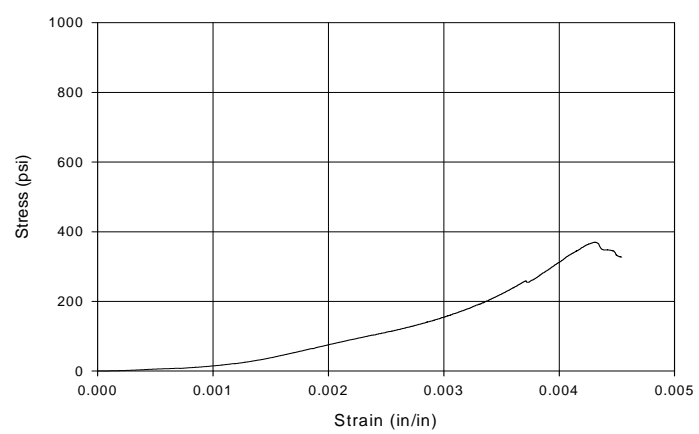

Figure 43. Stress-strain curve for Old cement prism.

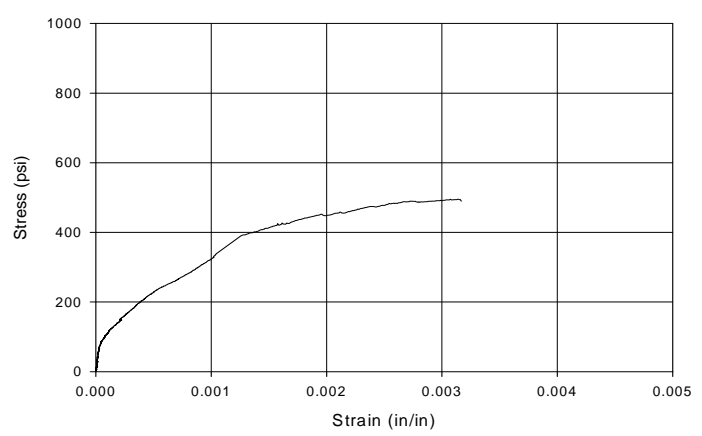

Figure 45. Stress-strain curve for Old glass prism.

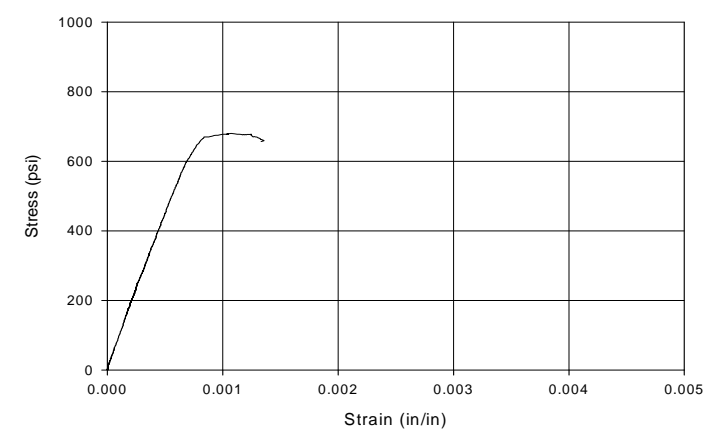

Figure 40. Stress-strain curve for New 1 prism (0).

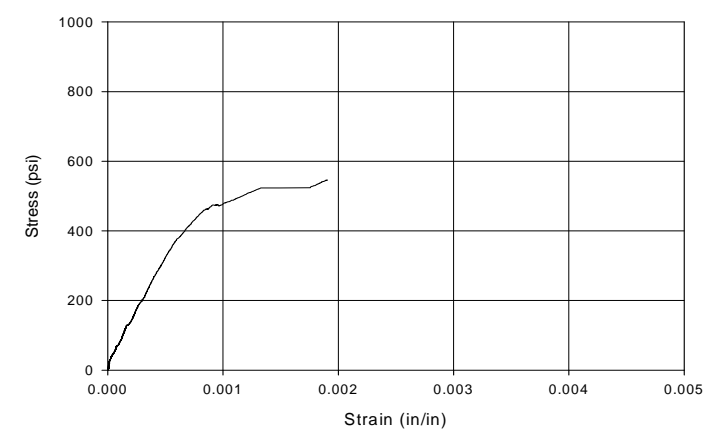

Figure 42. Stress-strain curve for New 2 prism (0).

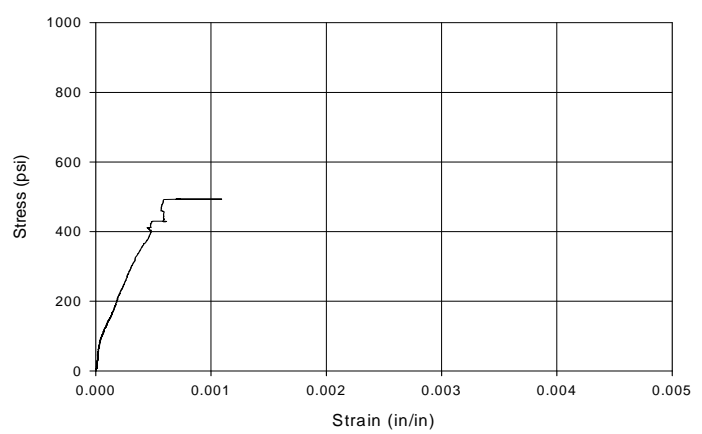

Figure 44. Stress-strain curve for New cement prism.

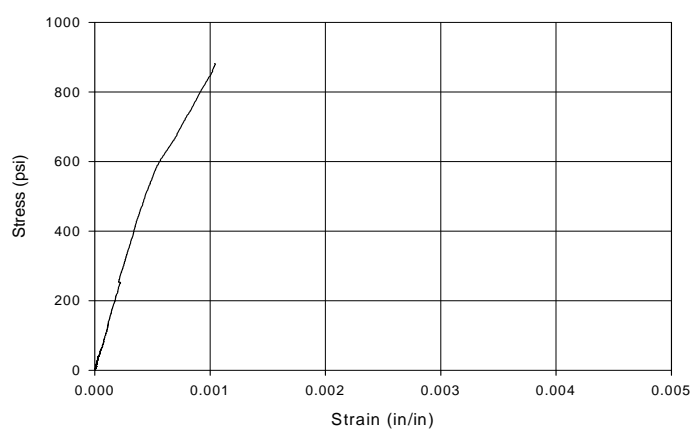

Figure 46. Stress-strain curve for New glass prism. 
Table 5. Summary of maximum compressive stress and corresponding strain of prisms.

\begin{tabular}{|c|c|c|c|c|}
\hline Prisms ID & $\begin{array}{c}\text { Strain } \\
\text { corresponding } \\
\text { to max. stress } \\
\text { (in./in.) }\end{array}$ & $\begin{array}{l}\text { Max. Stress } \\
\quad(p s i)\end{array}$ & $\begin{array}{c}\text { Average } \\
\text { Stress } \\
\text { (psi) }\end{array}$ & $\begin{array}{c}\text { Factored } \\
\text { Maximum } \\
\text { Stress (psi) }\end{array}$ \\
\hline Old 1 & 1.379E & 314 & \multirow{2}{*}{300} & \multirow{2}{*}{321} \\
\hline Old 2 & $1.234 \mathrm{E}$ & 285 & & \\
\hline New 1 & 1.073E & 680 & \multirow{2}{*}{613} & \multirow{2}{*}{656} \\
\hline New 2 & 1.894E & 546 & & \\
\hline Old (1) Cement & 4.313E & 370 & \multirow{2}{*}{$432 *$} & \multirow{2}{*}{462} \\
\hline Old (2) Cement & $7.359 \mathrm{E}$ & 494 & & \\
\hline Old Glass & $3.145 \mathrm{E}$ & 495 & \multirow{2}{*}{689} & \multirow{2}{*}{737} \\
\hline New Glass & $1.039 \mathrm{E}$ & 882 & & \\
\hline
\end{tabular}

Per Uniform Building Code (UBC) Standard, use correction factor of 1.07 $\mathrm{X}$ maximum compressive strength to get $\mathrm{f}_{\mathrm{m}}$ 


\section{Test Setup}

\subsection{Introduction}

Two sets of specimens were built. The first set consisted of three doublewythe walls that measure about $67 \mathrm{in}$. long, $60 \mathrm{in}$. high, and 9 in. thick, built on $\mathrm{R} / \mathrm{C}$ base beams and capped with a $\mathrm{R} / \mathrm{C}$ header beam to transfer the lateral load over the entire wall during the in-plane testing. The second set consisted of 24 specimens of a double-wythe wall strip 11 courses high, used for out-of-plane testing. Every set consisted of three series:

1. Series G: For walls upgraded with unidirectional SikaWrap reinforcement on both sides

2. Series C: For walls upgraded with Saint Gobain SFC Saint Gobain glass cement-based FRP on both sides

3. Series 0: For bare walls used for comparison.

The walls (Figure 47) were built as instructed by the sponsor with every stretcher course topped by a header course, totaling 18 courses. The top and bottom courses were designed to be partially embedded in the concrete beam to prevent failure at the interface surfaces. Figure 48 shows brick configuration detail.
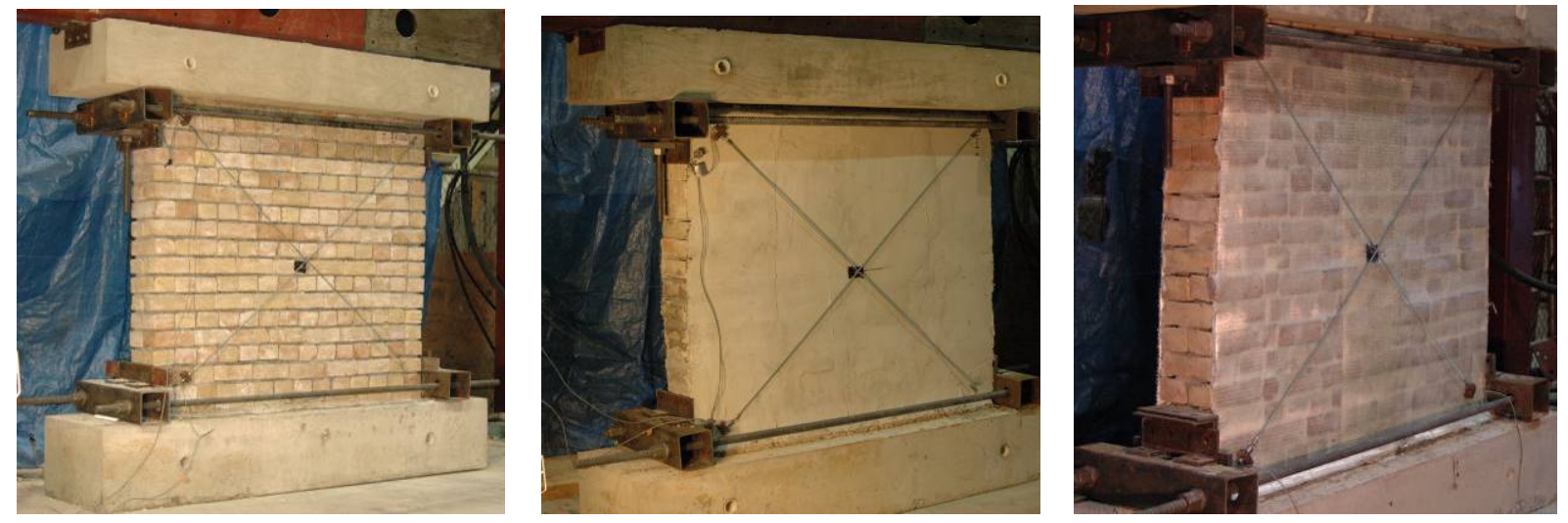

Figure 47. Bare wall (left), Saint Gobain cementitious FRP System (center), and SikaWrap FRP system (right). 


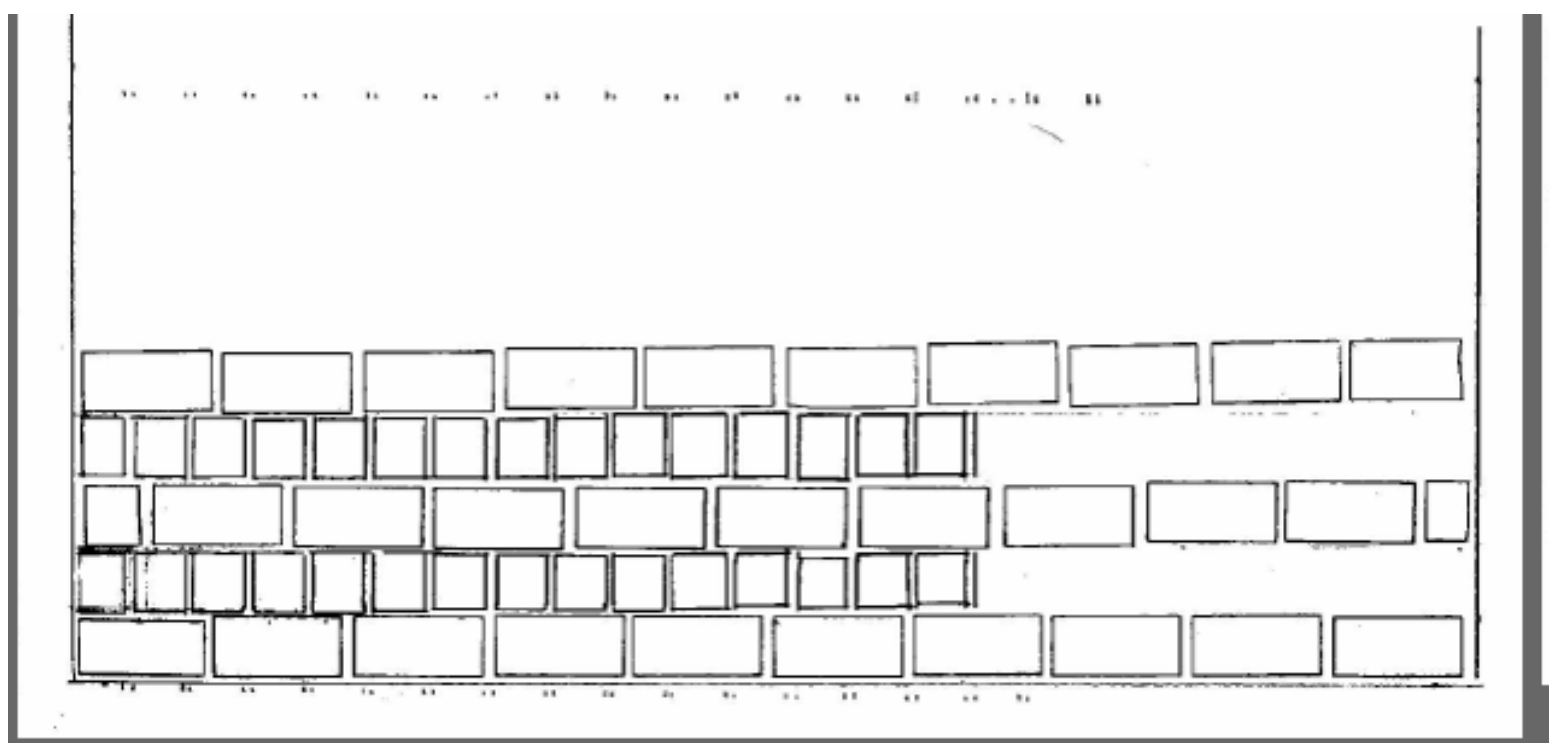

Figure 48. Brick configuration as instructed by the sponsor.

The out-of-plane set consists of 24 specimens of a double-wythe wall strip with 11 courses. The cross sectional area is $9 \times 9 \mathrm{in}$. and the height is $36 \mathrm{in}$. Six wall strips (two from each series) out of the 24 were tested under pure compressive load, i.e., zero lateral load. The purpose of these six wall strip tests is to determine maximum compressive stress values for each series and to apply percentages of these values on the 18 wall strips intended to be tested under out-of-plane cyclic load combined with percentage of vertical stress at failure. Figures 49 and 50 show representative specimens of each group.
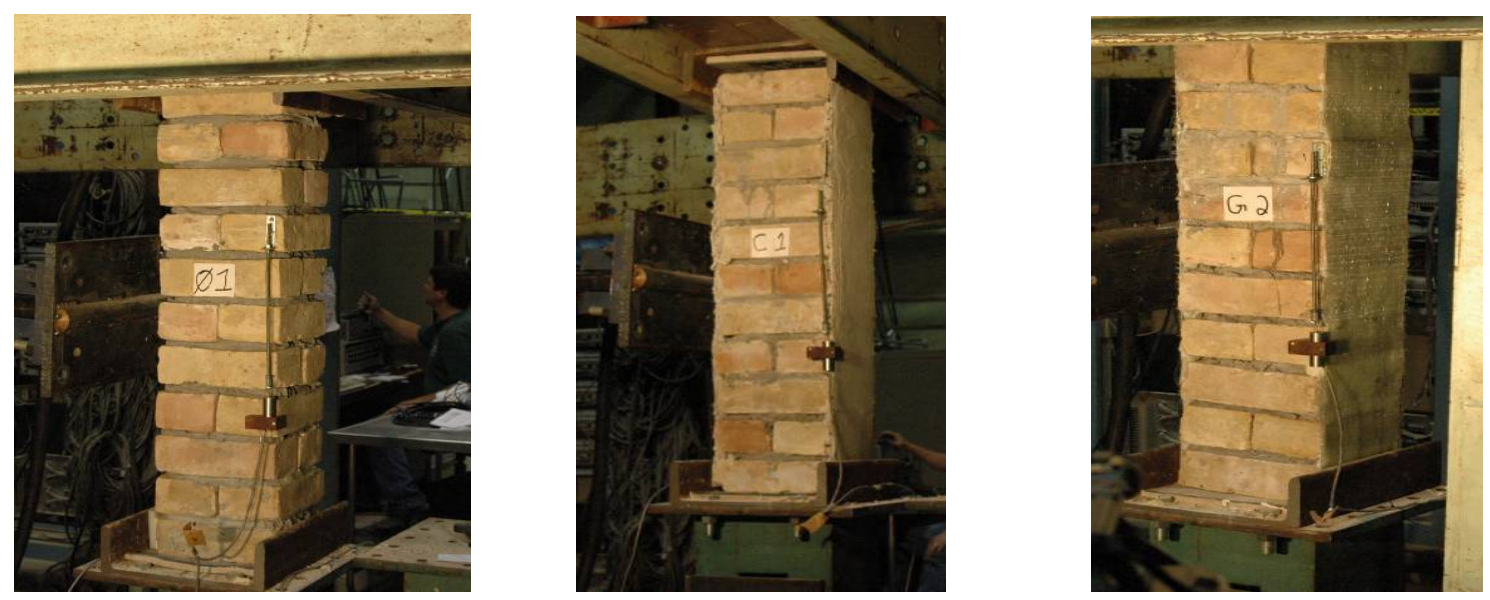

Figure 49. Representative specimens of all series tested under pure compression, bare specimen (left), Saint Gobain cementitious FRP system (center), and SikaWrap FRP system (right). 

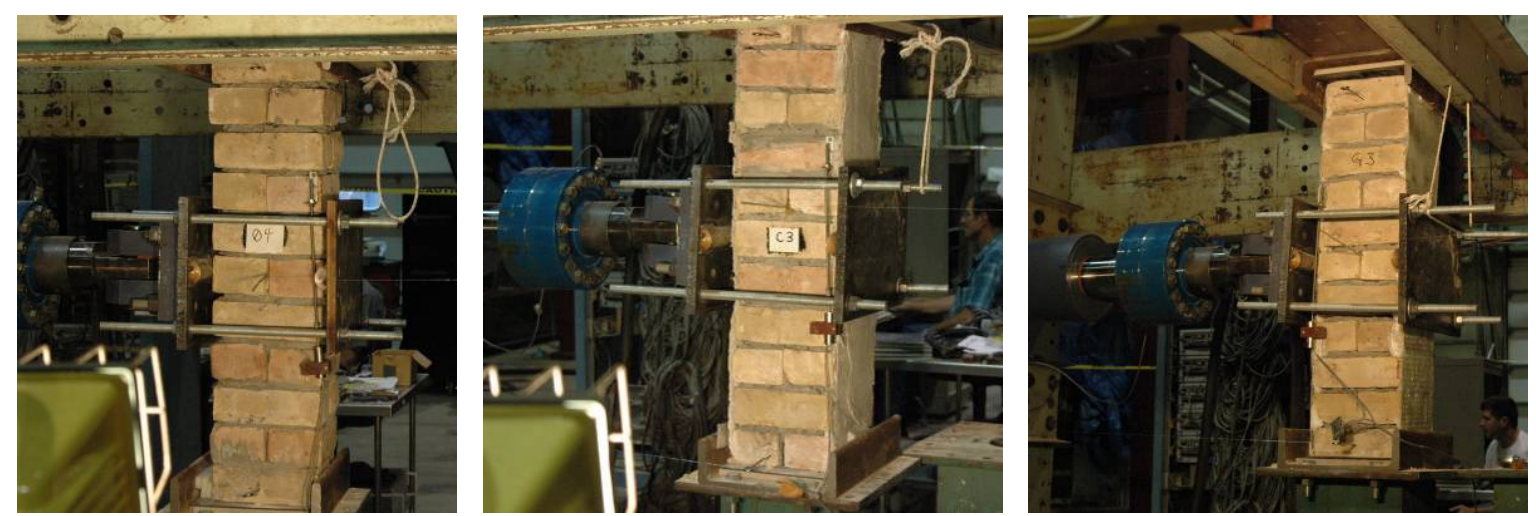

Figure 50. Representative specimens of all series tested under out-of-plane cyclic load combined with various levels of vertical loads, bare specimen (left), Saint Gobain cementitious FRP system (center), and SikaWrap FRP system (right).

\subsection{Description of the in-plane loading frame}

For the in-plane tests, a steel frame (Figure 51) was fitted with a horizontal steel header beam running north-south, attached to two 50-kip vertical actuators to put axial pressure on the specimen. A 100-kip actuator was fixed horizontally to a shear bearing wall and attached to the horizontal header beam at the south end. The 100-kip actuator has a minimum length of $107.75 \mathrm{in}$. with a 40-in. stroke. Supports were attached to the frame at the same end. The specimen was placed lengthwise in the northsouth direction beneath the steel beam and was fixed to the steel beam by its $\mathrm{R} / \mathrm{C}$ header beam and bolted to the floor through its $\mathrm{R} / \mathrm{C}$ base beam.

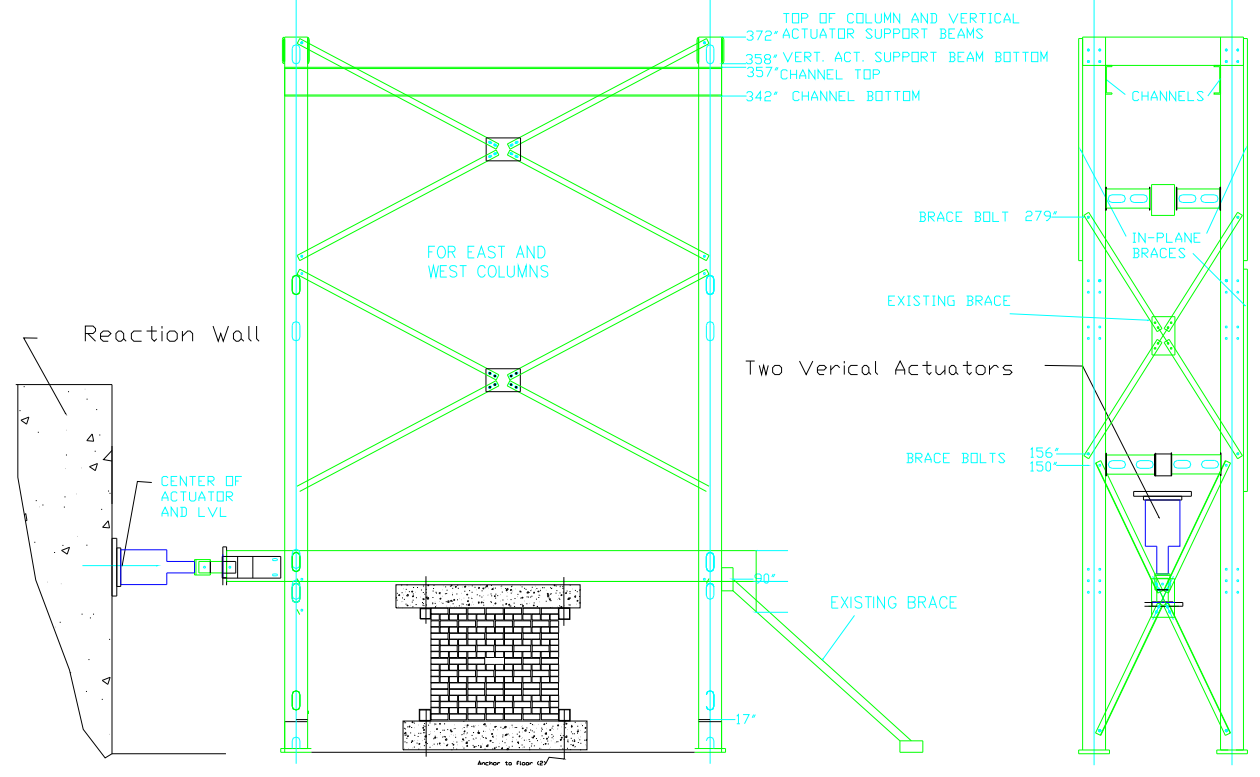

Figure 51. Loading frame for in-plane tests. 


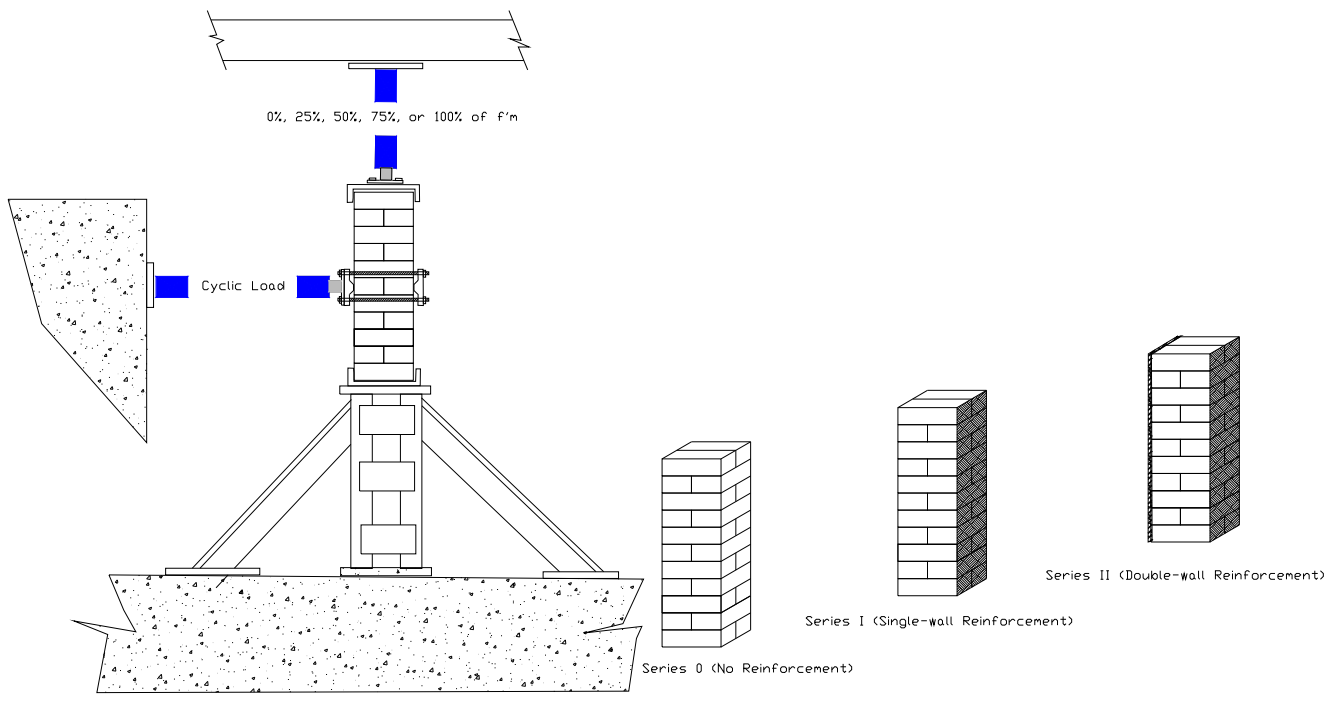

Figure 52. A sketch of the out-of-plane-test setup.

\subsection{Description of the out-of-plane loading frame}

The out-of-plane testing frame consisted of the following: a steel frame, the same 100-kip actuator fixed horizontally to a shear bearing wall at the west end of the frame, two vertical 50-kip actuators fixed to the top of the steel frame, and supports at the east end of the frame. Within the frame, a specimen was fixed at the base in the direction of actuator stroke. The horizontal actuator was centered on the specimen with a c-channel used to minimize movement in the north-south direction. The vertical actuators were fixed to a horizontal beam that put a vertical force on the specimen. Figure 52 shows a sketch of the out-of-plane-test setup.

\subsection{Glass fiber reinforcement polymer}

\subsubsection{Procedure for applying the Sika Wrap Hex 100G}

Wall panels and wall strip specimens were first cleaned with a wire brush, and then washed with water and allowed to dry. Sikadur 300, a two part epoxy consisting of polyoxypropylenediamine and an epoxy resin, was mixed for 2 minutes in the proportions supplied by the manufacturer. Cab-O-Sil TS-720, a treated fumed silica powder, was added to the resin until the mixture became thick enough to apply to a vertical surface. This thickened epoxy mixture was then trowelled onto two sides of each specimen. The mixture was applied generously to fill all mortar joints and uneven surfaces. After the resin had been given time to begin to gel (1-2 hrs), sheets of unidirectional fiberglass (E-glass), $27 \mathrm{oz}$. per square yard, were applied to the surfaces (Figure 53). Where two sheets were spliced to- 
gether, a minimum 6-in. of overlay was applied. Each sheet was then coated with Sikadur 300 epoxy using a paint roller until it became saturated and the bricks beneath could be clearly seen. The samples were then allowed to dry overnight. Table 6 lists the materials used for SikaWrap FRP system, and their proportions. Table 7 lists the basic material properties of SikaWrap FRP system.

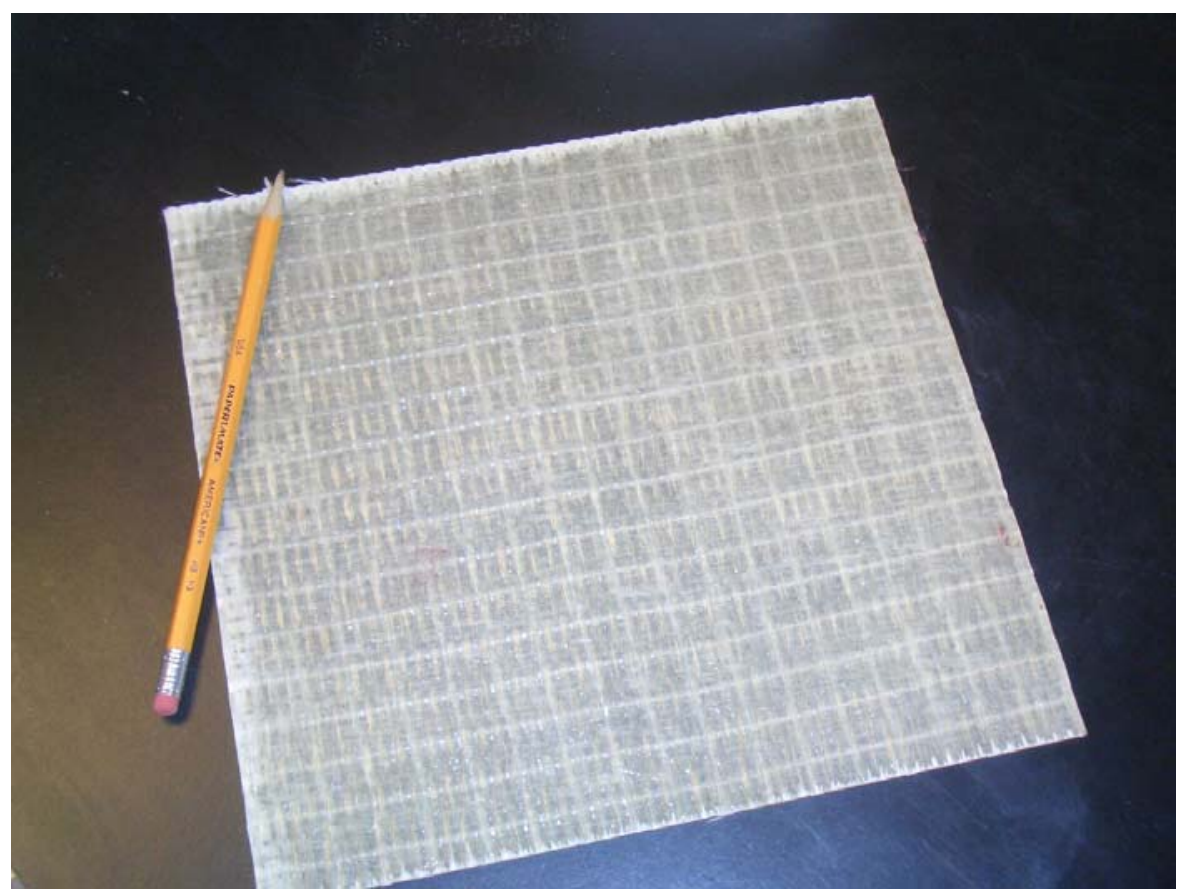

Figure 53. SikaWrap fabric.

Table 6. Materials used for SikaWrap and their proportions.

\begin{tabular}{|l|l|l|}
\hline \multicolumn{1}{|c|}{ Material } & \multicolumn{1}{|c|}{ Proportion } & \multicolumn{1}{c|}{ Remarks } \\
\hline Sikadur 300 & Part A: (Proprietary Epoxy Resin) & \\
\cline { 2 - 3 } & Part B: Polyoxyproplyenediamine & \\
\hline Thixatrope & Cabosil TS720 & (approx 4 gal for all the specimens) \\
\hline Reinforcing & 27 oz./ sq yd. unidirectional E-Glass & \\
\hline
\end{tabular}

Table 7. Basic Material properties of $27 \mathrm{oz}$ GFRP unidirectional glass with its epoxy matrix.

\begin{tabular}{|l|c|c|c|c|}
\hline FRP System & $\begin{array}{c}\text { Orientation } \\
\text { (deg) }\end{array}$ & $\begin{array}{c}\text { Number } \\
\text { of Plies }\end{array}$ & $\begin{array}{c}\text { Average } \\
\text { Ultimate } \\
\text { Strength (ksi) }\end{array}$ & $\begin{array}{c}\text { Average } \\
\text { Modulus of } \\
\text { Elasticity (ksi) }\end{array}$ \\
\hline 27-oz. Unidirectional Glass Reinforced Epoxy & 0 & 1 & 62.06 & 1773 \\
\hline 27-oz. Unidirectional Glass Reinforced Epoxy & 0 & 2 & 69.83 & 1365 \\
\hline 27-oz. Unidirectional Glass Reinforced Epoxy & 90 & 1 & 3.41 & 1001 \\
\hline 27-oz. Unidirectional Glass Reinforced Epoxy & 90 & 2 & 2.72 & 1052 \\
\hline
\end{tabular}




\subsubsection{Procedure for applying the Saint Gobain Glass cement-base system}

The surface preparation for the SFC system application consisted of spraying water on the surface of the wall where the SFC system was to be applied. Water was sprayed onto the wall so that the entire surface to receive the SFC Composite System was wetted to increase bond between the SFC system and the wall.

Wall strips on which the cementitious system was to be applied were cleaned using a wire brush and washed prior to application. One hundred pounds of CEMSHIELD Strengthening Reinforcement Grid (SRG) (Quikrete Quikwall), 1 gal of CEMSHIELD SRG liquid (Quikrete Concrete acrylic fortifier) and 2.5 gal of clean water were mixed using a paddle mortar mixer. The liquid components were added first and the Quikrete Quikwall added last. This was mixed until it reached a uniform consistency. Two sides of each column were thoroughly dampened prior to application. The cementitious material was then applied to two sides of each column by trowel to a thickness of $1 / 8$ to $1 / 4$ in. A sheet of Saint Gobain glass grid was pressed into the wet cementitious material on both sides, and another layer of the cementitious material was troweled on top of the grids to provide a smooth surface finish.

The wall was cleaned with a wire brush on both sides and watered down. While the wall was still wet, a cementitious matrix of the same materials and mix ratio as used for the wall strips was applied in $1 / 8$ to $1 / 4 \mathrm{in}$. sheet on one side of the wall. Saint Gobain SRG was applied in two strips with a 4 in. overlay, and 2 in. of which was curled onto the header and base beams. Another sheet of the cementitious material was applied over the grid. The same procedure was used on the other side of the wall, except the grid had a 6 in. overlay.

The brick wall strengthened with SFC, a composite of Saint Gobain Glass grid (Figure 54) produced by Saint Gobain Technical Fabrics; and QuickWall ${ }^{\circledR}$, manufactured by the Quickcrete Companies was tested in in-plane shear. Table 8 lists the proportions of materials used in the Saint Gobain Glass grid system. 


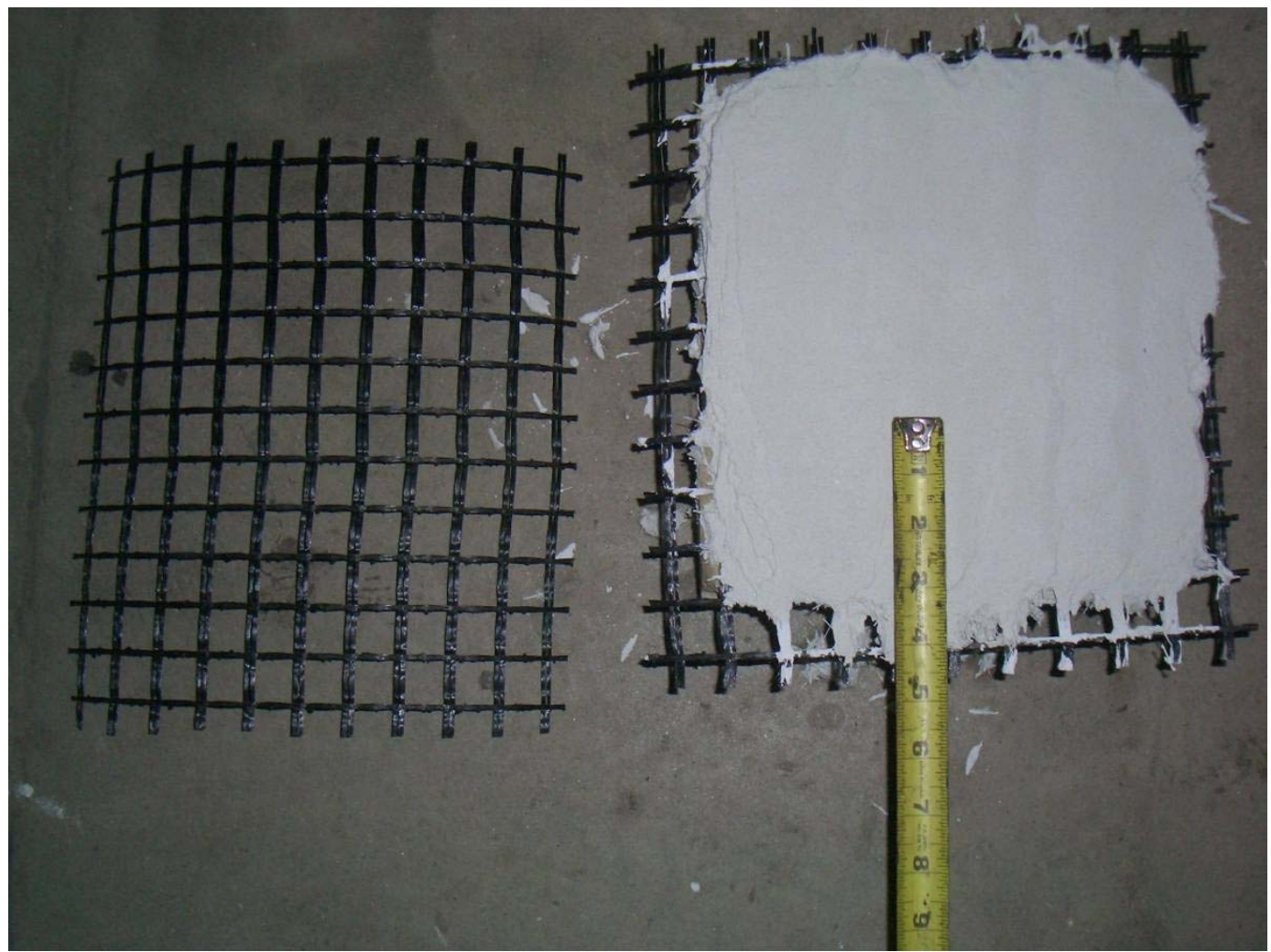

Figure 54. Coated Saint Gobain glass grid produced by Saint Gobain technical fabrics.

Table 8. Saint Gobain glass cement-base system.

\begin{tabular}{|l|l|l|}
\hline \multicolumn{1}{|c|}{ Material } & \multicolumn{1}{c|}{ Proportion } & \multicolumn{1}{c|}{ Remarks } \\
\hline Cementitious Material & Quikrete Quikwall & About 165 lb for all specimen \\
\hline Fortifier & Quikrete Concrete Acrylic Fortifier & About 2 gal and water \\
\hline & Water & 2.5 gal \\
\hline Reinforcing & Saint Gobain SRG grid & \\
\hline
\end{tabular}

The SFC system tested consisted of a coated Saint Gobain glass grid and a cementitious QuickWall ${ }^{\circledR}$ binder. The Saint Gobain glass grid was cut to the desired dimensions from a 30-in. wide roll for the wall reinforcement. The QuickWall ${ }^{\circledR}$ binder was mixed in an electric mortar mixer with water and an acrylic fortifier. The QuickWall ${ }^{\circledR}$ mix was then trowelled onto the wall approximately $1 / 8$-in. thick. The glass grid was pressed by hand into the wet QuickWall ${ }^{\circledR}$ in a vertical orientation parallel with the edge of the wall. At the butt joints where two separate sheets of Saint Gobain glass grid met, the edges of the sheets were overlapped 4 to 6 in. An additional layer of glass was applied by trowelling on another 1/8-in. thick layer of QuickWall ${ }^{\circledR}$ oriented perpendicular to the first and pressed by hand into the QuickWall ${ }^{\circledR}$. A final 1/8-in. thick layer of QuickWall ${ }^{\circledR}$ was applied to the wall and trowelled to a relatively smooth surface. 
The cementitious wall had a gap at the mortar joint between the fourth and $5^{\text {th }}$ courses in the top 90-degree grid ply approximately 1 -in. wide.

Each test specimen was allowed to cure for 30 days. Upon completion of the SFC application, QuickWall ${ }^{\circledR}$ extended beyond the edges of the wall specimens. The material that extended beyond the edge of the specimens was removed using a Sawsall with a masonry blade followed by a grinder to ensure the SFC did not extend above the top and bottom of the specimen. These steps ensured the vertical loading during testing was on the cementitious wall substrate and not on the SFC system itself.

\subsection{Instrumentation}

\subsubsection{Instrumentation and data acquisition}

Three types of instrumentation were employed during the tests to measure the response of the test wall: electrical resistance strain gages, linear variable displacement transformers (LVDTs), and cable extension transducers. The applied load and displacement of the hydraulic actuators were also measured.

\subsubsection{Strain gauges}

Electrical resistance strain gage rosettes were installed at the center brick of the in-plane test specimens. These strain gage rosettes were Vishay Micro-Measurements Group Model CEA-06-250UR-350 electrical resistance strain gages with constantan grids and complete polyamide encapsulation. The rectangular rosette consisted of three gages in a +45/o/-45 arrangement. Each sensing grid is $0.250 \mathrm{in}$. long by $0.120 \mathrm{in}$. wide. Each gauge was connected to a Vishay Measurements Group Model 2120B signal conditioner and 2110B Power supply to provide excitation voltage, balancing, and signal amplification. In this configuration, the strain gage formed one arm of the wheatstone bridge, and the remaining three arms were composed of precision resistors located in the signal conditioner.

\subsubsection{Linear variable displacement transducers (LVDTs)}

The Schaevitz Model 200HR LVDTs were used as extensiometers to measure the axial strain in the compression and out-of-plane tests and the diagonal strain on the in-plane wall specimens. The 200HR LVDTs have a range of $\pm 0.2 \mathrm{in}$. These transducers are AC-powered units that contain a set of transformer windings and a movable metal core, which is attached to the measurement point; when displacement occurs, the movement of the 
core changes the electrical coupling between the windings, which then changes the output signal. The LVDTs were connected to an RDP Group Modular 600 AC signal conditioner, which provided AC power, signal amplification, AC-to-DC conversion, and electrical balancing.

\subsubsection{Absolute displacement transducers}

Celesco Model PT101-10 cable extension displacement transducers were used to measure the absolute displacement at various locations on the outof-plane and in-plane test walls. These units employ a spring-loaded precision rotary potentiometer with a flexible steel cable wrapped around the potentiometer shaft. The other end of the cable is attached to the point where the displacement is to be measured. When displacement occurs, the cable motion rotates the shaft of the potentiometer, causing a change in resistance. These transducers were mounted on a steel reference frame affixed to the load floor, but independent of the test wall or the loading fixture. The transducer sensing elements were attached to the wall using standard steel extension wires. These transducers were connected to a Pacific Instruments 6000 series data acquisition and signal conditioning systems using their 6033-3 DC signal conditioning boards, which provide DC power, electrical balancing, and digital amplification.

\subsubsection{Data acquisition and test control}

All of the transducer output signals were connected to a 128 channel Pacific Instruments Model 6000 series data acquisition system and 6033-3 DC signal conditioning boards (Figure 55). The 6033-3 boards can provide DC signal conditioning, and can also be configured to measure the voltage outputs from the other signal conditioning used in the tests. The system was controlled by a personal computer through an instrument controller interface buss. The record channels were scanned at a predetermined sampling rate, and the data were recorded as unformatted binary files on the personal computer.

The loading system consisted of two CGS/Lawrence Model 307-50 and one Satec 100 kip servo-hydraulic actuator controlled by closed-loop servo controllers and an Instron 8800 multi-axis controller and RS Plus testing software.* The Satec actuator was operated in displacement control mode, and the 50 kip CGS actuators were operated in modal control mode.

\footnotetext{
*Instron, 825 University Ave, Norwood, MA 02062-2643, http://www.instron.com
} 


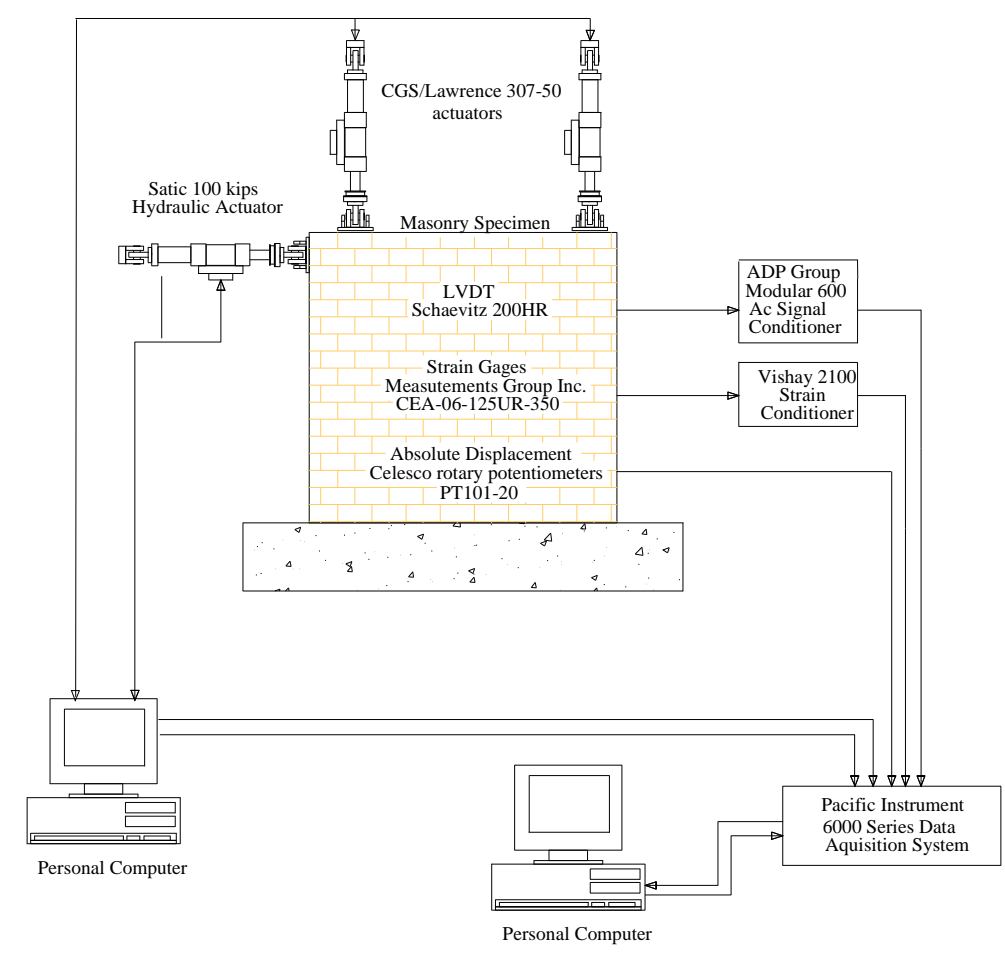

Figure 55. Functional block diagram of instrumentation, data acquisition, and test control systems.

In modal control mode, the actuators can be operated together in either displacement control or load control. The Instron controller sends a drive signal to each of the actuators, which causes them to move until the displacement or load measured by the LVDTs or by the loadcell located inside each actuator is equal to the command signal. The actuators displacement and load signals can be accessed on the Instron 8800 controller as an input into an external data acquisition system.

\subsection{Channels notation and description for the in-plane and out-of- plane testing}

Table 9 lists instrumentation notation and description for the In-Plane Testing. Figure 56 shows the instrumentation for the in-plane testing while Figure 57 shows the instrumentation for the out-of-plane testing. Table 10 provides a summary list of all tested specimens, dates, and vertical load control type. 
Table 9. Instrumentation Notations

\begin{tabular}{|l|l|l|}
\hline Name & \multicolumn{1}{|c|}{ Description } & Notes \\
\hline FH & Horizontal force in kips & 200 kip loadcell \\
\hline DH & Horizontal displacement in inches & Long stroke actuator LVDT \\
\hline F TOTAL & Total vertical force in kips & Sum of the two vertical 50 kip loadcells \\
\hline DV & Vertical displacement & Average of the two vertical actuator LVDTs \\
\hline ELVDT & LVDT placed on the east side of the specimen & $+/-0.2$ in. LVDT \\
\hline WLVDT & LVDT placed on the west side of the specimen & $+/-0.2$ in. LVDT \\
\hline Diff D & Differential displacement between vertical actuators & \\
\hline FVN & Force in the north vertical actuator in kips & 50 kip loadcell \\
\hline FVS & Force in the south vertical actuator in kips & 50 kip loadcell \\
\hline DB & Displacement at bottom of specimen in inches & $+/-10$ in. yoyo gage \\
\hline DC & Displacement at center of specimen in inches & $+/-10$ in. yoyo gage \\
\hline DT & Displacement at top of specimen in inches & $+/-10$ in. yoyo gage \\
\hline SG -45 & Rosette Vertical Node & For in-plane testing only \\
\hline SG Vertical & Rosette -45I Node & For in-plane testing only \\
\hline SG + 45 & Rosette +45 I Node & For in-plane testing only \\
\hline
\end{tabular}

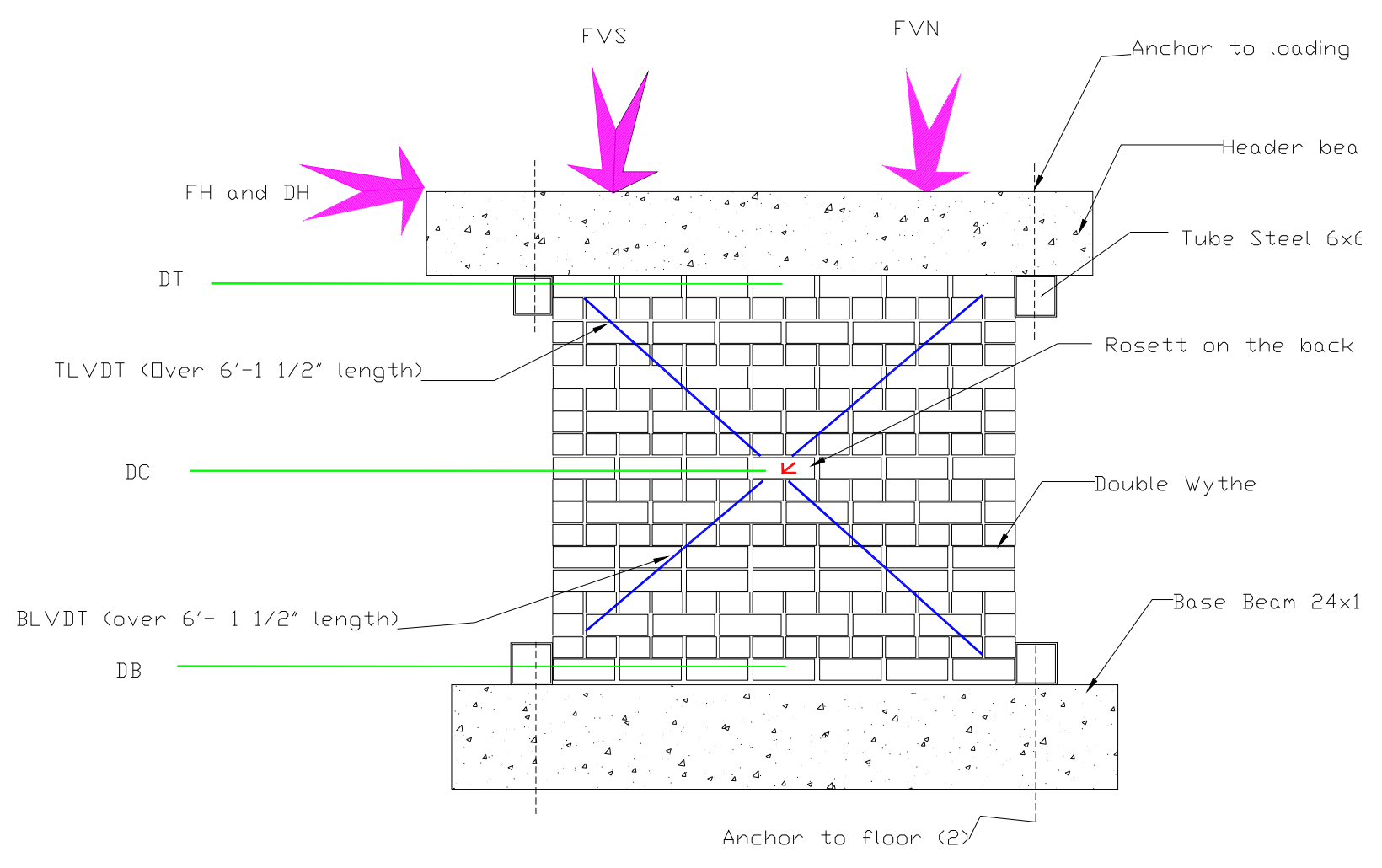

Figure 56. Instrumentation for the in-plane testing. 


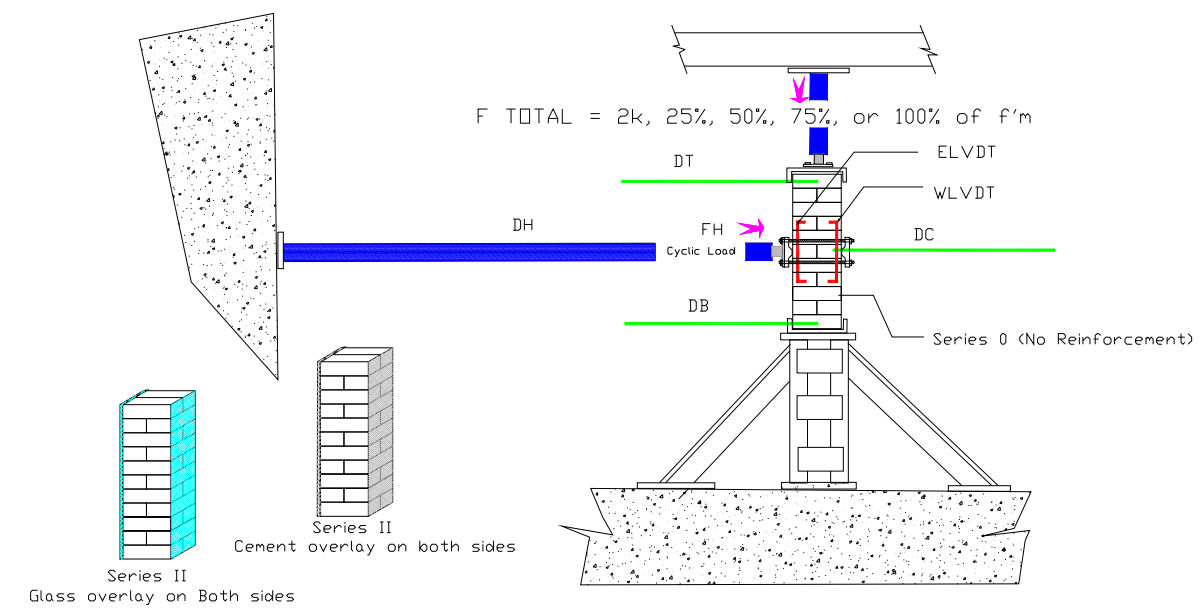

Figure 57. Instrumentation for the out-of-plane plane testing.

Table 10. All tested specimens, dates, and vertical load control type.

\begin{tabular}{|l|c|c|c|c|c|}
\hline Specimen ID* & $\begin{array}{c}\text { Date Bricks } \\
\text { Assembled }\end{array}$ & $\begin{array}{c}\text { Date GFRP } \\
\text { Applied }\end{array}$ & $\begin{array}{c}\text { Date } \\
\text { Tested }\end{array}$ & $\begin{array}{c}\text { Control } \\
\text { of } \\
\% \text { of f'm }\end{array}$ & $\begin{array}{c}\text { Vertical } \\
\text { Loads }\end{array}$ \\
\hline OP-01 & $7 / 11 / 2007$ & N/A & $8 / 16$ & $100 \%$ & Load \\
\hline OP-02 & $7 / 16 / 2007$ & N/A & $8 / 16$ & $100 \%$ & Load \\
\hline OP-04 & $7 / 12 / 2007$ & N/A & $8 / 23$ & $8.4 \%$ & Load \\
\hline OP-06 & $7 / 12 / 2007$ & N/A & $8 / 23$ & $8.4 \%$ & Load \\
\hline OP-07 & $7 / 12 / 200$ & N/A & $8 / 23$ & $50 \%$ & Load \\
\hline OP-09 & $7 / 12 / 2007$ & N/A & $9 / 14$ & $50 \%$ & Load \\
\hline OP-010 & $7 / 11 / 2007$ & N/A & $9 / 14$ & $25 \%$ & Load \\
\hline OP-011 & $7 / 12 / 2007$ & N/A & $9 / 14$ & $75 \%$ & Load \\
\hline OP-012 & $7 / 11 / 2007$ & N/A & $8 / 28$ & $75 \%$ & Load \\
\hline OP-C1 & $7 / 16 / 2007$ & $7 / 17 / 2007$ & $8 / 16$ & $100 \%$ & Load \\
\hline OP-C2 & $7 / 12 / 2007$ & $7 / 17 / 2007$ & $8 / 16$ & $100 \%$ & Load \\
\hline OP-C3 & $7 / 11 / 2007$ & $7 / 17 / 2007$ & $8 / 21$ & $6.3 \%$ & Load \\
\hline OP-C4 & $7 / 12 / 2007$ & $7 / 17 / 2007$ & $8 / 23$ & $6.3 \%$ & Load \\
\hline OP-C5 & $7 / 12 / 2007$ & $7 / 17 / 2007$ & $8 / 27$ & $75 \%$ & Load \\
\hline OP-C6 & $7 / 12 / 2007$ & $7 / 17 / 2007$ & $8 / 27$ & $25 \%$ & Stroke \\
\hline OP-C7 & $7 / 11 / 2007$ & $7 / 17 / 2007$ & $8 / 28$ & $25 \%$ & Load \\
\hline OP-C8 & $7 / 11 / 2007$ & $7 / 17 / 2007$ & $8 / 24$ & $50 \%$ & Load \\
\hline OP-G1 & $7 / 11 / 2007$ & $7 / 17 / 2007$ & $8 / 16$ & $100 \%$ & Load \\
\hline OP-G2 & $7 / 12 / 2007$ & $7 / 17 / 2007$ & $8 / 16$ & $100 \%$ & Load \\
\hline OP-G3 & $7 / 12 / 2007$ & $7 / 17 / 2007$ & $8 / 21$ & $6 \%$ & Load \\
\hline OP-G4 & $7 / 11 / 2007$ & $7 / 17 / 2007$ & $8 / 23$ & $6 \%$ & Load \\
\hline OP-G5 & $7 / 12 / 2007$ & $7 / 17 / 2007$ & $8 / 28$ & $50 \%$ & Load \\
\hline OP-G6 & $7 / 11 / 2007$ & $7 / 17 / 2007$ & $8 / 28$ & $25 \%$ & Load \\
\hline
\end{tabular}




\begin{tabular}{|l|c|c|c|c|c|}
\hline & Specimen ID* & $\begin{array}{c}\text { Date Bricks } \\
\text { Assembled }\end{array}$ & $\begin{array}{c}\text { Date GFRP } \\
\text { Applied }\end{array}$ & $\begin{array}{c}\text { Date } \\
\text { Tested } \\
\text { of } \\
\text { Vertical } \\
\text { Loads }\end{array}$ & $\begin{array}{c}\text { Planned } \\
\% \text { of f'm }\end{array}$ \\
\hline OP-G7 & $7 / 11 / 2007$ & $7 / 17 / 2007$ & $8 / 24$ & $50 \%$ & Load \\
\hline OP-G8 & $7 / 11 / 2007$ & $7 / 17 / 2007$ & $8 / 24$ & $75 \%$ & Load \\
\hline IP-01 & $6 / 8 / 2007$ & N/A & Not tested & N/A & Load \\
\hline IP-02 & $6 / 8 / 2007$ & N/A & $9 / 11 / 2007$ & $8.4 \%$ & Load \\
\hline IP-G1 & $6 / 8 / 2007$ & $7 / 27 / 2007$ & $9 / 10 / 2007$ & $6.0 \%$ & Load \\
\hline IP-C1 & $6 / 8 / 2007$ & $7 / 22 / 2007$ & $9 / 9 / 2007$ & $6.3 \%$ & Load \\
\hline * OP= out-of-plane, IP=in plane, O=no reinforcement, C=Cement base polymer, \\
G= Glass FRP, \#: sequence numbers.
\end{tabular}

Figure 58 shows the test specimens' notation.

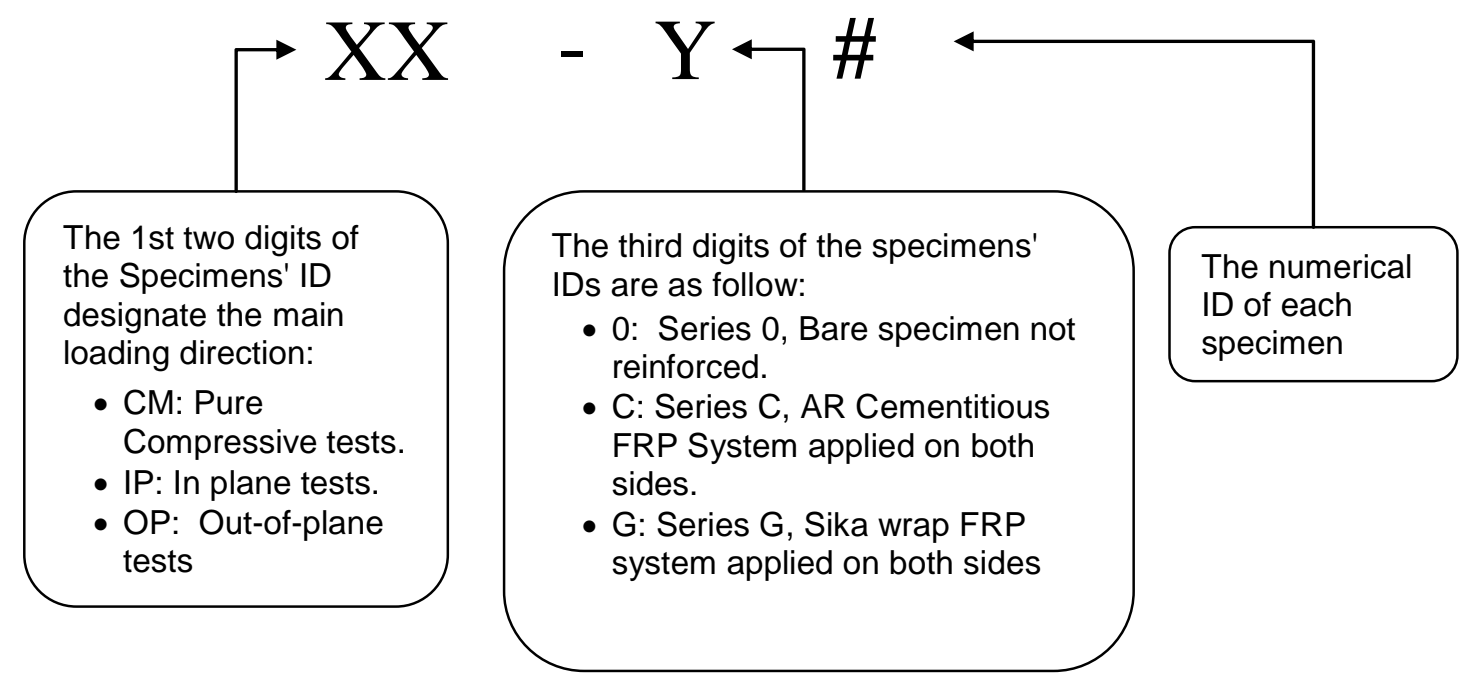

Figure 58. Test specimen notation.

\subsection{Selection of cyclic loading protocol for the masonry specimens}

Loading laboratory specimens for seismic tests were selected so the data from various tests can be compared and the laboratory loadings can be representative of actual seismic demands. Although no single loading protocol is perfect, procedures were selected to minimize variations induced from building material, system response and configuration, or field variability.

Five methods were examined for the project to determine their characteristics and their suitability for the experimental model. These methods con- 
sist of the ACI Acceptance Criteria for Moment Frames Based on Structural Testing, the Applied Technology Council 24 (ATC-24) Guidelines for Cyclic Seismic Testing of Components of Steel Structures, the California Universities for Research in Earthquake Engineering (CUREe) Testing Protocol for Wood Frame Structures, the Scientific Advisory Committee (SAC) Basic Loading History for Beam-to-Column Assemblies, and the Structural Engineers Association of Southern California (SEAOC) Standard Method of Cyclic Load Test for Shear Resistance of Framed Walls for Buildings. Even though these methods were developed for various system types, their basis and logic can be justified.

Comparisons of these methods are based on the assumptions governing the loading protocol, the structural system for which the method was designed, the variable controlling the magnitude of load increments, the general increase in amplitude for each load increment, the general pattern of the cyclic load history, and the number of cycles required to reach a predetermined maximum expected displacement. For the experiment at hand, the maximum displacement is set at 3 in. For the purpose of comparison, all of these methods are based on an exaggerated loading time of 120 minutes while the most tests are expected to last a maximum of 13 minutes. The loading time can be adjusted as desired.

\subsubsection{Investigation of existing cyclic loading methods}

Loading protocols are often characterized by number of cycles, loading time and rate, loading patterns, amplitude of cycles, and deformation increments. The first step to generate a loading protocol is to choose the deformation parameter that controls the loading history. This parameter can be the interstory drift angle $(\theta)$, deformation at yield ( $\delta$ y), deformation at ultimate load ( $\delta \mathrm{u}$ ), or first major event (FME). Loading patterns consist of load steps in which every load step has an equal number of cycles with equal amplitude. Loading patterns also may have trailing or decay cycles. In all protocols, the initial load steps and initial load increments are designed to fall within the elastic zone of the experimental model.

For each of the test methods discussed in this report, the deformation controlling parameter was chosen based on previous experimental data of single-story models. In the lack of experimental data, the deformation controlling parameter can be estimated analytically. A value of $0.15 \mathrm{in}$. was found to be the value of single-story displacement at ultimate load. Since the test specimen lacks a well-defined yield point, a value of one-third $\delta_{u}$ was used to describe the linear elastic limit. For each cyclic loading his- 
tory, the test was assumed to end once a displacement of approximately 3 in. had been reached. Initially, a frequency of $0.1 \mathrm{~Hz}$ for each cycle was chosen to calculate the number of cycles required to complete the loading history.

\subsubsection{ACI method}

The ACI method was originally designed for $\mathrm{R} / \mathrm{C}$ moment frames. The initial displacement is specified to be within the linear elastic range of the test specimen. A value of 0.0005 was chosen as the initial drift ratio. This value is well within the linear response of the experimental model and followed closely with initial amplitudes calculated for the other loading histories studied. Values of subsequent cycles were set to 1.25 times the previous drift ratio. Three fully reversed cycles at each load increment would be performed. This loading pattern is continued for 50 cycles when the specified displacement of 3 in. is finally reached.

\subsubsection{ATC-24 method}

The cyclic loading method proposed by ATC-24 was originally designed for steel structures. However, a comparison of this test procedure versus other cyclic loading methods (Table 11) might be useful. The amplitude of each cycle is based on the yield deformation, $\delta_{\mathrm{y}}$. ATC-24 requires a minimum of at least six cycles below $\delta_{y}$, three cycles equal to $\delta_{y}$, three cycles equal to $2 \delta_{\mathrm{y}}$, three cycles equal to $3 \delta_{\mathrm{y}}$, and two cycles at $4 \delta_{\mathrm{y}}$. Load steps possessing two cycles each were continued for integral values of $\delta_{\mathrm{y}}$ until a displacement of 3 in. had been achieved. Furthermore, ATC-24 recommended that three cycles be performed at $0.75 \mathrm{Q}_{\mathrm{y}}$, where $\mathrm{Q}_{\mathrm{y}}$ is the yield force.

Table 11. ATC-24 Method type and number of cycles.

\begin{tabular}{|l|l|c||c|l|c|}
\hline Displacement & $\begin{array}{c}\text { Type of } \\
\text { Cycle }\end{array}$ & $\begin{array}{c}\text { No. of } \\
\text { Cycles }\end{array}$ & Displacement & $\begin{array}{c}\text { Type of } \\
\text { Cycle }\end{array}$ & $\begin{array}{c}\text { No. of } \\
\text { Cycles }\end{array}$ \\
\hline 0 & - & 0 & $0.4 \Delta$ & Primary & 1 \\
\hline $0.05 \Delta$ & Initiation & 6 & $*$ & Trailing & 2 \\
\hline $0.075 \Delta$ & Primary & 1 & $0.7 \Delta$ & Primary & 1 \\
\hline$*$ & Trailing & 6 & $*$ & Trailing & 2 \\
\hline $0.1 \Delta$ & Primary & 1 & $1.0 \Delta$ & Primary & 1 \\
\hline$*$ & Trailing & 6 & $*$ & Trailing & 2 \\
\hline $0.2 \Delta$ & Primary & 1 & $1.5 \Delta$ & Primary & 1 \\
\hline$*$ & Trailing & 3 & $*$ & Trailing & 2 \\
\hline $0.3 \Delta$ & Primary & 1 & $0.4 \Delta$ & Primary & 1 \\
\hline$*$ & Trailing & 3 & $*$ & Trailing & 2 \\
\hline
\end{tabular}




\begin{tabular}{|l|c|c||l|c|c|}
\hline Displacement & $\begin{array}{c}\text { Type of } \\
\text { Cycle }\end{array}$ & $\begin{array}{c}\text { No. of } \\
\text { Cycles }\end{array}$ & Displacement & $\begin{array}{c}\text { Type of } \\
\text { Cycle }\end{array}$ & $\begin{array}{c}\text { No. of } \\
\text { Cycles }\end{array}$ \\
\hline Note: * symbolizes $75 \%$ of the magnitude \\
\hline
\end{tabular}

\subsubsection{CUREe protocol}

The loading history discussed in this section was developed for the CUREe/Caltech Woodframe Project. The method was designed to capture the demand characteristics unique to the wood structures in their project. The loading history is based on the results of nonlinear dynamic analysis of representative hysteretic systems subjected to ordinary and near-fault ground motions. The loading history is comprised of initiation, primary, and trailing cycles. Initiation cycles are executed at the beginning of the load history. They serve to check loading equipment, measurement devices, and the force-deformation response of the test specimen. Primary cycles are of larger magnitude than all of the previous cycles and are followed by trailing cycles. Trailing cycles have amplitudes equal to 75 percent of the preceding primary cycle. All cycles are based on a reference deformation, $\Delta$. This deformation is the maximum deformation the test specimen is expected to sustain according to a prescribed acceptance criterion. To reach 3 in. of displacement, 40 cycles were required by this loading protocol

\subsubsection{SAC method}

This loading history is based on the ATC-24 method. However, changes in the loading history were made to address a single-specimen testing program. The SAC testing protocol is concerned with beam-to-column assemblies. The deformation parameter used to control the loading history is the interstory drift angle, $\theta$. Modification of this parameter was necessary to address the masonry. Table 12 lists data that illustrate the modified SAC testing protocol using the factor mentioned above. To reach 3 in. of displacement, 50 cycles were required by this loading protocol.

Table 12. SAC method description.

\begin{tabular}{|c|c|c|c|}
\hline $\begin{array}{c}\text { Recommended } \\
\text { Amplitude }\end{array}$ & $\begin{array}{c}\text { Scaled } \\
\text { Amplitude }\end{array}$ & $\begin{array}{c}\text { Equivalent } \\
\text { Displacement }\end{array}$ & $\begin{array}{c}\text { No. of } \\
\text { cycles }\end{array}$ \\
\hline $0.00375 \theta$ & $0.00047 \theta$ & 0.084 in. & 6 \\
\hline $0.005 \theta$ & $0.00063 \theta$ & 0.113 in. & 6 \\
\hline $0.0075 \theta$ & $0.00094 \theta$ & 0.169 in. & 6 \\
\hline $0.01 \theta$ & $0.00125 \theta$ & 0.225 in. & 4 \\
\hline $0.015 \theta$ & $0.00188 \theta$ & 0.338 in. & 2 \\
\hline $0.02 \theta$ & $0.00250 \theta$ & 0.45 in. & 2 \\
\hline
\end{tabular}




\begin{tabular}{|l|c|c|c|}
\hline $\begin{array}{c}\text { Recommended } \\
\text { Amplitude }\end{array}$ & $\begin{array}{c}\text { Scaled } \\
\text { Amplitude }\end{array}$ & $\begin{array}{c}\text { Equivalent } \\
\text { Displacement }\end{array}$ & $\begin{array}{c}\text { No. of } \\
\text { cycles }\end{array}$ \\
\hline $0.03 \theta$ & $0.00375 \theta$ & 0.675 in. & 2 \\
\hline$\star$ & & & $2,2, \ldots$ \\
\hline $\begin{array}{l}\text { Note: * represents load increments increasing in } \theta \text { by } 0.01 \\
\text { until a displacement of } 3 \text { in. is reached. }\end{array}$ \\
\hline
\end{tabular}

\subsubsection{SEAOC method}

The SEAOC method was developed to determine shear stiffness and shear strength of framed shear wall systems. The increments selected for the sequential phased displacement procedure are based on the First Major Event, which is the first significant Limit State to occur. The loading procedure consists of applying three cycles of fully-reversing displacement, at each displacement increment representing 25, 50, and 75 percent of FME. Then, wall displacement is increased for one cycle to 100 percent FME. Next, "decay" cycles each at 75, 50, and 25 percent of maximum displacement are applied, followed by three cycles of displacement at maximum displacement, to stabilize the force-displacement response of the wall. Then, the next increment of increased displacement (125 percent of FME) is applied, followed by similar decay and stabilization cycles. The incremental force-displacement and decay cycles are repeated for 150, 175, 200, 250, and 300 percent of FME. The load increments are increased by 50 percent of FME until 3 in. of displacement has been reached.

\subsubsection{Selection of loading history}

After considering all of these loading protocols, the CUREe method seemed best suited for the test on the brick wall models. The main reason was the incorporation of trailing cycles into the loading history. This enables the force-displacement relationship to stabilize before reaching the next primary cycle. Although the SEAOC method also included similar cycles, the total number of cycles needed to complete this test would have caused too much damage to the test specimen. Table 13 lists the different cyclic loading methods. The CUREe Loading History was modified to meet the test duration and loading rate appropriate for tested models (Figure $59)$. 
Table 13. Comparison of different cyclic loading methods.

\begin{tabular}{|c|c|c|c|c|c|c|}
\hline & $\begin{array}{l}\text { Method } \\
\text { designed } \\
\text { for... }\end{array}$ & $\begin{array}{l}\text { Load } \\
\text { Increments } \\
\text { based on... }\end{array}$ & $\begin{array}{l}\text { “General” Cyclic } \\
\text { Description }\end{array}$ & $\begin{array}{c}\text { \# of Cycles } \\
\text { until 3" } \\
\text { Displacement }\end{array}$ & $\begin{array}{l}\text { "General" } \\
\text { Increase in } \\
\text { Amplitude } \\
\text { for Each } \\
\text { Load } \\
\text { Increment }\end{array}$ & Remarks \\
\hline $\bar{O}$ & $\begin{array}{l}\text { R/C Mo- } \\
\text { ment } \\
\text { Frames }\end{array}$ & Drift ratio $\theta$ & $\begin{array}{l}3 \text { fully reversed } \\
\text { cycles for each } \\
\text { load increment }\end{array}$ & 50 & $\begin{array}{l}\theta_{\mathrm{i}}=1.25 \\
\star \theta_{\mathrm{i}-1}\end{array}$ & $\begin{array}{l}\text { Amplitude for first } \\
\text { cycle must be in } \\
\text { the linear elastic } \\
\text { range determined } \\
\text { by the experi- } \\
\text { menter }\end{array}$ \\
\hline స̃ & $\begin{array}{l}\text { Steel } \\
\text { Structures }\end{array}$ & $\delta_{y}$ & $\begin{array}{l}3,3,3,3,3,2, \\
2, \ldots\end{array}$ & 49 & $\begin{array}{l}\text { Increase } \\
\text { displace- } \\
\text { ment by } \delta_{y}\end{array}$ & $\begin{array}{l}\text { Suggests cycles in } \\
\text { the elastic range } \\
\text { be performed with } \\
\text { force control, while } \\
\text { all other cycles be } \\
\text { performed with } \\
\text { deformation control }\end{array}$ \\
\hline 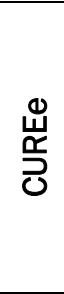 & $\begin{array}{l}\text { Wood } \\
\text { shear } \\
\text { panels }\end{array}$ & $\Delta$ & $\begin{array}{l}6 \text { initiation cy- } \\
\text { cles, then } 1 \text { pri- } \\
\text { mary cycle and } \\
\text { several trailing } \\
\text { cycles for each } \\
\text { load increment }\end{array}$ & 40 & $\begin{array}{l}\text { Increase } \\
\text { displace- } \\
\text { ment by } \\
0.5 * \Delta\end{array}$ & $\begin{array}{l}\text { Initiation cycles are } \\
\text { performed only at } \\
\text { start of test. } \\
\text { Two variations of } \\
\text { this method sim- } \\
\text { plify and reduce } \\
\text { the \# of cycles }\end{array}$ \\
\hline ले & $\begin{array}{l}\text { Beam- } \\
\text { column } \\
\text { tests } \\
\text { (based on } \\
\text { ATC) }\end{array}$ & $\begin{array}{l}\text { Interstory } \\
\text { drift angle } \theta\end{array}$ & $\begin{array}{l}6,6,6,4,2,2, \\
\cdots\end{array}$ & 50 & $\begin{array}{l}\text { Increase } \theta \\
\text { by } 0.01\end{array}$ & $\begin{array}{l}\text { Displacement in- } \\
\text { crements were } \\
\text { modified to take } \\
\text { into consideration } \\
\text { infill effects }\end{array}$ \\
\hline 安 & $\begin{array}{l}\text { Framed } \\
\text { shear wall } \\
\text { systems } \\
\text { (based on } \\
\text { ASTM E } \\
564-76)\end{array}$ & $\begin{array}{l}\text { First major } \\
\text { even (FME) }\end{array}$ & $\begin{array}{l}3 \text { stabilization } \\
\text { cycles, } 1 \text { peak } \\
\text { displacement } \\
\text { cycle, } 3 \text { "decay" } \\
\text { cycles for each } \\
\text { load increment }\end{array}$ & 296 & $\begin{array}{l}\text { Increase } \\
\text { displace- } \\
\text { ment by } \\
50 \% \text { FME }\end{array}$ & $\begin{array}{l}\text { Many more cycles } \\
\text { than other meth- } \\
\text { ods. Decay and } \\
\text { stabilization cycles } \\
\text { are used to stabi- } \\
\text { lize the force- } \\
\text { displacement re- } \\
\text { sponse of the test } \\
\text { specimen }\end{array}$ \\
\hline
\end{tabular}




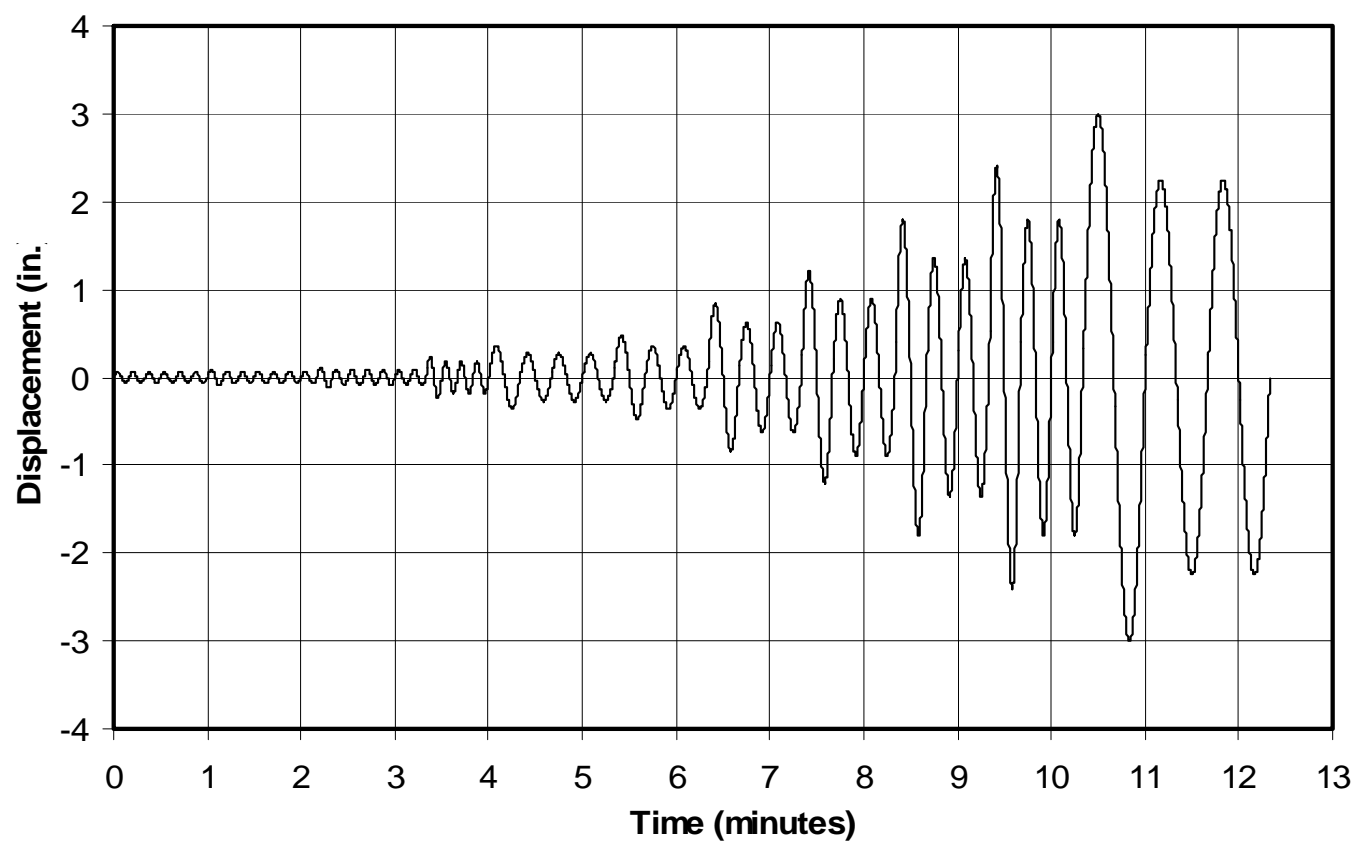

Figure 59. Modified CUREe loading history used for all lab specimens. 


\section{Experimental Results}

This chapter will discuss the experimental results for the in-plane wall tests and out-of-plane strip tests. The in-plane tests will be discussed first, followed by the compressive tests results. The maximum value of the compressive tests would be used as a base line to determine the vertical load to achieve a desired percentage of stress for each case of the out-of-plane cyclic load tests. Finally, the out-of-plane results will be discussed and compared. This chapter will also describe the modes of failure visually observed during testing. The modes of failure are important in load comparison and also in predicting the failure in the field. The duration from the initiation of the crack until ultimate failure can indicate the system's capability to absorb energy. The locations where cracks are initiated denote the weak links in the tested member.

\subsection{In-plane tests on wall specimens with and without FRP}

The three in-plane wall tests were conducted using a predetermined vertical stress as designated by the project design team (the protocol as discussed in Chapter 4). Table 14 lists the dimensions, configuration, and the desired pre-vertical load.

\subsection{Modes of failure and experimental results for specimen IP-02}

This specimen was tested supplementally with four steel tubes to provide direct loading to the upper and lower corners of the wall. Figure 60 shows failure at several stages of the test. The first indication of damage was spalling observed on a single brick along one of the diagonals (Figure $60 b)$. Figure 6oc and 6od show the "X" shear cracks formed as the wall deformed under increased cyclic loading. Spalling of brick units occurred in many places. One edge of the wall failed under the vertical load and collapsed (Figure 6oe and 6of).

Table 14. Geometric properties of the walls and their design stress.

\begin{tabular}{|l|c|c|c|c|c|}
\hline & $\begin{array}{c}\text { Length } \\
\text { (in) }\end{array}$ & $\begin{array}{c}\text { Thickness } \\
\text { (in) }\end{array}$ & $\begin{array}{c}\text { Area } \\
\text { (in }{ }^{2}\end{array}$ & $\begin{array}{c}\text { Vertical Stress } \\
\text { at 15kips * }\end{array}$ & Height \\
\hline Wall IP 02 & 67.75 & 9 & 609.75 & 24.6 & 60 \\
\hline Wall IP C1 & 67 & 9 & 603 & 24.9 & 60 \\
\hline Wall IP G1 & 66 & 9 & 594 & 25.3 & 60 \\
\hline * 15 kips is given by the designer.
\end{tabular}




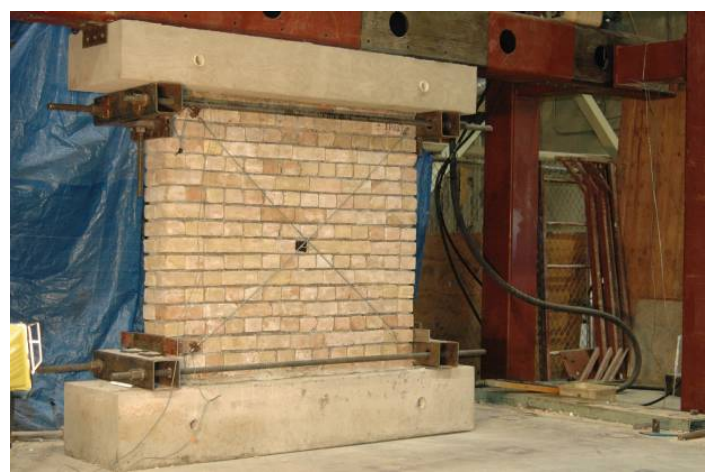

a. Wall prior to testing.

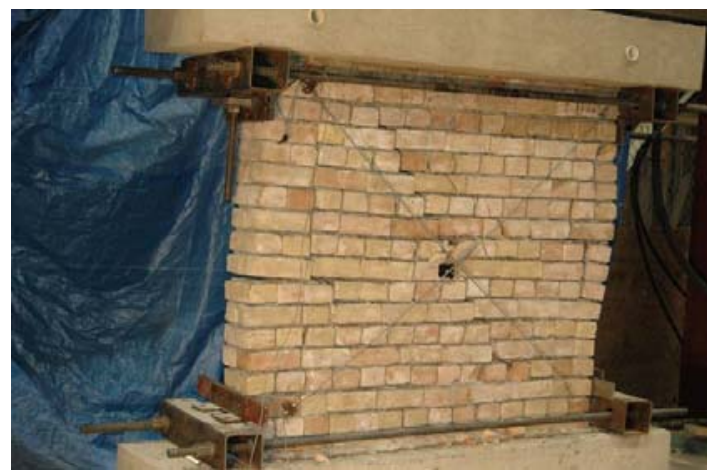

c. Wall formation of $\mathrm{X}$ cracks under cyclic loads.

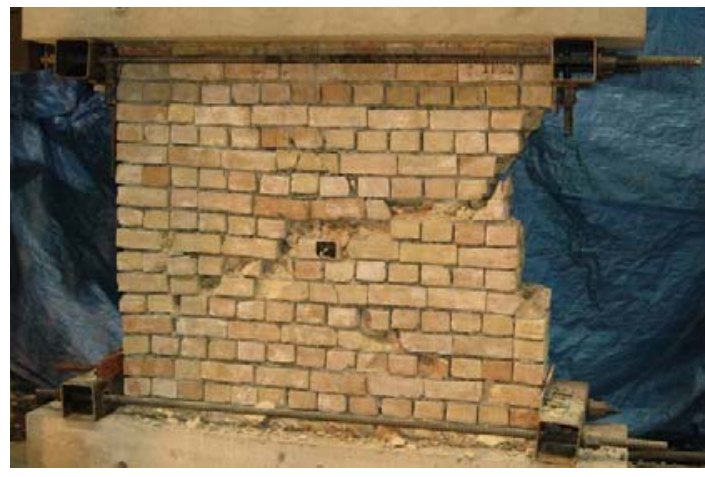

e. Collapsed edge of the wall (front view).

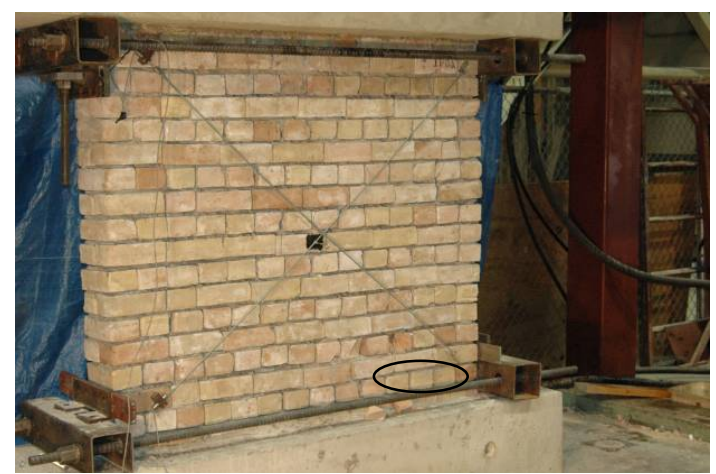

b. Wall spalling in a brick in the 4 th course.

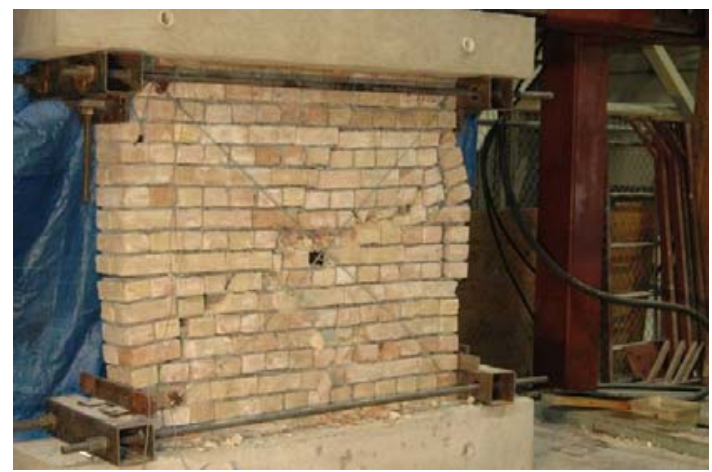

d. Cambered wall edge.

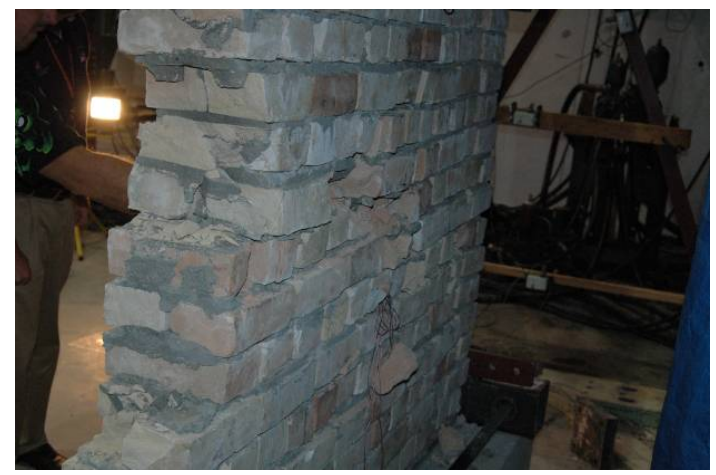

f. Collapsed edge of the wall (Section view).

Figure 60. The modes of failure for IP-02 specimens.

For analysis, the horizontal load data was converted to pounds and divided by the cross-sectional area of the appropriate specimen to obtain the stress value in pounds per square inch (psi). The corresponding displacement values were adjusted by the initial offset value such that the values would start at zero. The data was examined for slippage and unstable behavior, and data collected during the unstable behavior of the model was trimmed. This modified data was transferred to SigmaPlot and graphed (Figure 61). From the load displacement curves shown in light grey, a backbone curve was developed (shown in black). The backbone curve was developed by drawing a single line through the intersecting points of the first cycle of each increasing displacement cycle. 


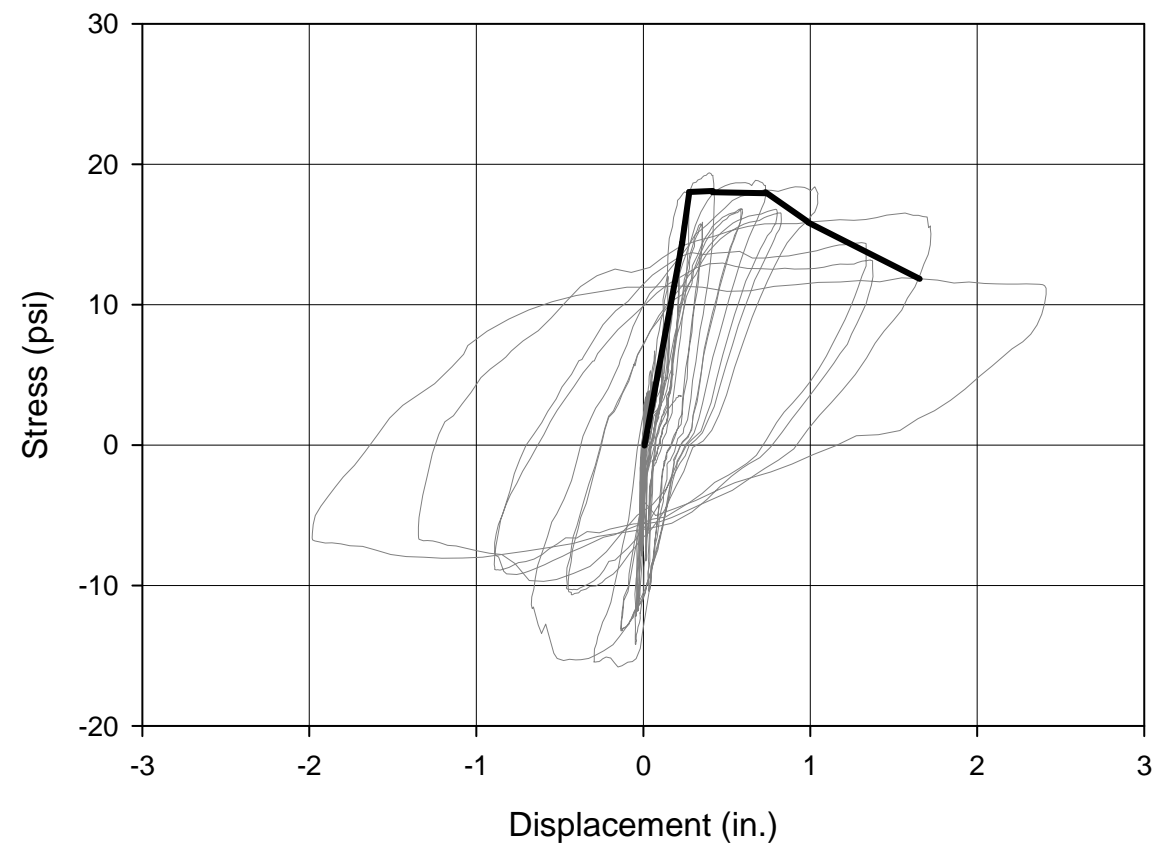

Figure 61. Specimen IP02 hysteresis curve for load versus displacement and backbone curves.

The maximum value of stress reached in the unimproved (bare) specimen is $19.4 \mathrm{psi}$ at displacement of $0.4 \mathrm{in}$. The maximum displacement value reached is $2.4 \mathrm{in}$., which corresponds to the stress value of $11.1 \mathrm{psi}$. The maximum stress value on the backbone curve is $17.5 \mathrm{psi}$, which corresponds to displacement value of 0.25 in.

\subsubsection{Specimen IP-C1}

As the first wall was tested, issues with the loading set up and test protocol were identified and adjustments were made. Because of the changes, three test runs were actually carried out on this specimen. Figure 62 shows various modes of failure.

\subsubsection{1st run}

This run was tested without the corner loading steel tubes. All load transfer from the loading beam to the wall had to occur through shear between the concrete loading beam and the brick. Because the FRP overlay was not bonded to the concrete loading beam, the FRP did not contribute to the transfer of load. Because of this, a weak shear plane existed, and horizontal shear failure in the top brick course was observed. 


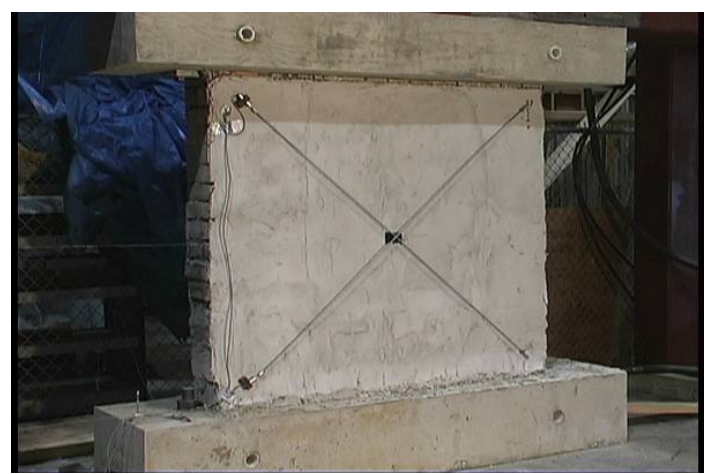

a. IP-C1 Wall prior to testing. Direct load on the header concrete beam.

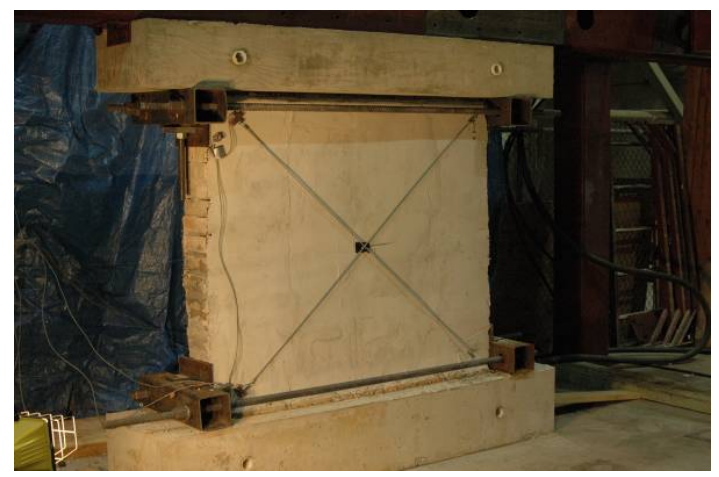

c. IP-C1 Wall prior to testing with loading tube steel beam at the corners.

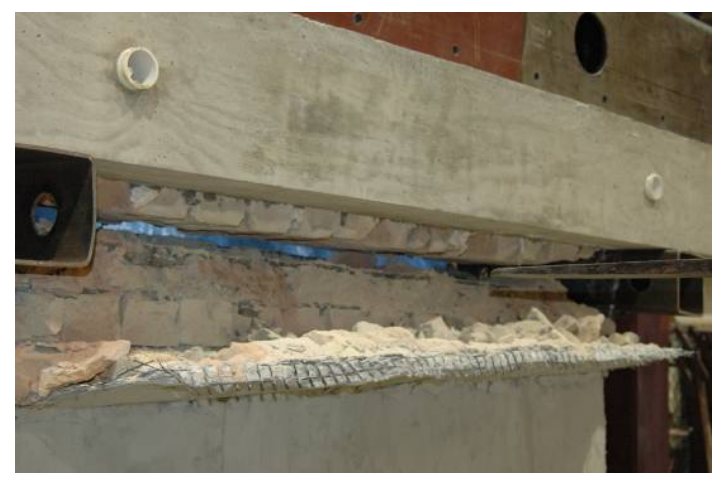

e. IP-C1 Wall after monotonic loading follow the above cyclic testing. Horizontal shear failure through the FRP.

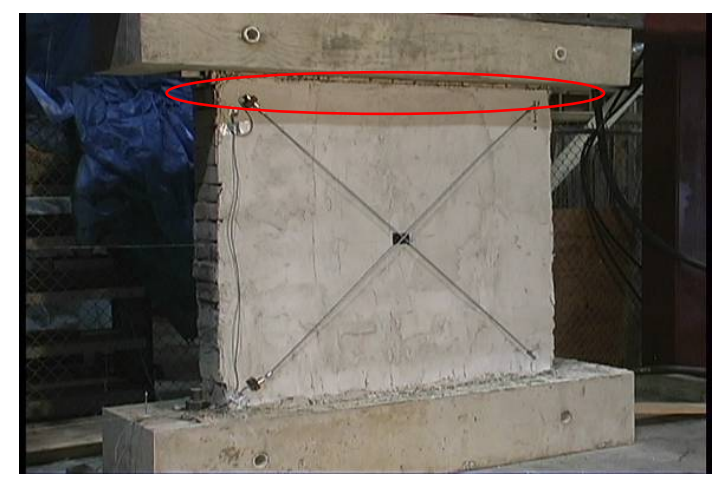

b. IP-C1 Wall after testing horizontal shear failure in the top course of the brick.

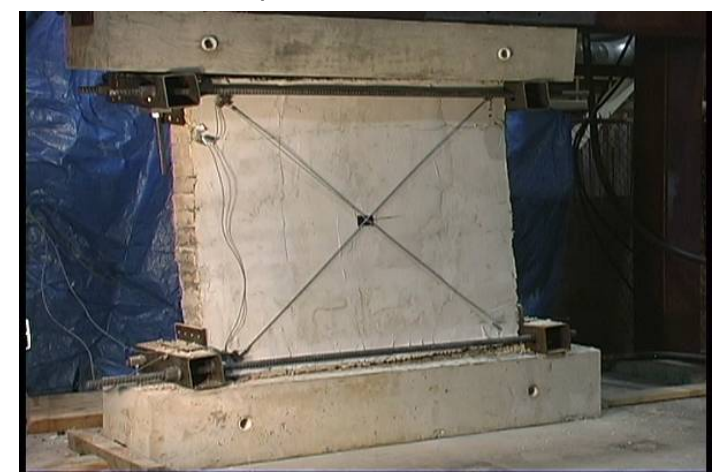

d. IP-C1 Wall during cyclic testing shown uplift as the specimen rocks (with loading tube steel beam at the corners).

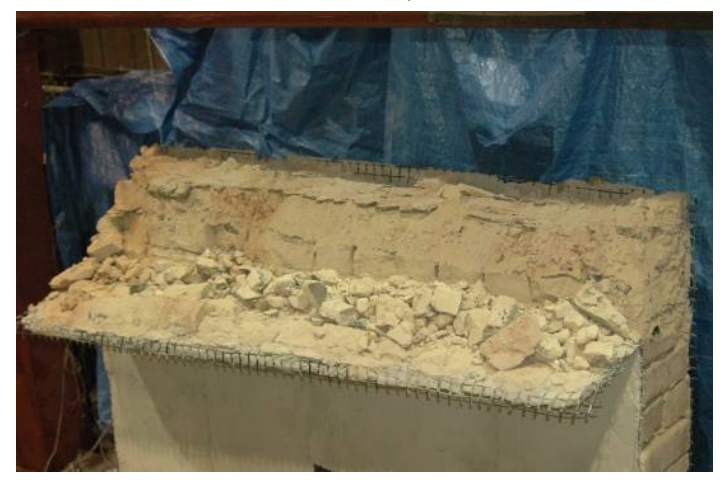

f. IP-C1 Wall after monotonic loading and after removing the unsound brick along the failure surface.

Figure 62. The modes of failure for IP-C1 specimens.

This mode of failure is not desirable because the wrap is not effective in this section and test results will not capture the contribution of the overlay wrap system. No damage to the wall other than debonding of the wall to the load beam occurred.

The maximum value of stress reached in this run was $19.3 \mathrm{psi}$ at a displacement of $0.1 \mathrm{in}$. The maximum displacement value reached was $1.8 \mathrm{in}$ and corresponded to a stress value of 13.4 psi (Figure 63). 


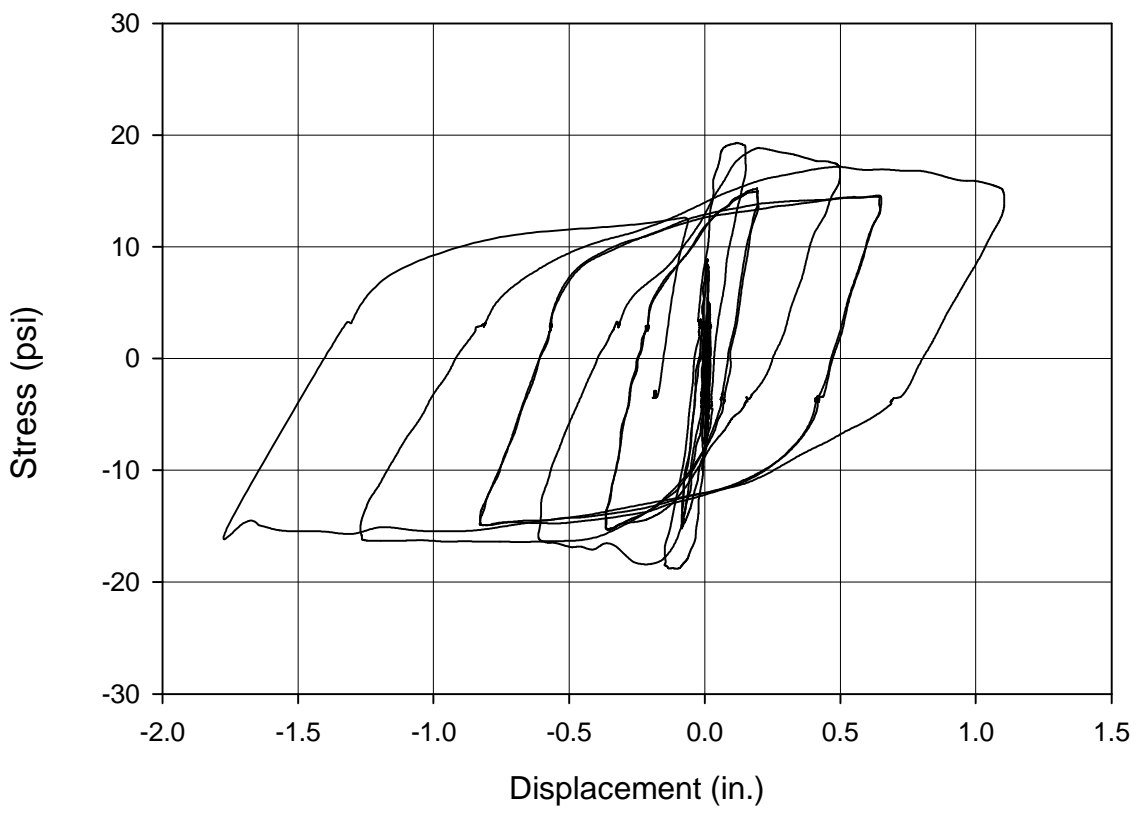

Figure 63. IPC1 pretest.

\subsubsection{2nd run}

To prevent the shear failure seen in the Run 1 from occurring, four corner loading steel tubes were added to the model to load the wall at the upper and lower corners, and to force the failure in the wrap reinforced section. In this test, which is considered to be the test that accurately represents the behavior of the wall under shear load, the wall became unbonded from the top and bottom load beams and rocked as a solid unit under cyclic loading (Figure 62d). Corner cracks were observed at the toe. Figure 64 shows the stress-displacement curve. The maximum value of stress reached is $23.0 \mathrm{psi}$ at a displacement of $1.4 \mathrm{in}$. The maximum displacement value reached is 1.5 in and the corresponding stress value was 18.8 psi. The maximum stress value on the backbone curve is $23.1 \mathrm{psi}$, which corresponds to a displacement value of $1.4 \mathrm{in}$.

\subsubsection{3rd run}

The purpose of this run was to load the specimen to a higher level of deformation to induce shear failure in the GFRP wrap. A single monotonic horizontal displacement to failure was used. Horizontal shear failure developed in the wrap at the $15^{\text {th }}$ course on one side of the wall only (Figures 62e and 62f). The data for the stress versus displacement were acquired and graphed and plotted (Figure 65). The maximum stress achieved is 31.7 psi at a displacement of 2.0 in. 


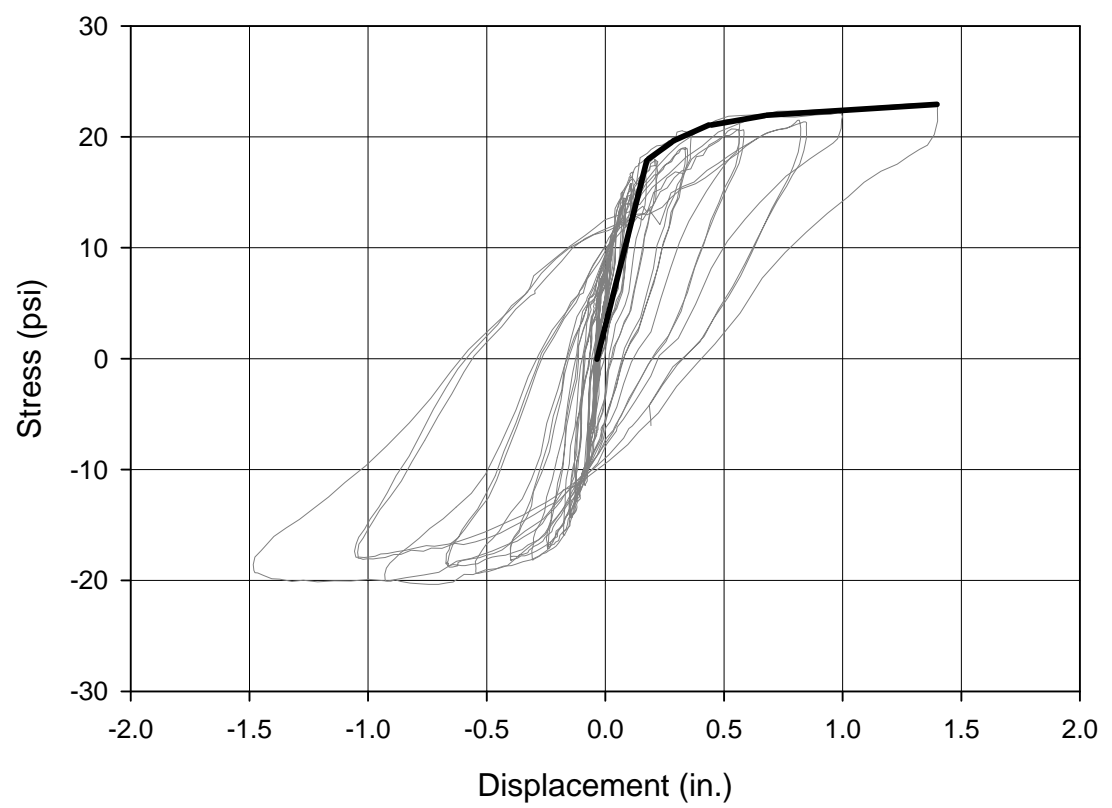

Figure 64. IPC1 cyclic with backbone curve.

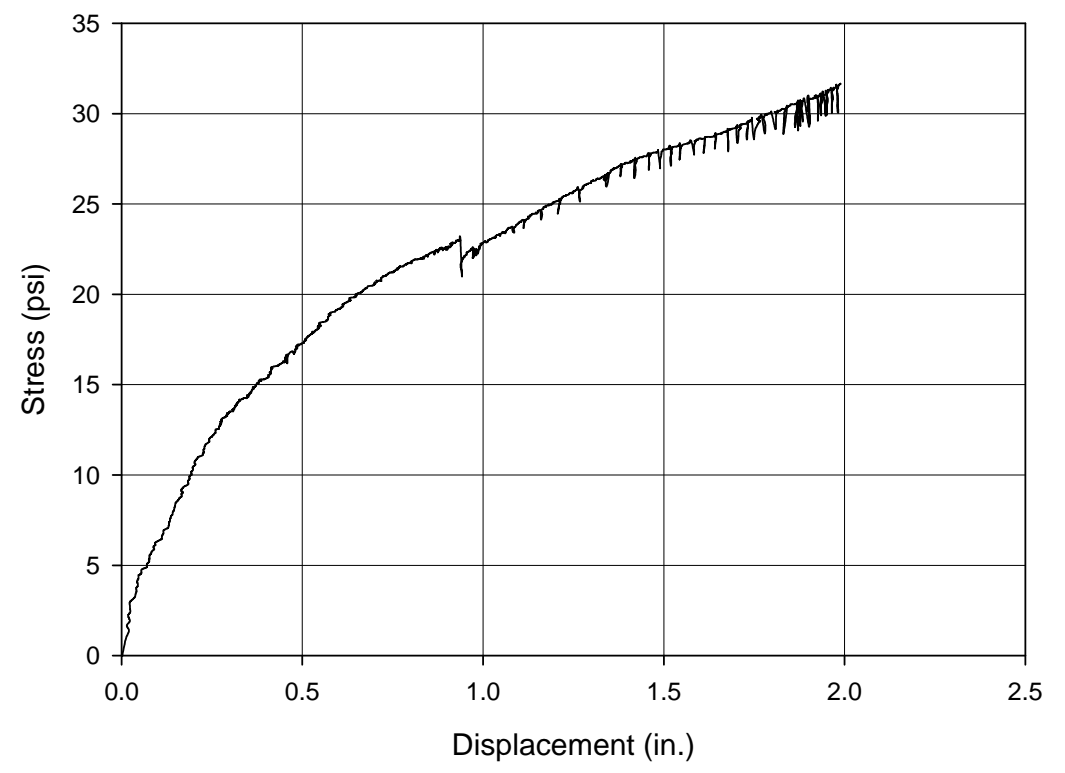

Figure 65. The modes of failure for IP-C1 specimens.

\subsubsection{Specimen IP-G1}

Two runs were performed on this specimen to match Run 2 and Run 3 of specimen IP-C1. 


\subsubsection{1st run}

This run was tested under cyclic loading with steel tubes in place to load the top and bottom corners of the specimen. The wall displaced in rocking behavior under cyclic load and corner cracks were observed (Figure 66b and 66c). Figure 67 shows the stress-displacement hysteresis. The maximum value of stress reached is $21.7 \mathrm{psi}$ at a displacement of $0.2 \mathrm{in}$. The maximum displacement value reached is $1.3 \mathrm{in}$., which corresponds to a stress of $19.8 \mathrm{psi}$. The maximum stress value on the backbone cure is 21.1 psi, which corresponds to a displacement value of $0.1 \mathrm{in}$.

\subsubsection{2nd run}

The purpose of this run was to load the specimen to a higher level of deformation to induce shear failure in FRP overlay. A single monotonic horizontal displacement to failure was used. This wall was also tested with the corner loading steel tubes in place. A horizontal shear failure developed through the FRP at the $15^{\text {th }}$ course on one side of the wall only. Figure $66 \mathrm{~d}$ and 66e show the modes of failure and Figure 68 shows the stressdisplacement curve. The maximum stress achieved is $36.4 \mathrm{psi}$ at displacement of 1.6 in.

Table 15 lists maximum stresses and displacements for all the in-plane testing. The Saint Gobain overlay increased the in-plane strength of the wall by 36.4 percent and the SikaWrap increased the shear strength by 245 percent.

A comparison of the maximum stresses from the backbone curves shows that the Saint Gobain GFRP yielded strength 32 percent higher than the bare wall and the SikaWrap GFRP yielded strength 20.6 percent higher than the bare wall. Also, it is worth noting that maximum displacement of the Saint Gobain GFRP occurred at a higher value than SikaWrap. 


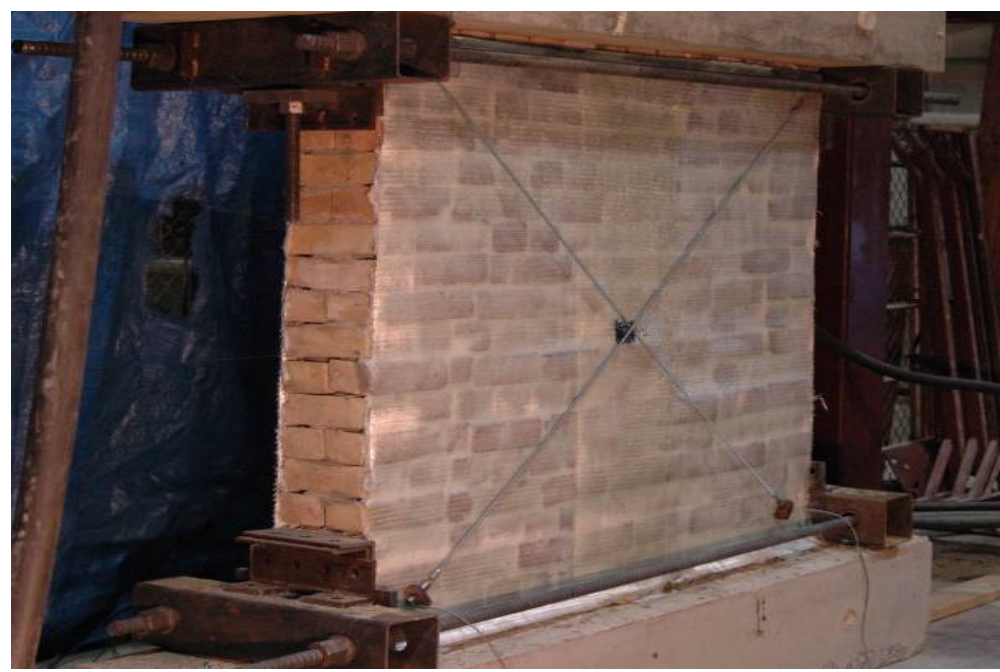

a. IP-G1 Wall prior to testing; direct load on the header concrete beam.

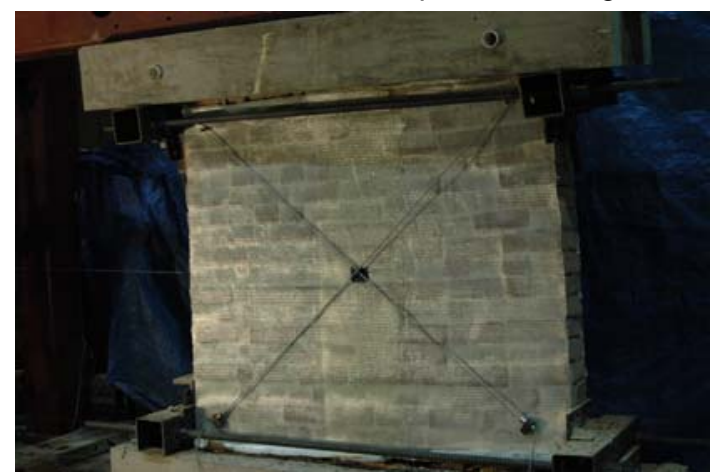

b. IP-G1 Wall during cyclic testing shown uplift as the specimen rocks (with loading tube steel beam at the corners).

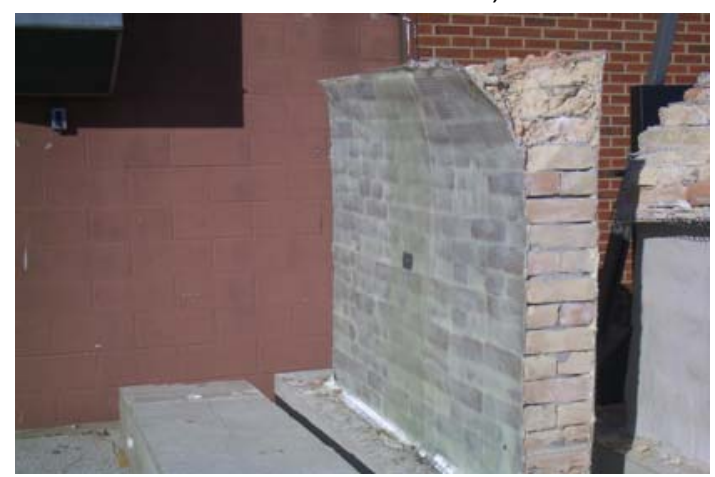

d. IP-G1 Wall after monotonic loading follow the above cyclic testing. Horizontal shear failure underneath the FRP is evident.

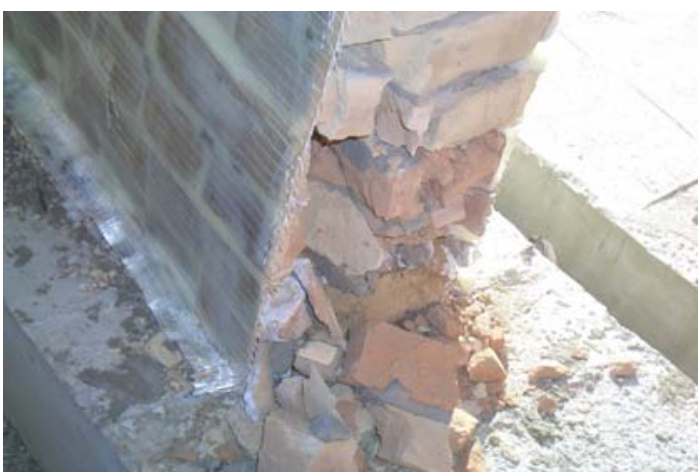

c. IP-G1 Wall corner crushing started under cyclic testing loading and was aggravated under monotonic loading.

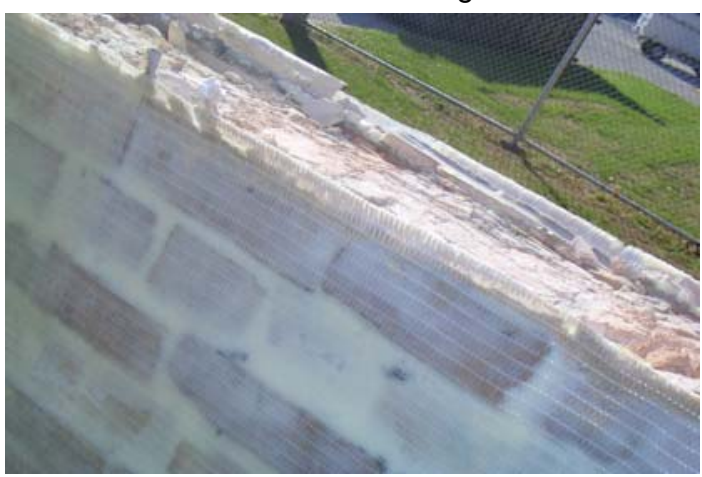

e. IP-G1 Wall after monotonic loading and after removing the unsound brick along the top failure surface.

Figure 66. The modes of failure for IP-G1 specimens. 


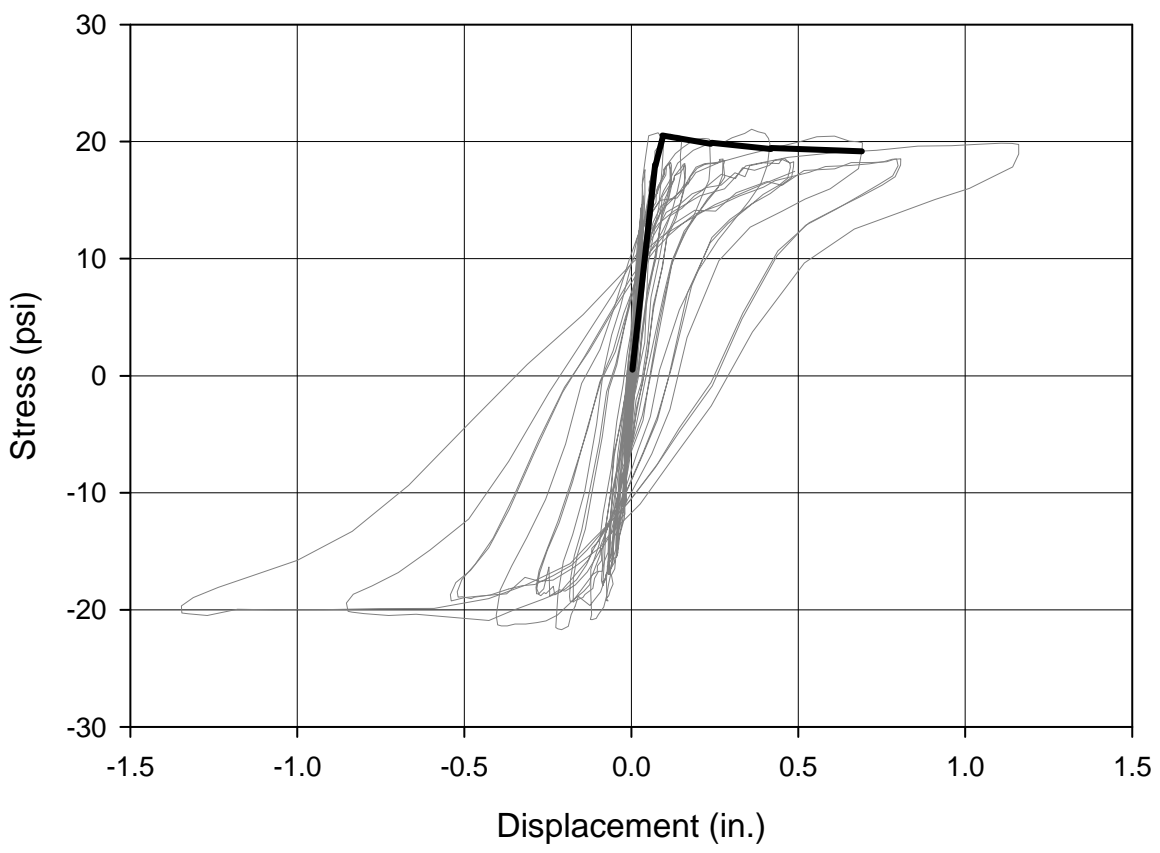

Figure 67. IPG1 stress-displacement hysteresis with backbone.

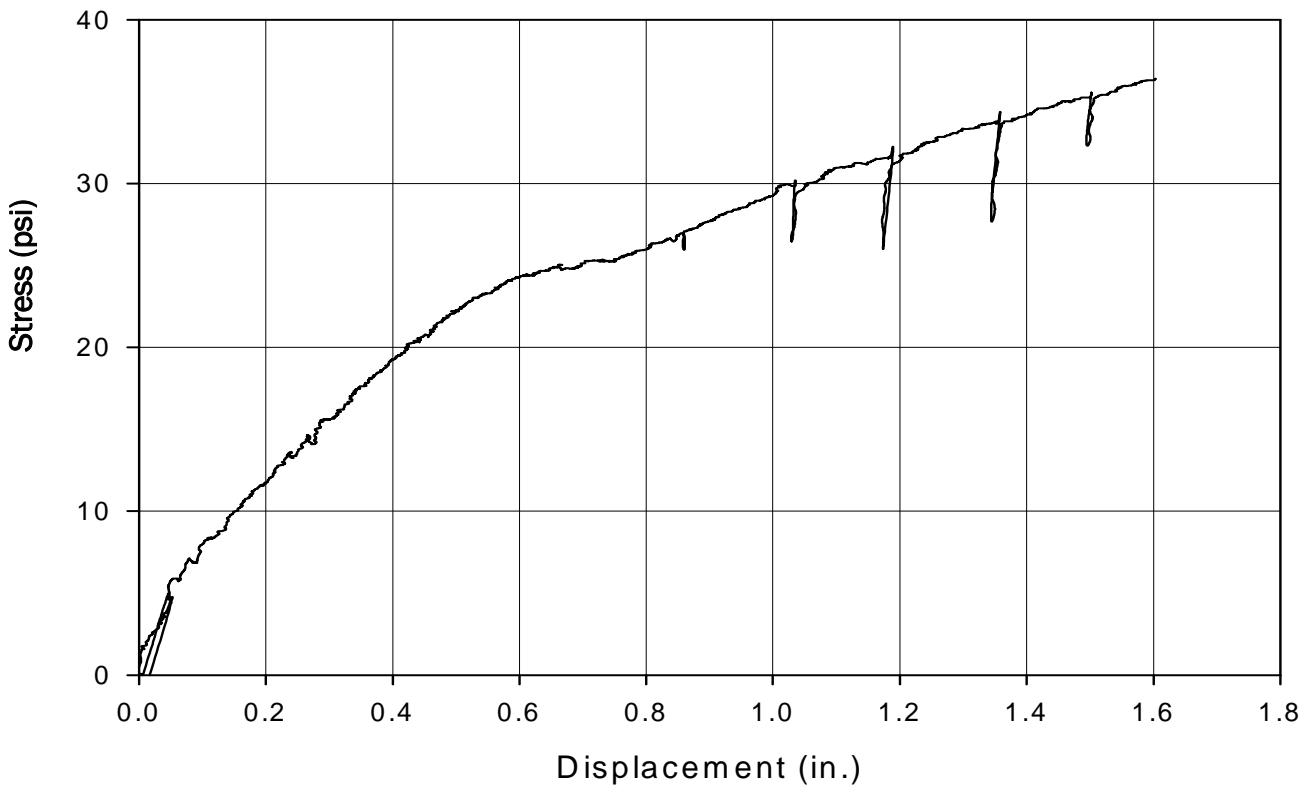

Figure 68. IPG1 Stress-deformation under monotonic loading. 
Table 15. Summary of maximum stress and displacement.

\begin{tabular}{|c|c|c|c|c|c|c|}
\hline \multirow[b]{2}{*}{ Specimen } & \multirow[b]{2}{*}{$\begin{array}{l}\sigma_{\max } \\
(\mathrm{psi})\end{array}$} & \multirow[b]{2}{*}{$\begin{array}{l}d_{\text {corresponding }} \\
\text { (in.) }\end{array}$} & \multirow[b]{2}{*}{$\begin{array}{l}d_{\max } \\
\text { (in.) }\end{array}$} & \multirow[b]{2}{*}{$\begin{array}{c}\sigma_{\text {corresponding }} \\
(\mathrm{psi})\end{array}$} & \multicolumn{2}{|c|}{ Backbone Curves } \\
\hline & & & & & $\begin{array}{l}\sigma_{\max } \\
(\mathrm{psi})\end{array}$ & $\begin{array}{l}d_{\text {corresponding }} \\
\text { (in.) }\end{array}$ \\
\hline 02 & 29.4 & 0.013 & 1.2 & 14.3 & 17.5 & 0.65 \\
\hline C1 (1 $1^{\text {st }}$ Run) & 32.1 & 0.015 & 0.64 & 4.3 & N/A & \\
\hline C1 (2 $2^{\text {nd }}$ Run) & 40.2 & 0.38 & 0.4 & 30.5 & 23.1 & 1.4 \\
\hline C1 (3rd Run) & 61.9 & 0.43 & 0.45 & 60.9 & N/A & \\
\hline G1 (1 st $^{\text {Run})}$ & 36.5 & 0.039 & 0.18 & 32.9 & 21.1 & 0.1 \\
\hline G1 (2nd Run) & 72.2 & 0.22 & 0.23 & 72.0 & N/A & \\
\hline
\end{tabular}

\subsection{Experimental results for compression tests on wall strip specimens with and without FRP}

\subsubsection{Bare specimens}

Two bare wall strip specimens were tested under pure compression load in the test setup described in Chapter 4 . Figure 69 shows the specimens before and after the tests.

\subsubsection{Specimen 01}

Failure initiated with cracks in the $10^{\text {th }}$ course starting a diagonal plane of failure through the $5^{\text {th }}$ course (Figure 69a). The ultimate load was 24.9 kips.

\subsubsection{Specimen 02}

At lower load levels, brick from course 10 started to spall, followed by two vertical cracks that initiated at the top course on two adjacent sides. One crack propagated and stopped on the $5^{\text {th }}$ course and the other arrested on the $7^{\text {th }}$ course. At near-collapse loading, the $10^{\text {th }}$ course crushed (Figure 69b). The ultimate load for this test was 23.0 kips.

\subsubsection{Specimens with Saint Gobain cement-based GFRP}

Two wall strip specimens protected with Saint Gobain cement-based GFRP were tested under pure compression load. Figure 70 shows the specimens before and after the tests. 

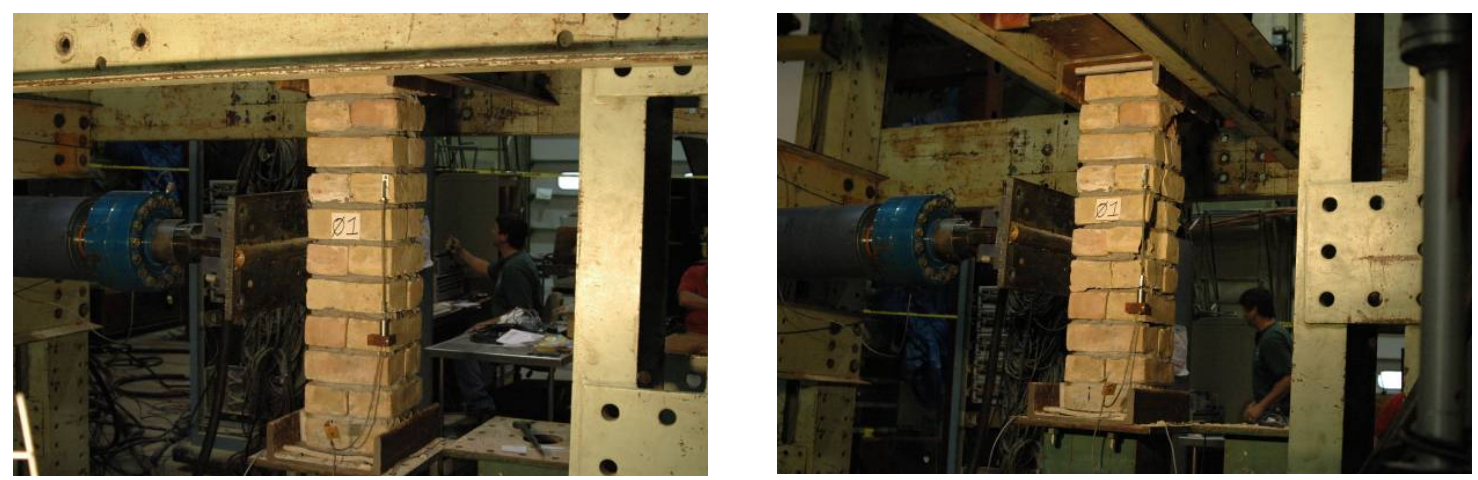

a. Bare specimen 01 before (left) and after (right).
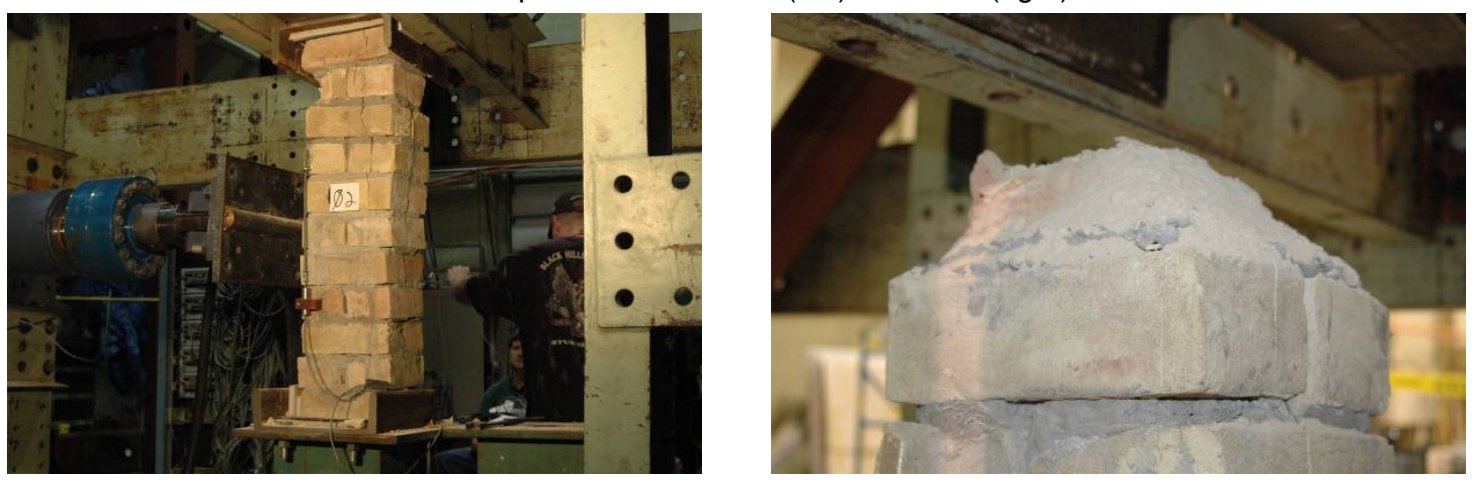

b. Bare specimen 02 before (left) and after (right).

Figure 69. Two unprotected wall strip specimens tested under pure compression load.
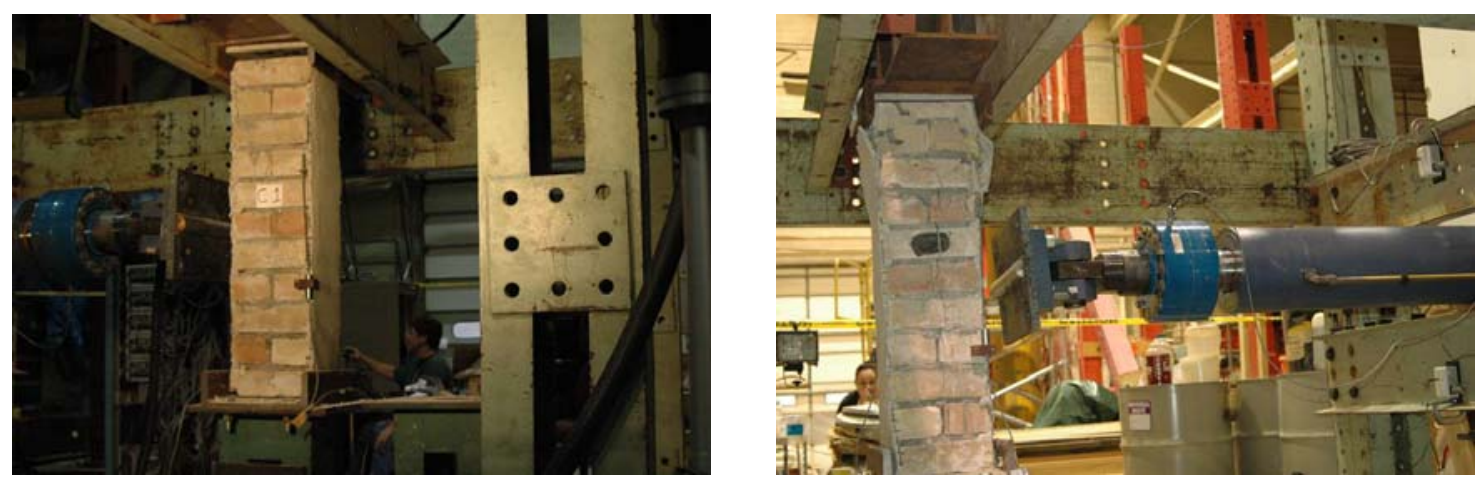

a. Bare specimen C1 before (left) and after (right).
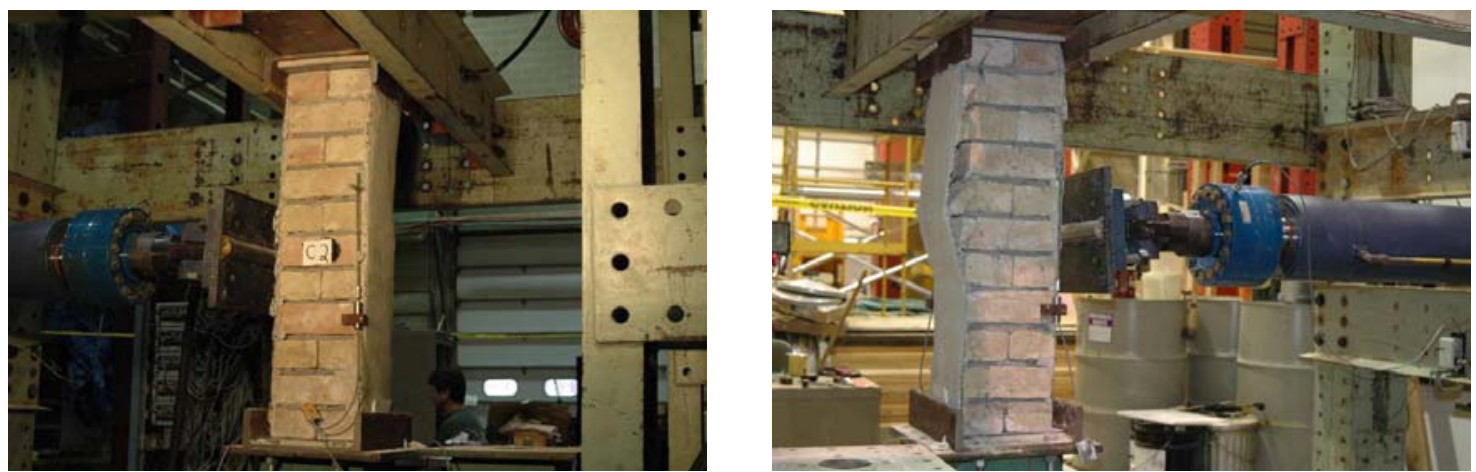

b. Bare specimen C2 before (left) and after (right).

Figure 70. Two Saint Gobain GFRP protected wall strip specimens tested under pure compression load. 


\subsubsection{Specimen C1}

Small cracks initiated at the top and bottom courses extended to the adjacent course. End-crushing was the ultimate mode of failure followed by delaminating of the cement base polymer at the top of the specimen. Horizontal shear cracks appeared in the FRP between the top and the $10^{\text {th }}$ courses. A vertical crack at the seventh course also developed late in the tests. As the specimen was rocking under cyclic load, corner failure was evident in the compressed side (Figure 70a). The ultimate compression load for this test was 37.3 kips.

\subsubsection{Specimen C2}

Delaminating occurred between the brick and the FRP on one side of the specimen between the $4^{\text {th }}$ course and the top of the $10^{\text {th }}$ course. In that area the FRP bowed out and the brick underneath started to crumble. Many small vertical cracks appeared at the $6^{\text {th }}, 7^{\text {th }}$, and $8^{\text {th }}$ courses of brick. Horizontal cracks formed on the $4^{\text {th }}$ course. The final stage of failure was the splitting of the specimen vertically in two pieces (Figure 70b). The ultimate compressive load for this test was 26.3 kips.

\subsubsection{Specimens with Sika Wrap GFRP}

Two wall strip specimens protected with Sika Wrap GFRP tested under pure compression load. Figure 71 shows the specimens before and after the tests.

\subsubsection{Specimen $\mathrm{G} 1$}

The first vertical crack appeared on the $10^{\text {th }}$ course followed by a vertical crack on the $8^{\text {th }}$ course and then the $9^{\text {th }}$ course. The FRP delaminated at 20 kips vertical load on one side between $7^{\text {th }}$ and $10^{\text {th }}$ courses, and on the other side between the $9^{\text {th }}$ and $11^{\text {th }}$ courses (Figure 71a), followed by crushing of the masonry. The ultimate load for this test was 35.5 kips.

\subsubsection{Specimen G2}

The first vertical crack initiated on the $2^{\text {nd }}$ course and propagated to the $7^{\text {th }}$ course. The FRP overlay held the faces of the brick together well. Another vertical crack appeared on the $2^{\text {nd }}$ course at the middle of the specimen and propagated parallel to the first crack in the second through the $5^{\text {th }}$ courses (Figure 71b). The ultimate load for this test was 33.5 kips. 

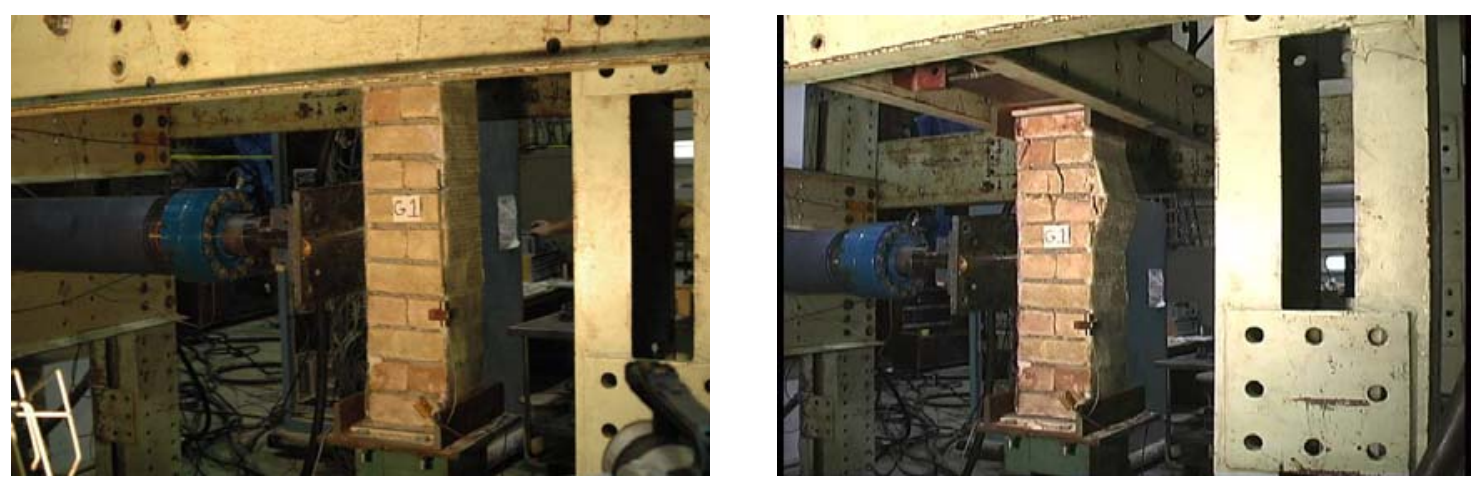

a. Bare specimen G1 before (left) and after (right).
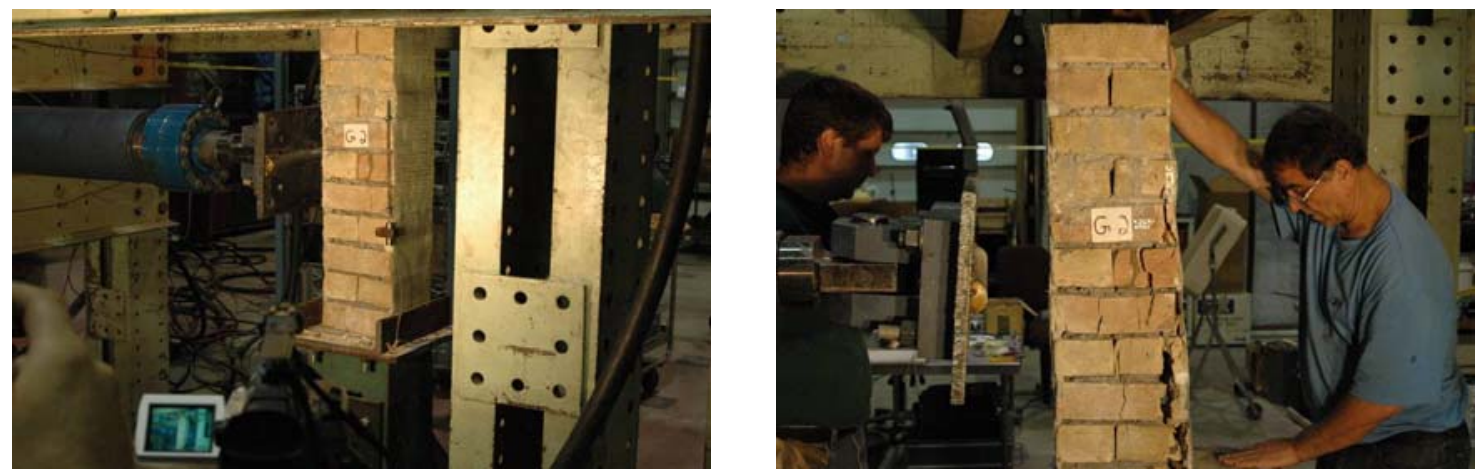

b. Bare specimen $\mathrm{G} 2$ before (left) and after (right).

Figure 71. Two unprotected wall strip specimens tested under pure compression load.

Table 16 lists maximum loads and stresses for the above six laboratory specimens.

Table 16. Summary of pure compression tests forces and stresses.

\begin{tabular}{|c|c|c|c|}
\hline Specimen & $\begin{array}{c}\text { Max. Force } \\
\text { (kips) }\end{array}$ & $\begin{array}{c}\text { Average Forces } \\
\text { in Each Series } \\
\text { (Kips) }\end{array}$ & \multirow{2}{*}{$\begin{array}{c}\text { Max. Stress } \\
\text { (ksi)* }\end{array}$} \\
\hline O1 & 24.884 & \multirow{2}{*}{23.963} & \multirow{2}{*}{0.296} \\
\hline 02 & 23.042 & & \multirow{2}{*}{0.392} \\
\cline { 1 - 2 } C1 & 37.265 & \multirow{2}{*}{31.746} & \multirow{2}{*}{0.426} \\
\cline { 1 - 2 } C2 & 26.227 & \multirow{2}{*}{34.500} & \\
\cline { 1 - 2 } G1 & 35.468 & &
\end{tabular}




\subsection{Experimental results of the out-of-plane cyclic load on wall specimens with and without FRP}

The results of the compression tests were used to determine the compression loads to be used for the horizontal cyclic load tests. Table 17 lists the values of the failure loads for the compressive tests of the wall strips and various vertical load level selected to be tested in combination with the horizontal cyclic loads.

Six specimens (two of each series) were tested for out-of-plane load resistance using a horizontal cyclic loading under a low-level vertical load combined with horizontal cyclic loading. This selected values of vertical loads corresponds to stress level of the wall specimens tested in Section 5.1 under vertical load of 15 kips given by the designer. Low level vertical loads are 8.4 percent for bare specimens, 6.3 percent for cement base FRP, and 6.o percent for glass FRP. The following paragraphs describe specimen modes of failure observed during testing.

\subsection{Out-of-plane tests of bare wall specimens}

\subsubsection{Specimen 04 (vertical load $=8.4 \%$ of $f^{\prime}{ }_{m}$ )}

Many small cracks initiated at the middle course at the point of loading. The cracks formed a hinge at the mid height of the specimen and as the specimen deformed under cyclic loads, the cracks opened and closed without slippage. Figure $72 a$ shows the test.

Table 17. Selected vertical loads for out-of-plane testing.

\begin{tabular}{|c|c|c|c|c|c|c|}
\hline \multirow[b]{2}{*}{ Specimen } & \multirow[b]{2}{*}{$\begin{array}{l}\text { Crushing } \\
\text { Load, P } \\
\text { (kips) }\end{array}$} & \multirow{2}{*}{$\begin{array}{l}\text { Average Crushing } \\
\text { Load, } \mathrm{P} \\
\text { in Each Series } \\
\text { (kips) }\end{array}$} & \multicolumn{4}{|c|}{$\begin{array}{c}\text { Vertical Load on The Wall Strip Specimens Subjected to } \\
\text { Out-of-Plane Cyclic Loads }\end{array}$} \\
\hline & & & $\begin{array}{l}\text { Low Level of } \\
\text { Crushing Load }\end{array}$ & $\begin{array}{l}25 \% \text { of } \\
\text { Crushing } \\
\text { Load }\end{array}$ & $\begin{array}{l}50 \% \text { of } \\
\text { Crushing } \\
\text { Load }\end{array}$ & $\begin{array}{c}75 \% \text { of } \\
\text { Crushing } \\
\text { Load }\end{array}$ \\
\hline 01 & 24.884 & \multirow{2}{*}{23.963} & \multirow{2}{*}{2.000} & \multirow{2}{*}{5.751} & \multirow{2}{*}{11.982} & \multirow{2}{*}{17.972} \\
\hline 02 & 23.042 & & & & & \\
\hline C1 & 37.265 & \multirow{2}{*}{31.746} & \multirow{2}{*}{2.000} & \multirow{2}{*}{7.619} & \multirow{2}{*}{15.873} & \multirow{2}{*}{23.810} \\
\hline $\mathrm{C} 2$ & 26.227 & & & & & \\
\hline G1 & 35.468 & \multirow{2}{*}{34.500} & \multirow{2}{*}{2.000} & \multirow{2}{*}{8.280} & \multirow{2}{*}{17.250} & \multirow{2}{*}{25.875} \\
\hline G2 & 33.533 & & & & & \\
\hline
\end{tabular}



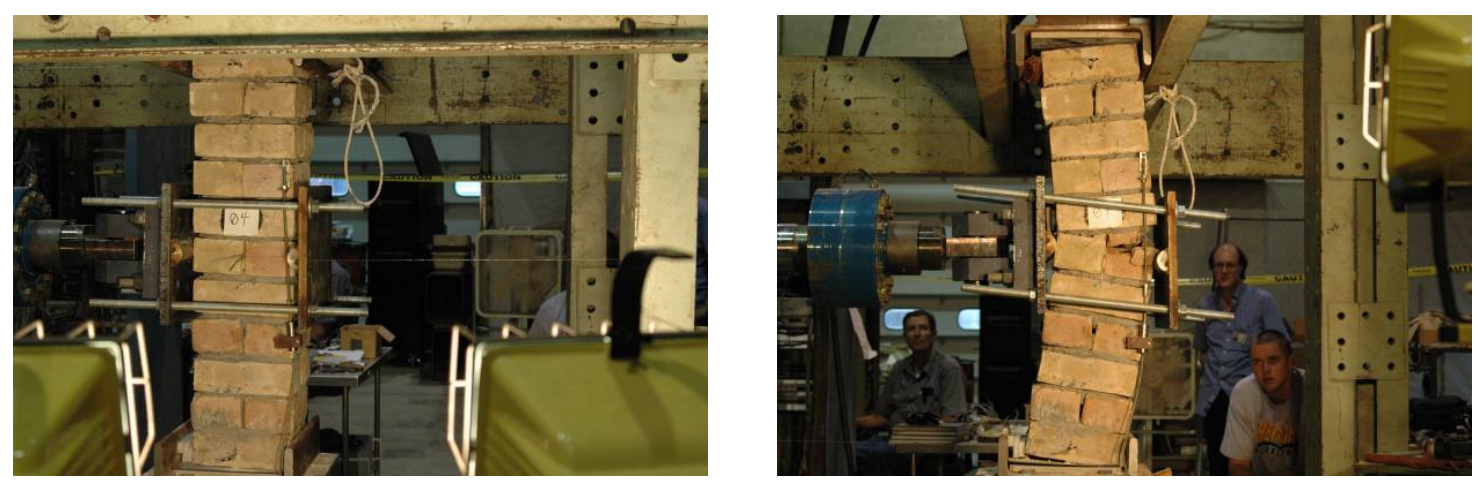

a. Bare Specimen 04, before test (left) after test (right).
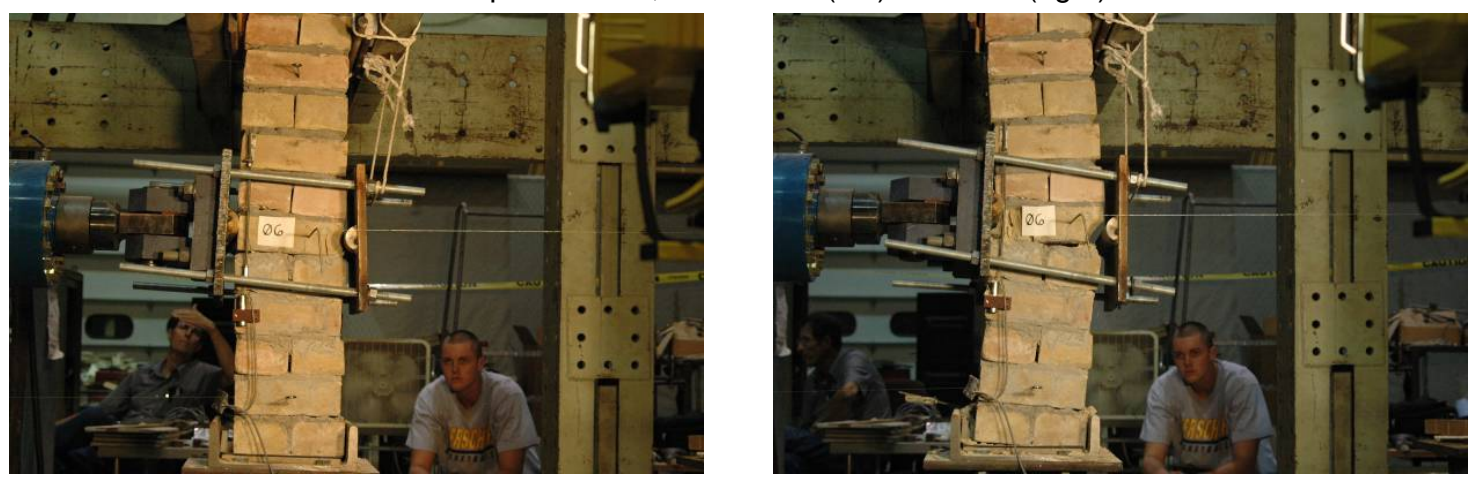

b. Bare Specimen 06, before test (left) after test (right).

Figure 72. Deformation of specimens 04 and 06 under cyclic and low level vertical load.

\subsubsection{Specimen 06 (vertical load $=8.4 \%$ of $\left.f^{\prime}{ }^{\prime} \mathrm{m}\right)$}

Many small cracks initiated at the middle course under the loading bar. The cracks formed hinges at the mid height of the specimen and as the specimen deformed under cyclic loads, the cracks opened and closed without slippage. Mortar failure appeared in the bottom of the middle course at 0.5 in. displacement. Local crushing under the loading bar appeared at 0.85 in. displacement (Figure 72b).

\subsubsection{Specimen 07 (vertical load $=50 \%$ of $f^{\prime}{ }_{m}$ )}

Failure with vertical load at 50 percent of compression load was different than for lower vertical loads. At about 0.5 in. displacement the $7^{\text {th }}$ course spalled and gradually crushed under higher levels of cyclic loading (Figure 74a). This crushing did not occur when the hinge formed at lower vertical loads. 


\subsubsection{Specimen 09 (vertical load $=50 \%$ of $f^{\prime} \mathrm{m}$ )}

Failure again initiated with spalling at the $7^{\text {th }}$ course at the point of loading, this time followed by sudden shear failure under vertical load (Figure 74b).

\subsubsection{Specimen 010 (vertical load $=25 \%$ of $\mathbf{f}^{\prime} \mathrm{m}$ )}

Failure initiated with spalling of the $7^{\text {th }}$ course followed by rocking about the hinge that formed at the point of loading (Figure 73).

\subsubsection{Specimen 011 (vertical load $=75 \%$ of $f^{\prime}$ m)}

Failure at 75 percent ultimate compressive load differed from lower load levels. In this instance, a vertical crack initiated at the $7^{\text {th }}$ course (point of loading) and rapidly propagated down to the middle of the $1^{\text {st }}$ course, followed by sudden, brittle crushing of the $2^{\text {nd }}$ and $3^{\text {rd }}$ courses (Figure 75 a).

\subsubsection{Specimen 012 (vertical load $=75 \%$ of $\left.f^{\prime}{ }^{\prime}\right)$}

This specimen also failed with sudden local crushing of the masonry. This specimen failed at mid-height at the point of loading. The brick units at the middle course crumbled (Figure 75b).
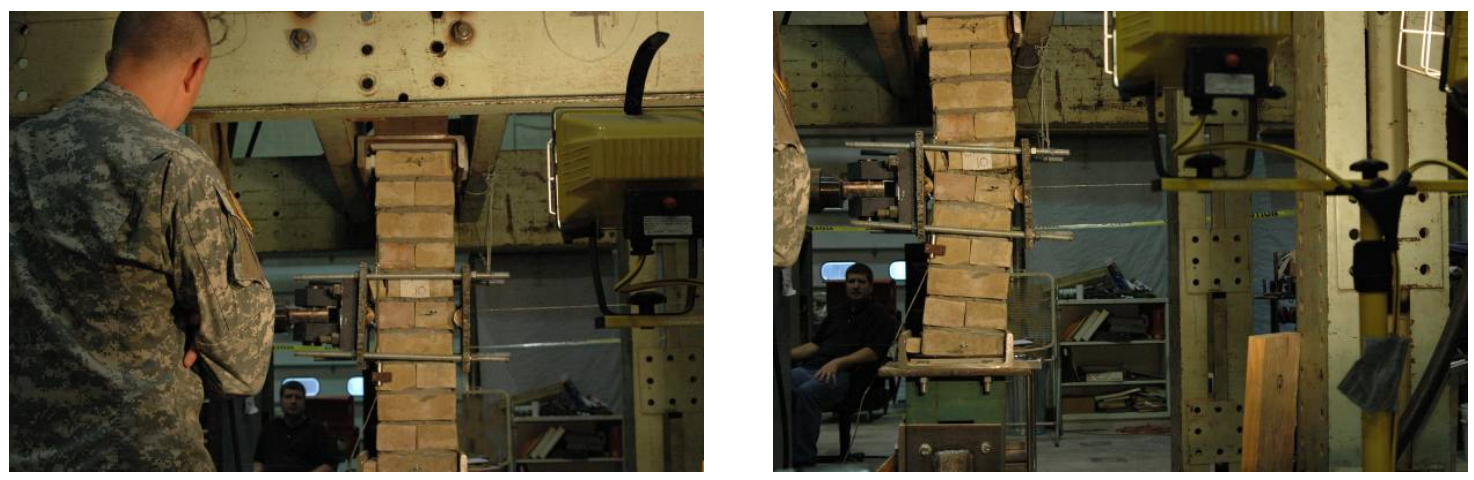

Figure 73. Bare Specimen 010, before test (left) and after test (right). 

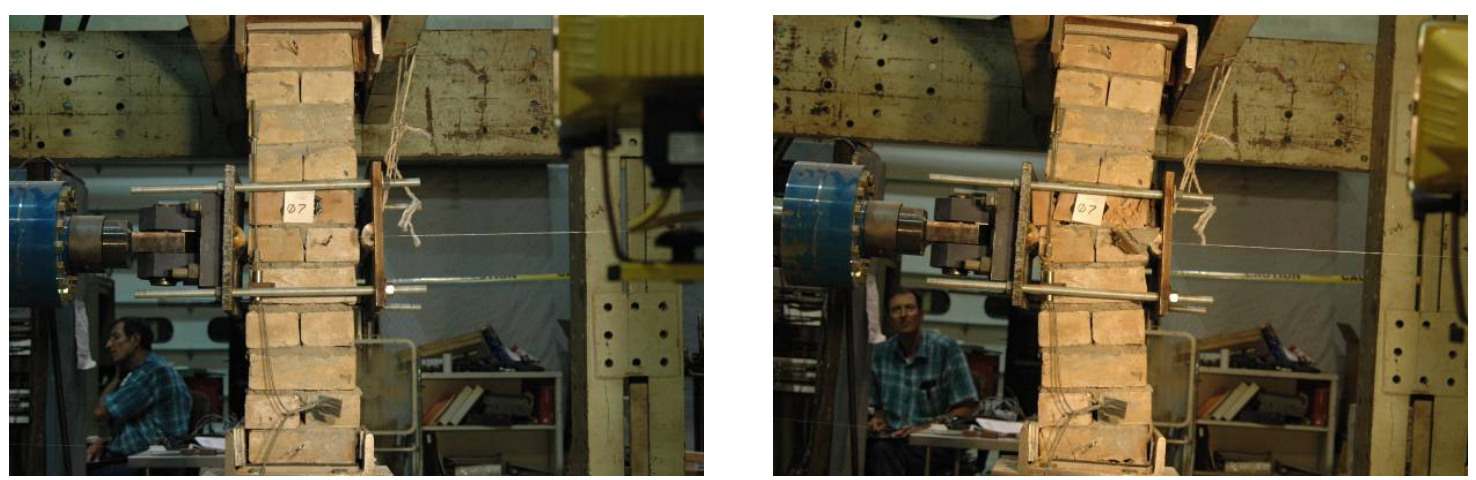

a. Bare Specimen 07, before test (left) after test (right).
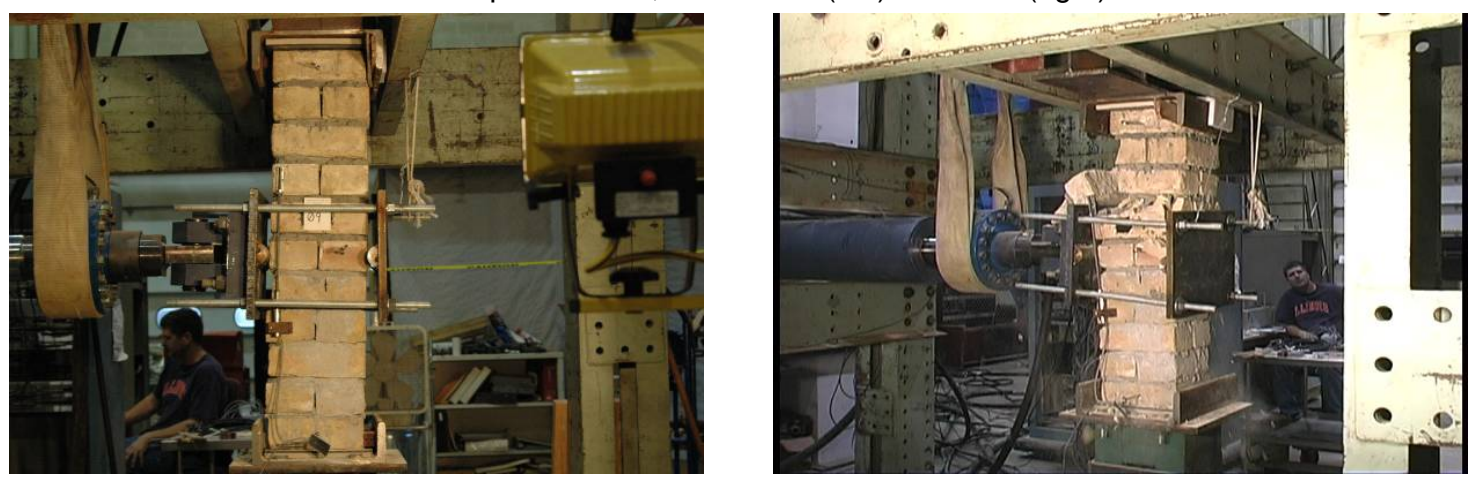

b. Bare Specimen 09, before test (left) after test (right).

Figure 74. Deformation of specimens 07 and 09 under cyclic and low level vertical load.
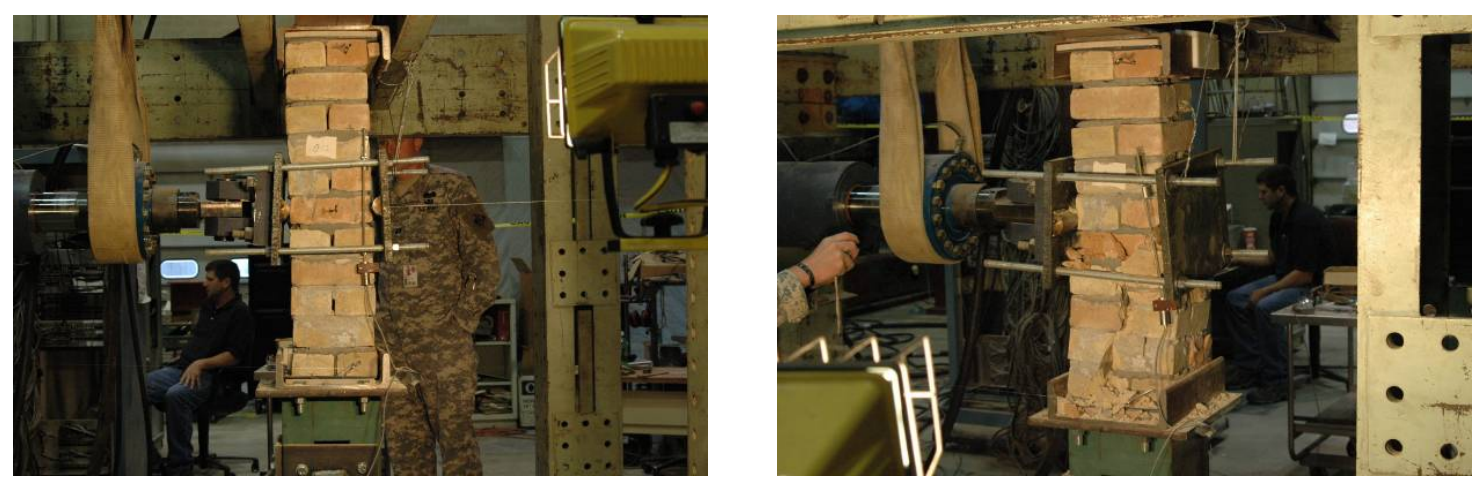

a. Bare Specimen 011, before test (left) after test (right).
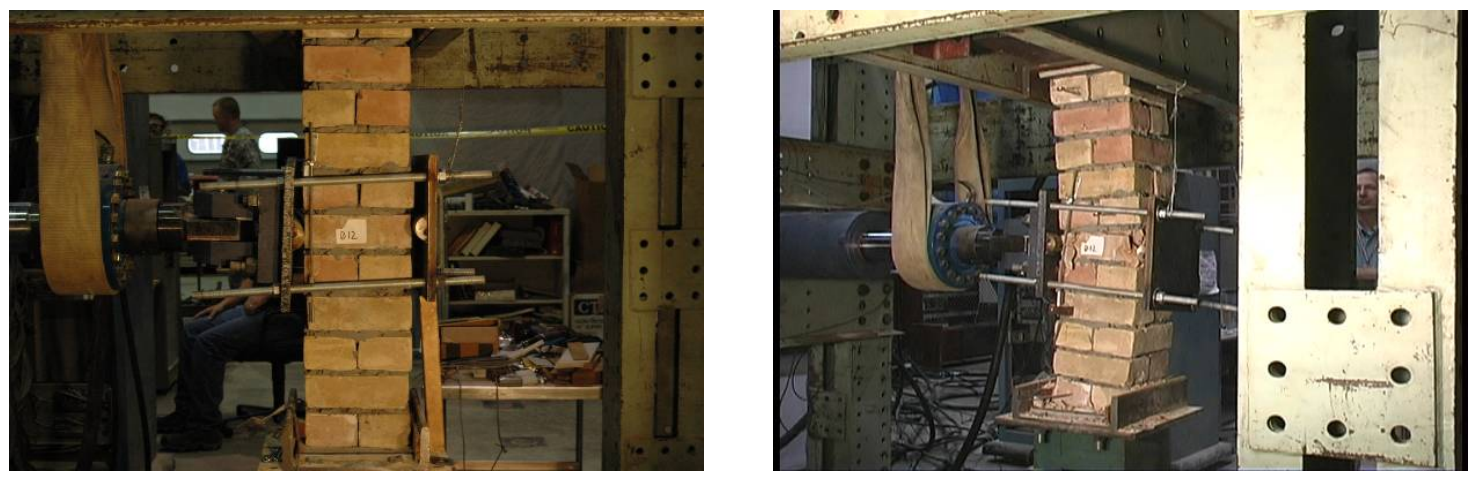

b. Bare Specimen 012, before test (left) after test (right).

Figure 75. Failure of Specimens 011 and 012. 


\subsection{Out-of-plane tests of wall specimens with saint gobain glass and cement based FRP}

\subsubsection{Specimen C3 (vertical load $=6.3 \%$ of $f^{\prime}{ }_{m}$ )}

Horizontal cracks formed in the middle course of the specimen at the point of loading. The specimen deformed in a rocking manner with a hinge at mid-height and eventually split in two pieces (Figure 76a)

\subsubsection{Specimen C4 (vertical load $=6.3 \%$ of $f^{\prime}{ }_{m}$ )}

This specimen failed identically to Specimen C3 (Figure 76b).

\subsubsection{Specimen C6 (vertical load $=25 \%$ of $f^{\prime} \mathrm{m}$ )}

This specimen was tested differently than all of the other specimens in this series as it was tested under stroke control for the vertical actuators. This means that although the starting load of 25 percent of $f^{\prime} m$ was the same as test $\mathrm{C}_{7}$, the vertical load increased significantly under cyclic load. The increase in load is due to the arching action. As the hinge in the center forms and the specimen begins to rock, the actual vertical dimension of the specimen increases.
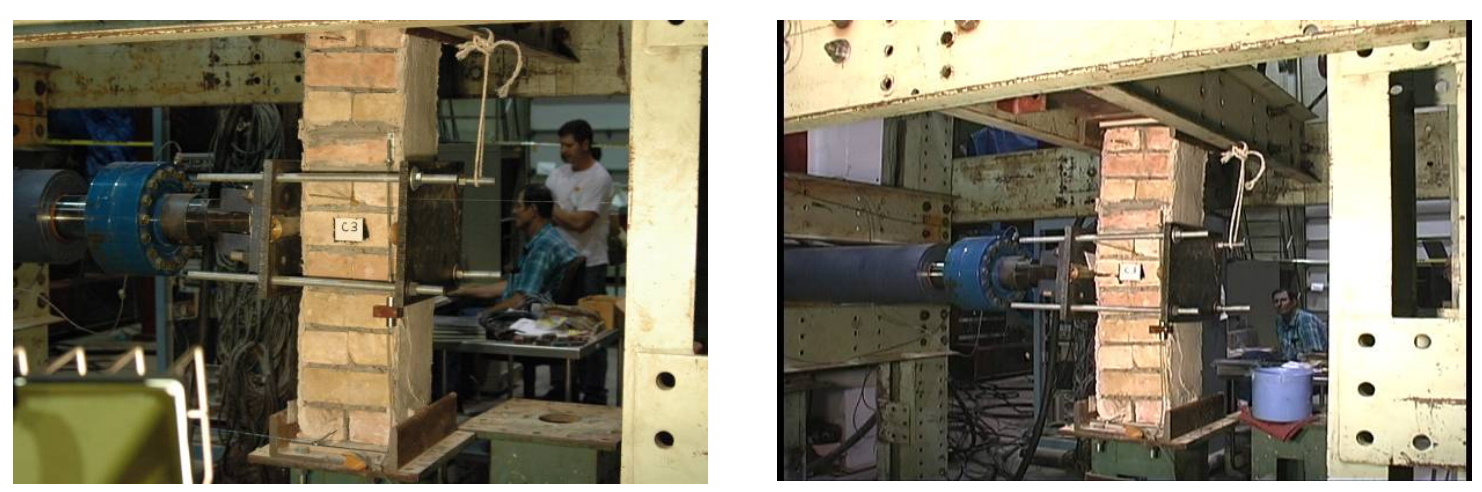

a. Saint Gobain Cement-Base Specimen C3, before test (left) after test (right).
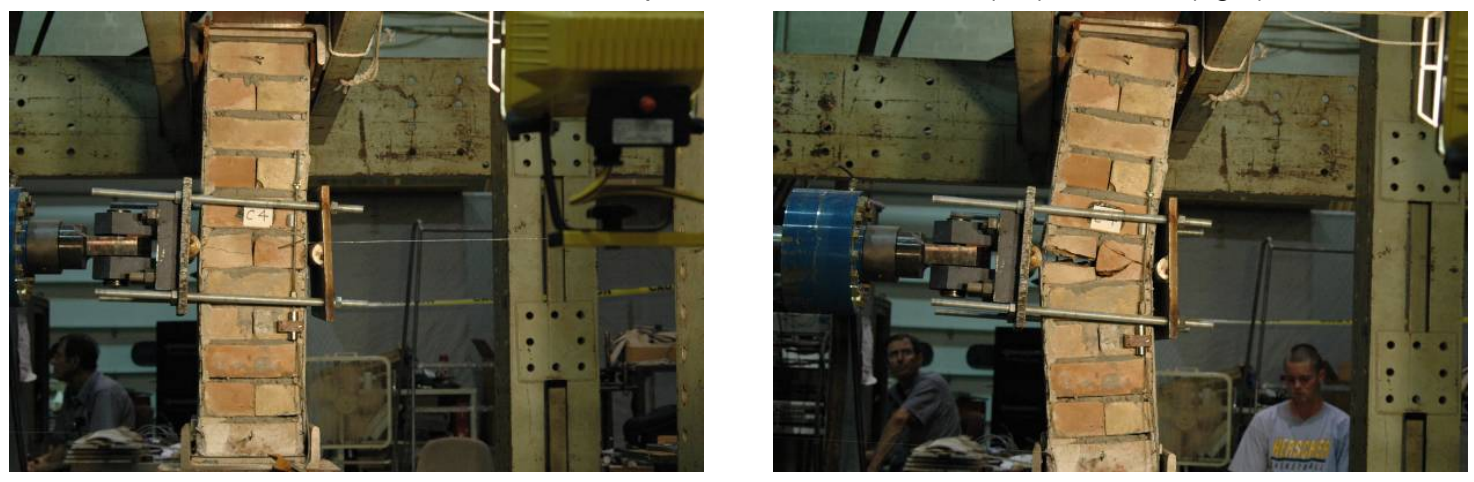

b. Saint Gobain Cement-Base Specimen C4, before test (left) after test (right).

Figure 76. Deformation of specimens 04 and 06 under cyclic and low level vertical load. 
Under stroke control, the loading system does not allow the loading device to move, therefore the force increases. Under load control (under which all of the other tests were conducted) the actuator is allowed to move to keep the vertical load constant. This change was done to see the difference in behavior of one specimen to the different loading protocol, and cannot be compared easily with load control specimens. Failure for this test initiated with a loss of the FRP bond at the mortar joint located below the middle course. The FRP continued to delaminate on both sides of the specimen between the $8^{\text {th }}$ and $11^{\text {th }}$ courses (Figure 77a). The ultimate failure was crushing of the masonry at the loading point in the center of the specimen.

\subsubsection{Specimen C7 (vertical load $=25 \%$ of $\mathbf{f}^{\prime} \mathrm{m}$ )}

Failure initiated with many vertical cracks in the $5^{\text {th }}$ course followed by spalling and local crushing. The FRP delaminated on one side of the specimen between the $3^{\text {rd }}$ and $5^{\text {th }}$ fifth course. Diagonal cracks appeared also on $2^{\text {nd }}$ and $3^{\text {rd }}$ courses. The test was stopped as it was observed that load is deceasing while displacement in increasing, indicating the specimen has reached its deformation beyond its ultimate stress (Figure 77b).
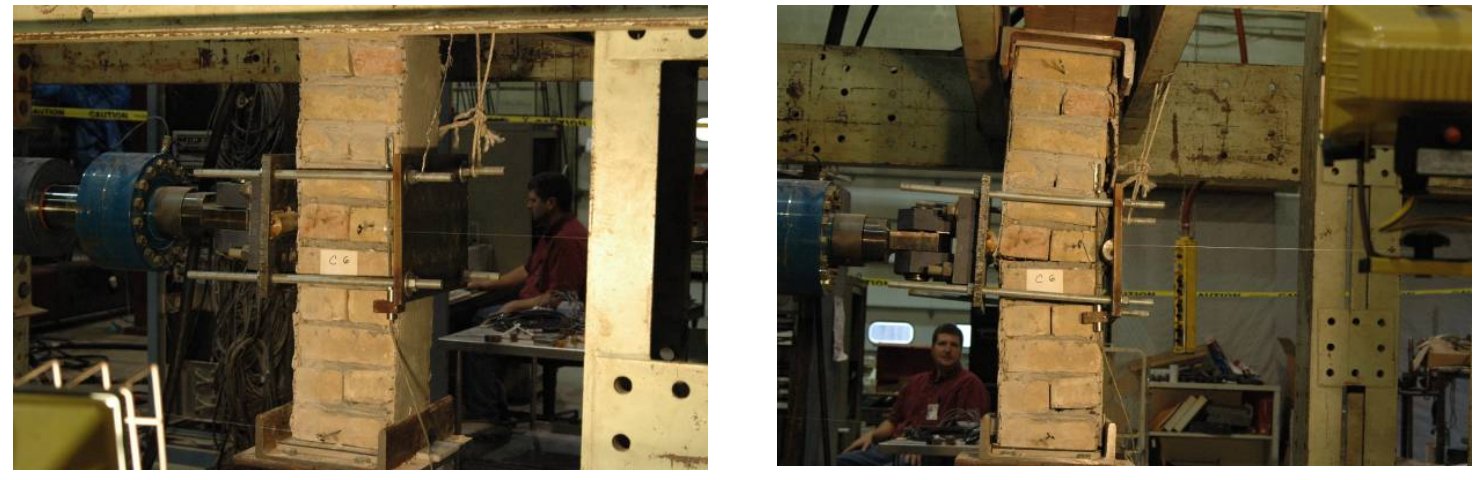

a. Saint Gobain Cement-Base Specimen C6, before test (left) after test (right).
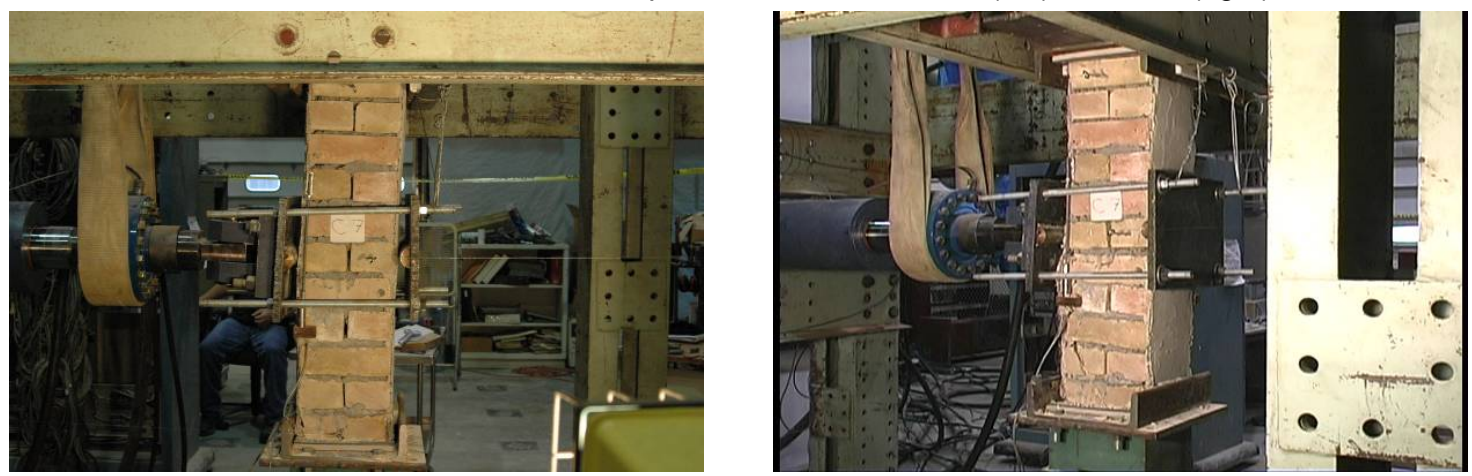

b. Saint Gobain Cement-Base Specimen C7, before test (left) after test (right).

Figure 77. Deformation of specimens C6 and C7 under cyclic and low level vertical load. 


\subsubsection{Specimen C8 (vertical load $=50 \%$ of $f^{\prime} \mathrm{m}$ )}

Cracks initiated at about the $0.25 \mathrm{in}$. displacement cycle. The $2^{\text {nd }}$ to $5^{\text {th }}$ courses crushed under high vertical load and lateral deformation occurred simultaneously with the delamination of the FRP on both sides of the crushed area (Figure 78).

\subsubsection{Specimen C5 (vertical load $=75 \%$ of $f^{\prime} \mathrm{m}$ )}

Failure of this specimen was sudden and brittle crushing between the $2^{\text {nd }}$ and the $5^{\text {th }}$ courses (Figure 79).

\subsection{Out-of-plane tests of wall specimens with sika wrap FRP}

\subsubsection{Specimen G3 (vertical load $=6.0 \%$ of $f^{\prime}{ }_{m}$ )}

A shear crack formed at about a 60 degree angle starting from the $10^{\text {th }}$ down to the $7^{\text {th }}$ course. Another diagonal crack appeared forming an Xshape with first crack under the reverse cycle of loading. The specimen failed in shear (Figure 80a).
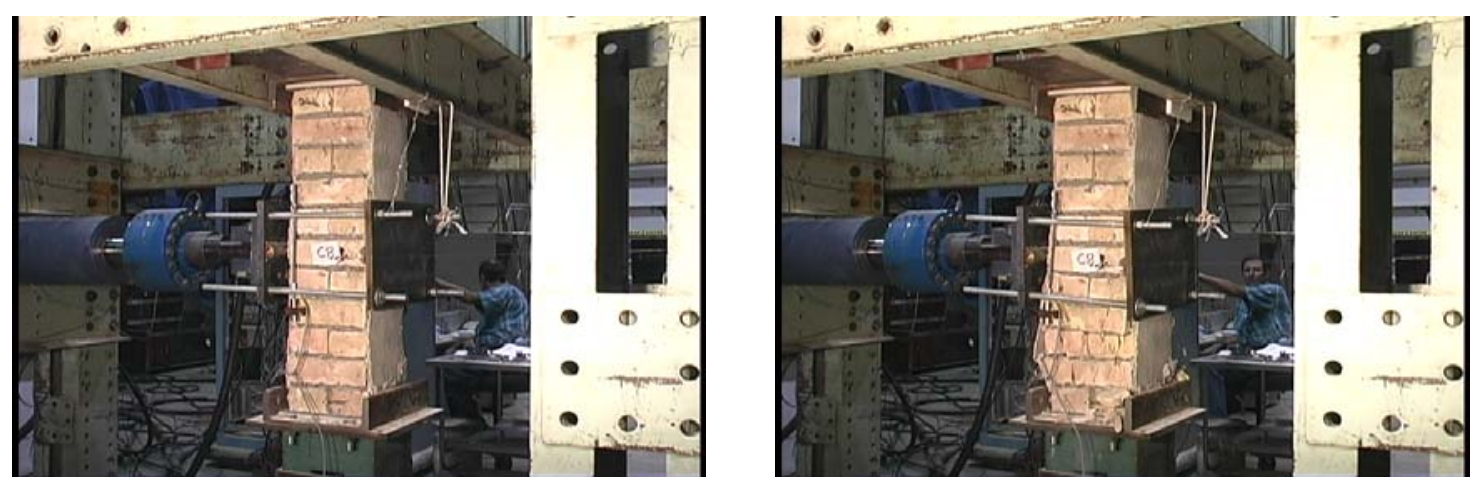

Figure 78. Specimen C8 before test (left) after test (right).
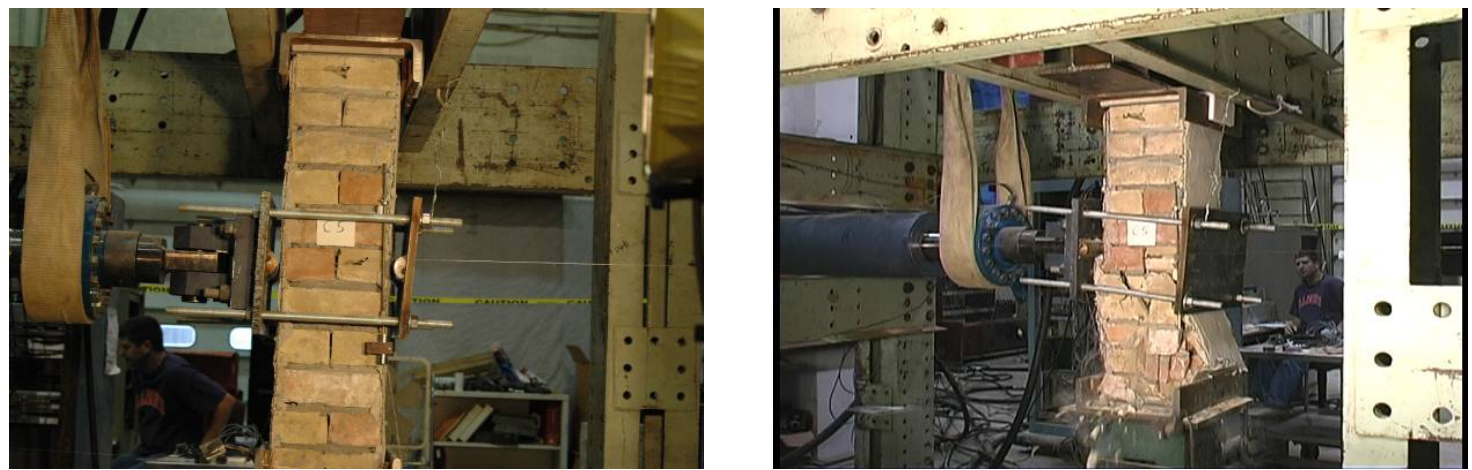

Figure 79. Saint Gobain Cement-Base Specimen C5, before test (left) after test (right). 

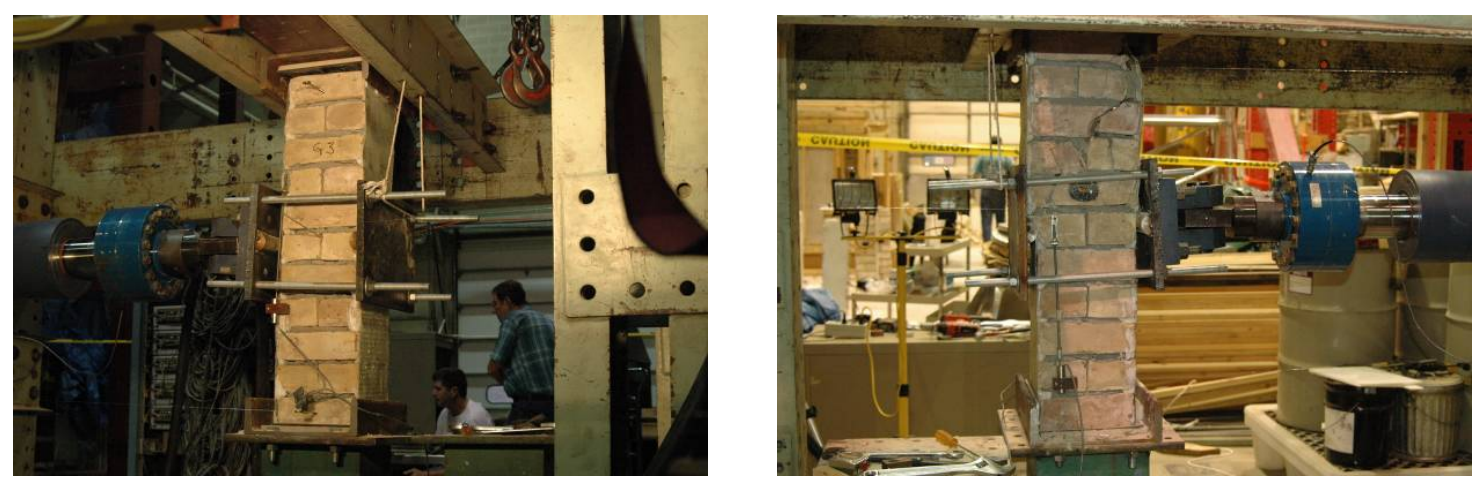

a. Specimen G3 with SikaWrap Hex, before test (left) after test (right).
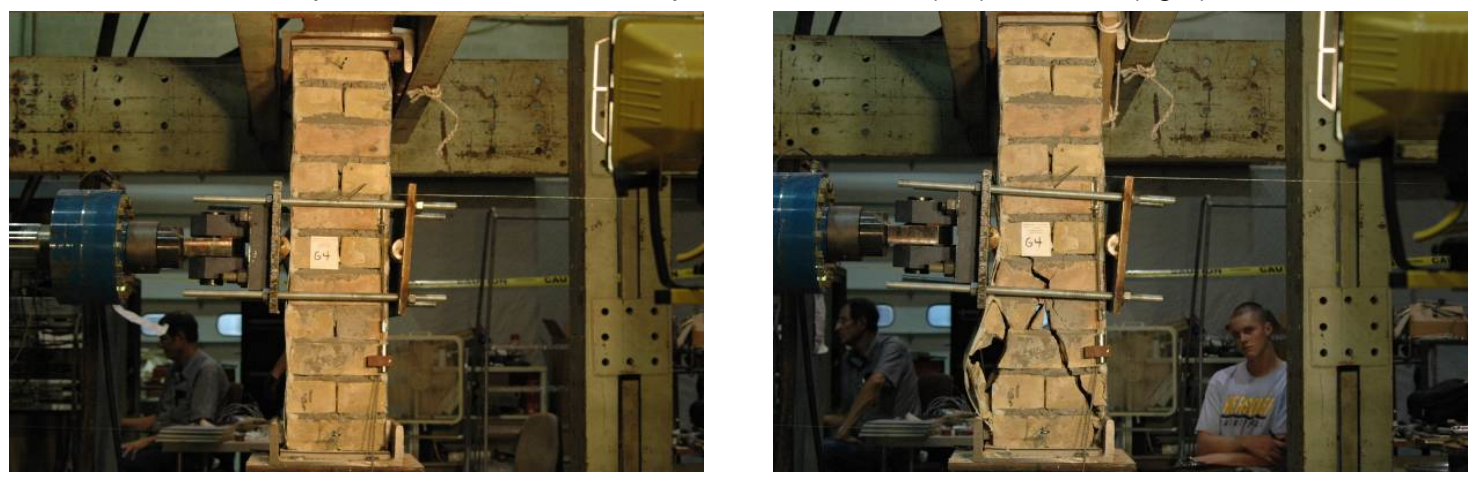

b. Specimen G4 with SikaWrap Hex, before test (left) after test (right).

Figure 80. Deformation of specimens 04 and 06 under cyclic and low level vertical load.

\subsubsection{Specimen G4 (vertical load $=6.0 \%$ of $f^{\prime} \mathrm{m}$ )}

A shear crack formed at about a 60 degree angle starting from the $2^{\text {nd }}$ up to the $5^{\text {th }}$ course. Another diagonal crack appeared forming an X-shape with first crack under the reverse cycle of loading. This specimen failed in shear (Figure 81b).

\subsubsection{Specimen G6 (vertical load $=25 \%$ of $f^{\prime} \mathrm{m}$ )}

Delaminating of the FRP occurred on one side followed by the appearance of shear cracks and brittle crushing failure just above the loading point (Figure 81).

\subsubsection{Specimen G5 (vertical load $=\mathbf{5 0} \%$ of $\mathbf{f}^{\prime}{ }_{\mathrm{m}}$ )}

Shear cracks in the $7^{\text {th }}$ through $9^{\text {th }}$ courses formed, followed by brittle crushing of the masonry just above the loading point (Figure 82a). 

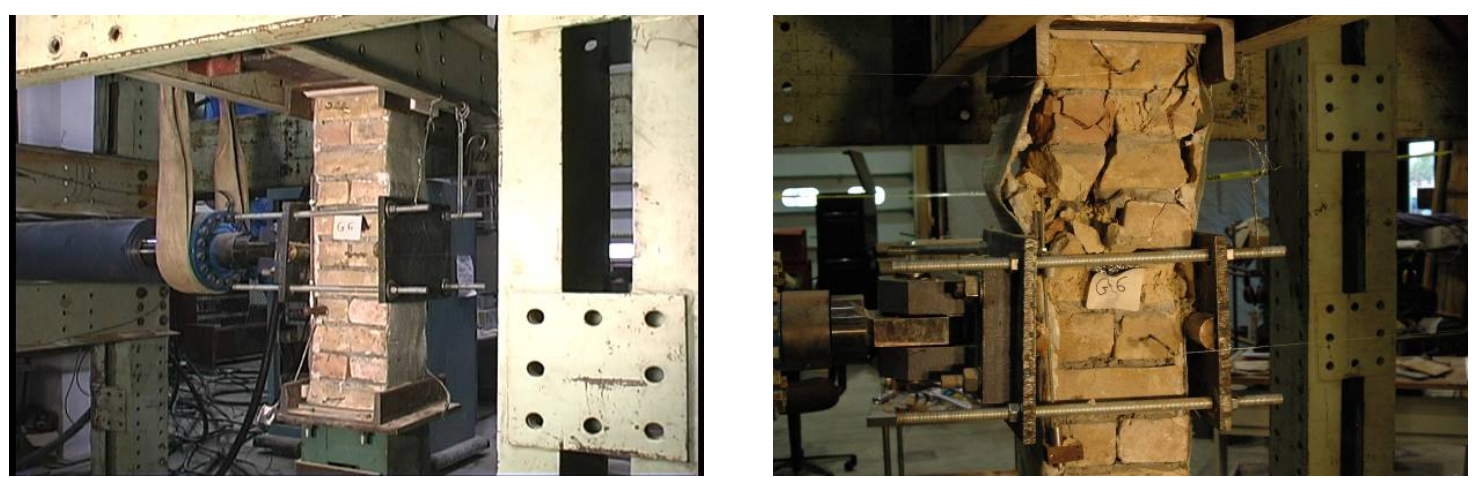

Figure 81. Specimen G6 with SikaWrap Hex, before test (left) after test (right).
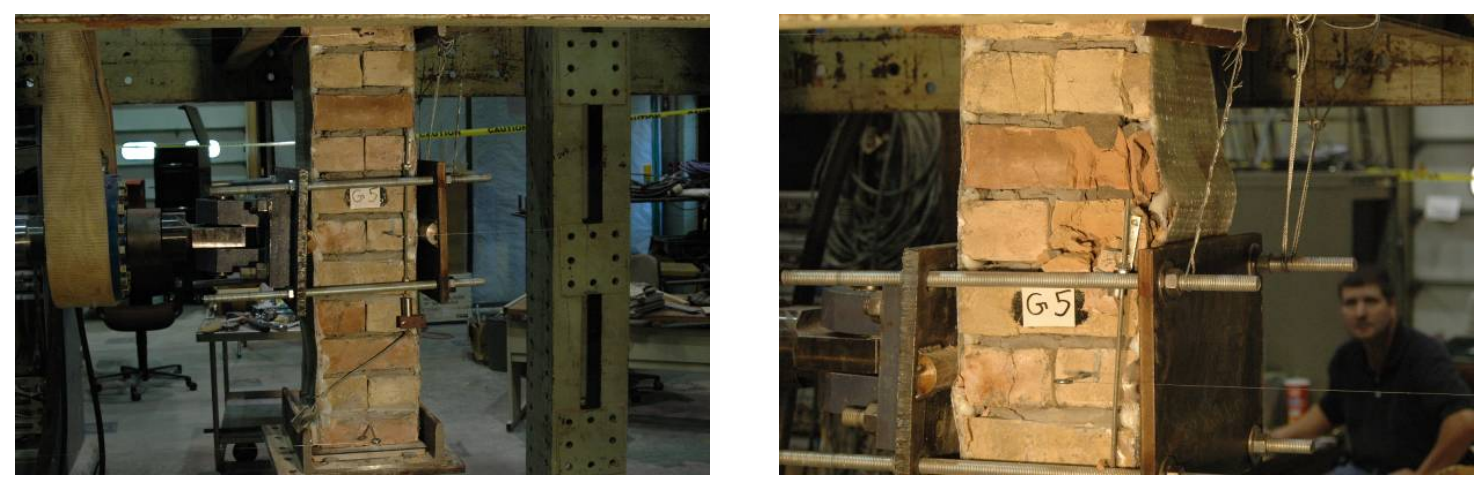

a. Specimen G5 with SikaWrap Hex, before test (left) after test (right).
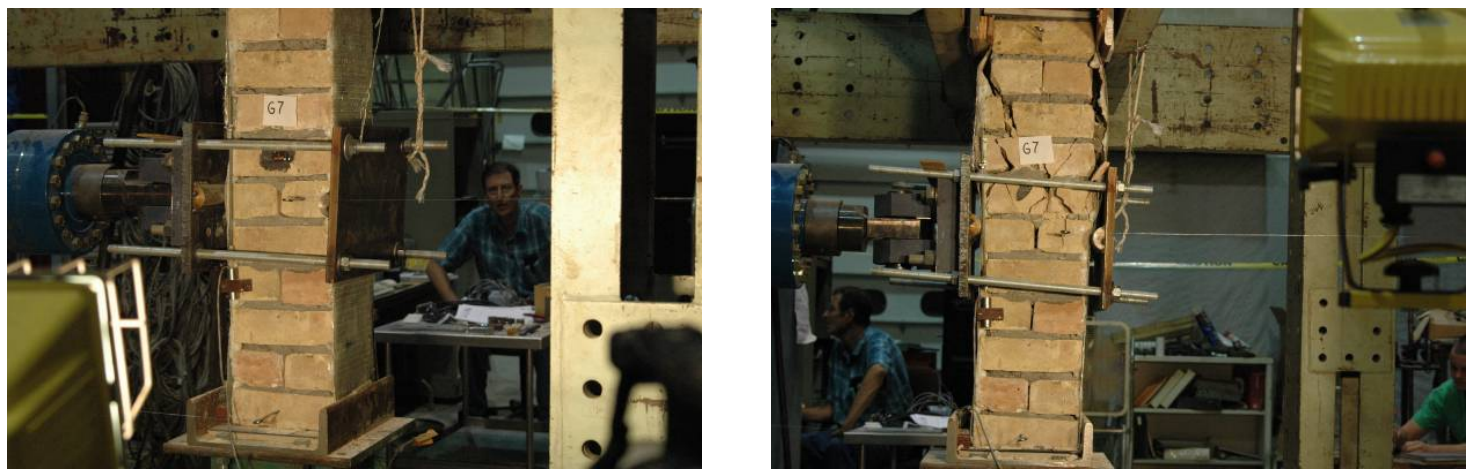

b. Specimen G7 with SikaWrap Hex, before test (left) after test (right).

Figure 82. Failure of Specimens G5 and G7.

\subsubsection{Specimen G7 (vertical load $=50 \%$ of $f^{\prime}{ }_{m}$ )}

Cracks were observed in the courses above the loading point. X-shaped shear cracks formed under cyclic loading followed by brittle crushing of the cracked section (Figure 83b).

\subsubsection{Specimen G8 (vertical load $=75 \%$ of $f^{\prime} \mathrm{m}$ )}

This specimen failed in a very sudden and brittle fashion, just below the loading point and resulted in loss of the specimen (Figure 83). 

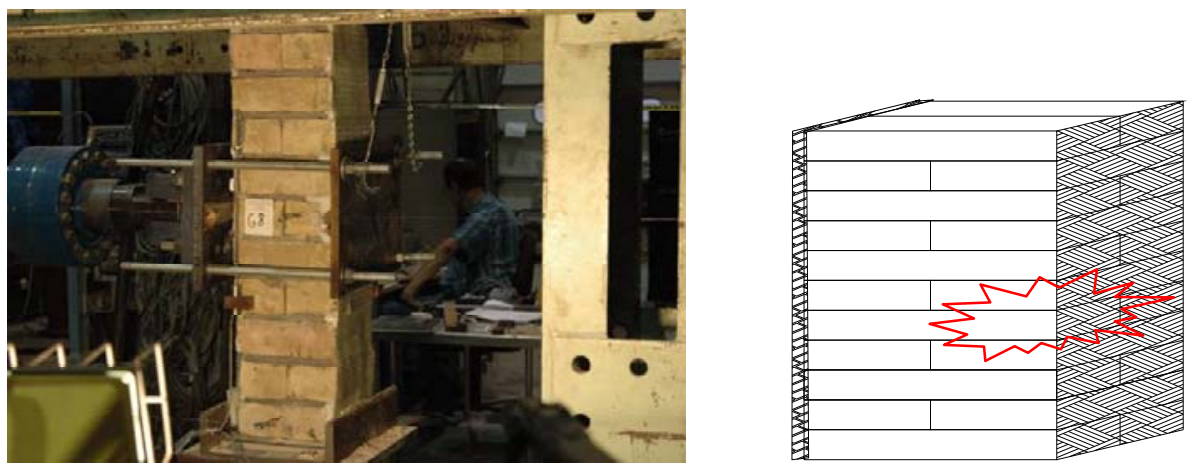

Figure 83. Specimen G8 with Sika Wrap Hex, before test (left), and sketch showing the point of failure (no picture is available) (right).

\subsection{Summary of out-of-plane tests of wall specimens}

Figures 84 through 102 plot the Stress-deformation hystereses for all test specimens. Table 18 lists the maximum stresses, their corresponding displacements and maximum displacements, and their corresponding stresses. Note that, although these figures do not show "backbone curves," they can be drawn similarly to Figure 61 by simply connecting the starting point of the each curve with its ultimate point value and the intersection points of the hysteresis loops.

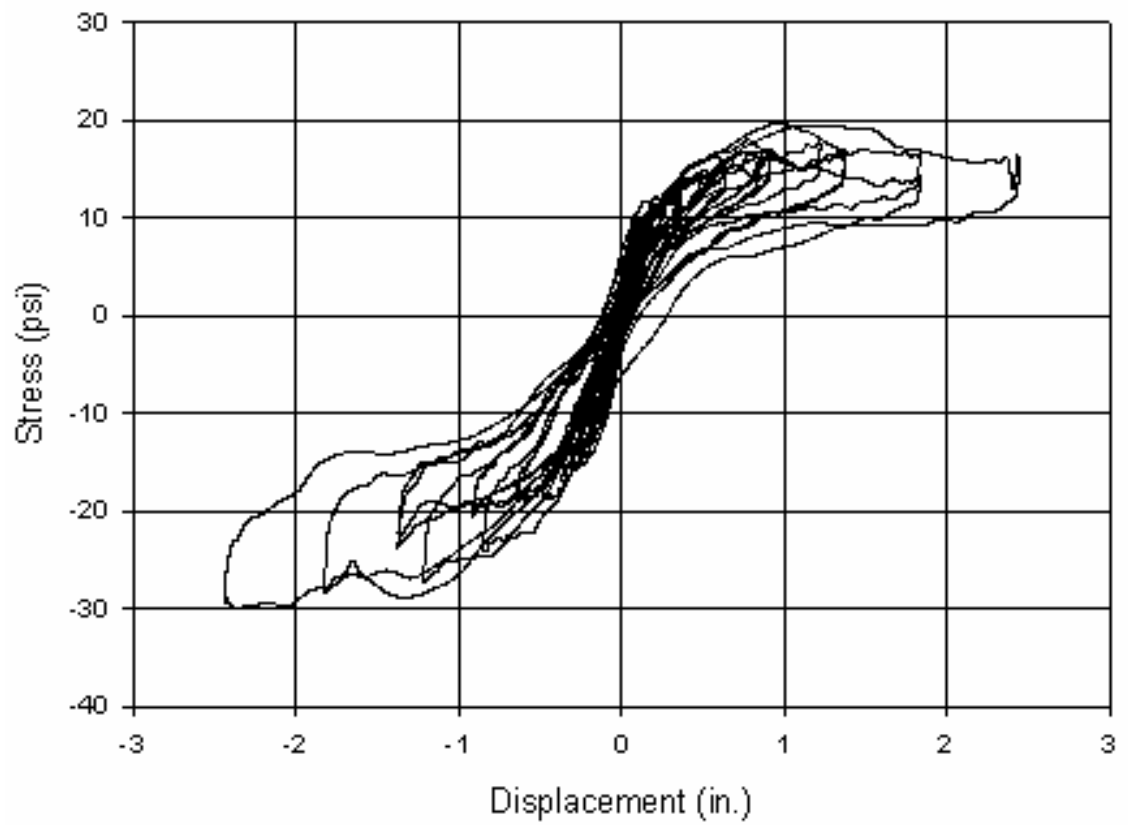

Figure 84. Hysteresis of Specimen 04 Bare Wall, 8.4 percent. 


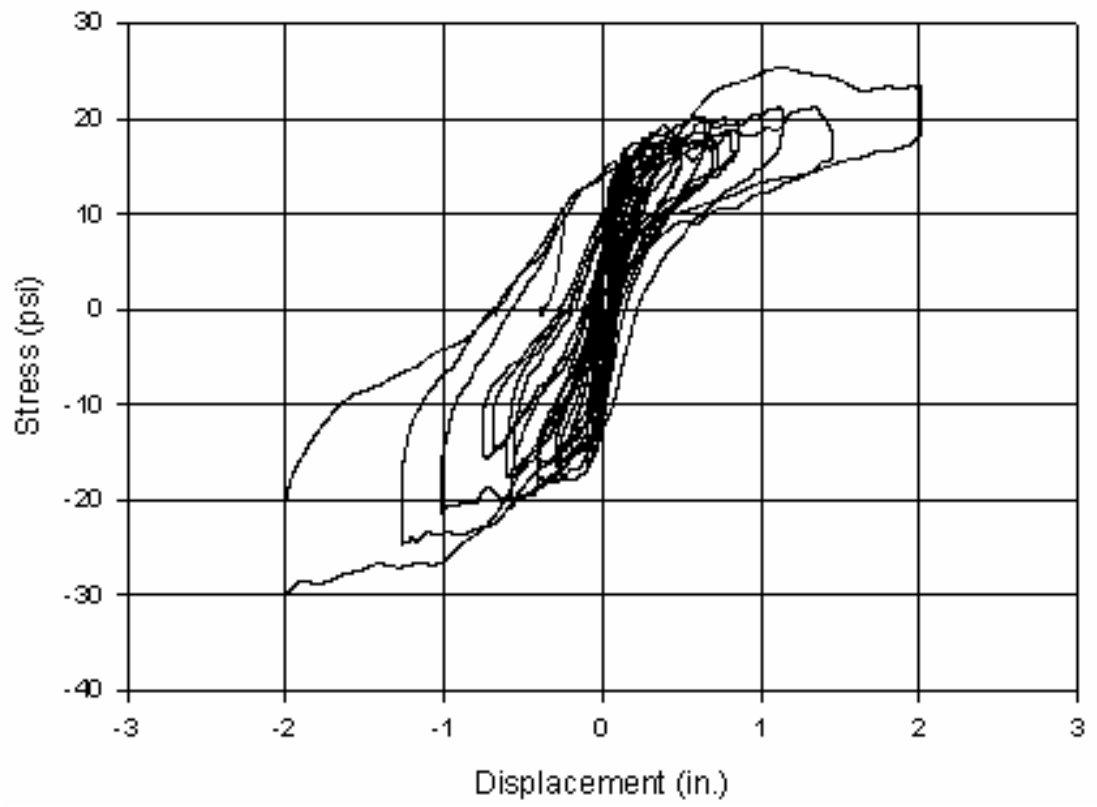

Figure 85. Hysteresis of Specimen 06 Bare Wall, 8.4 percent.

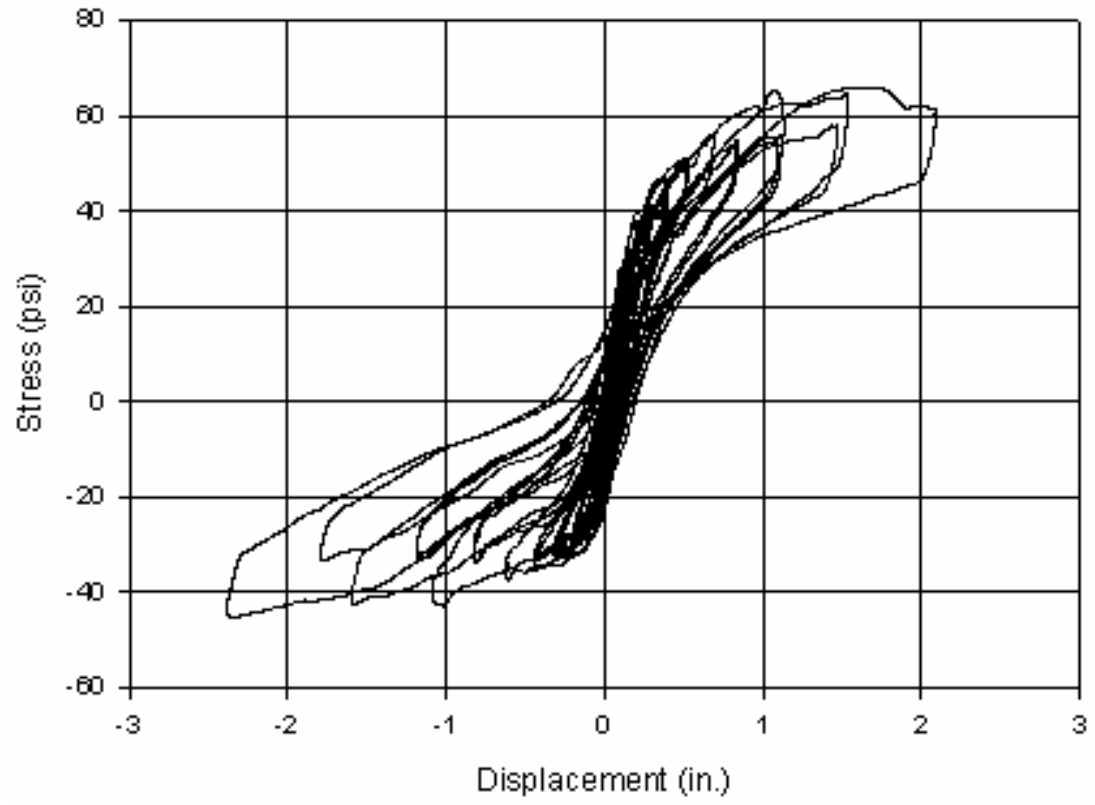

Figure 86. Hysteresis of Specimen 010 Bare Wall, 25 percent. 


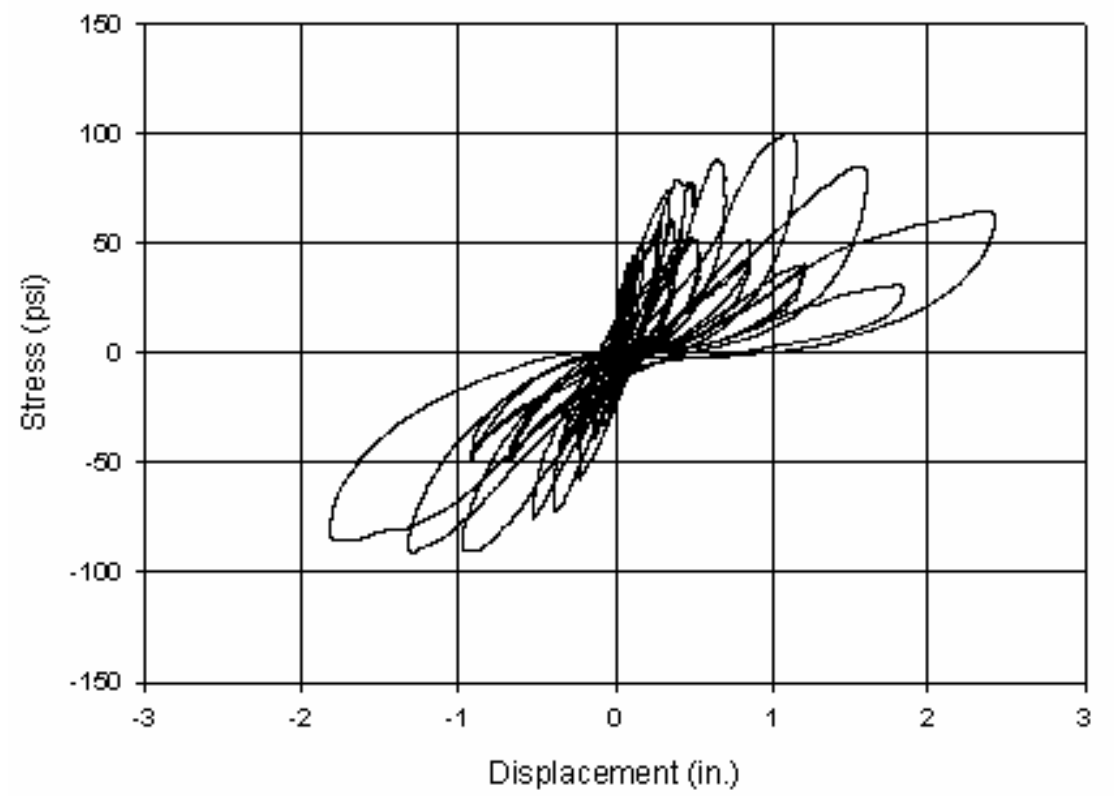

Figure 87. Hysteresis for Specimen 07 Bare Wall, 50 percent.

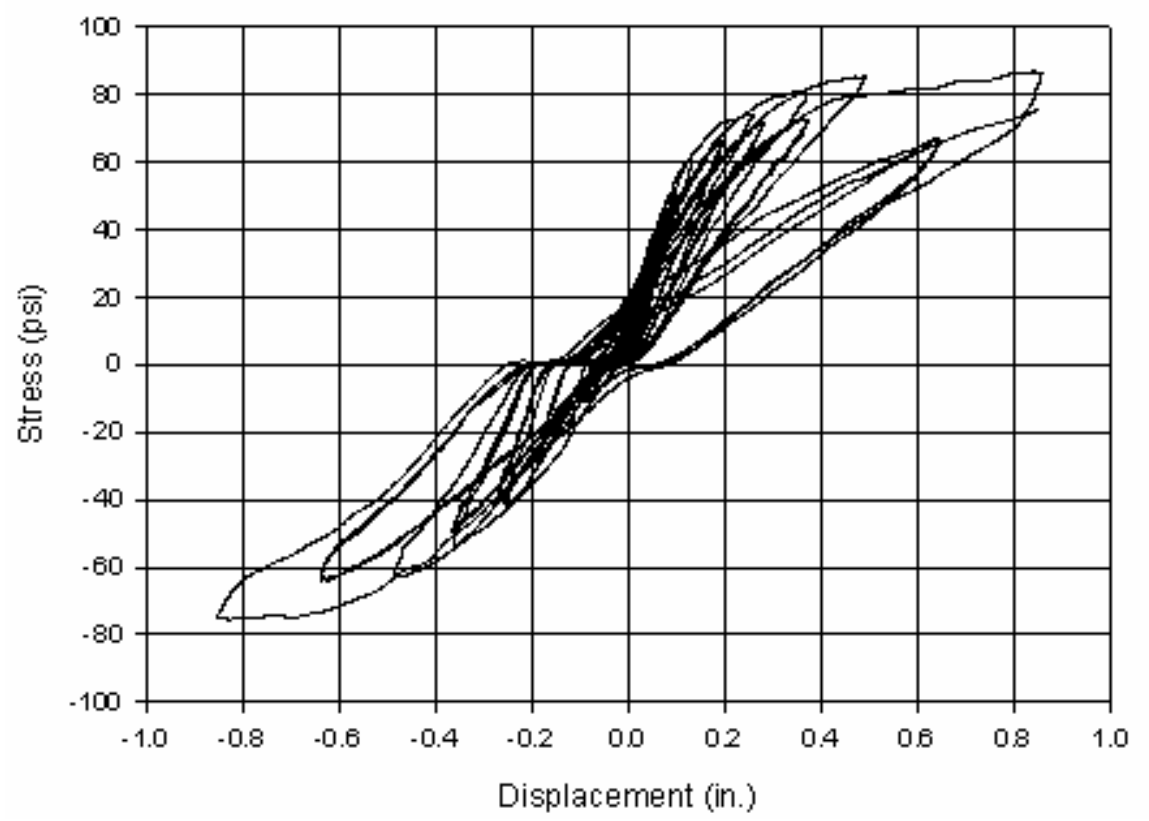

Figure 88. Hysteresis for Specimen 09 Bare Wall, 50 percent. 


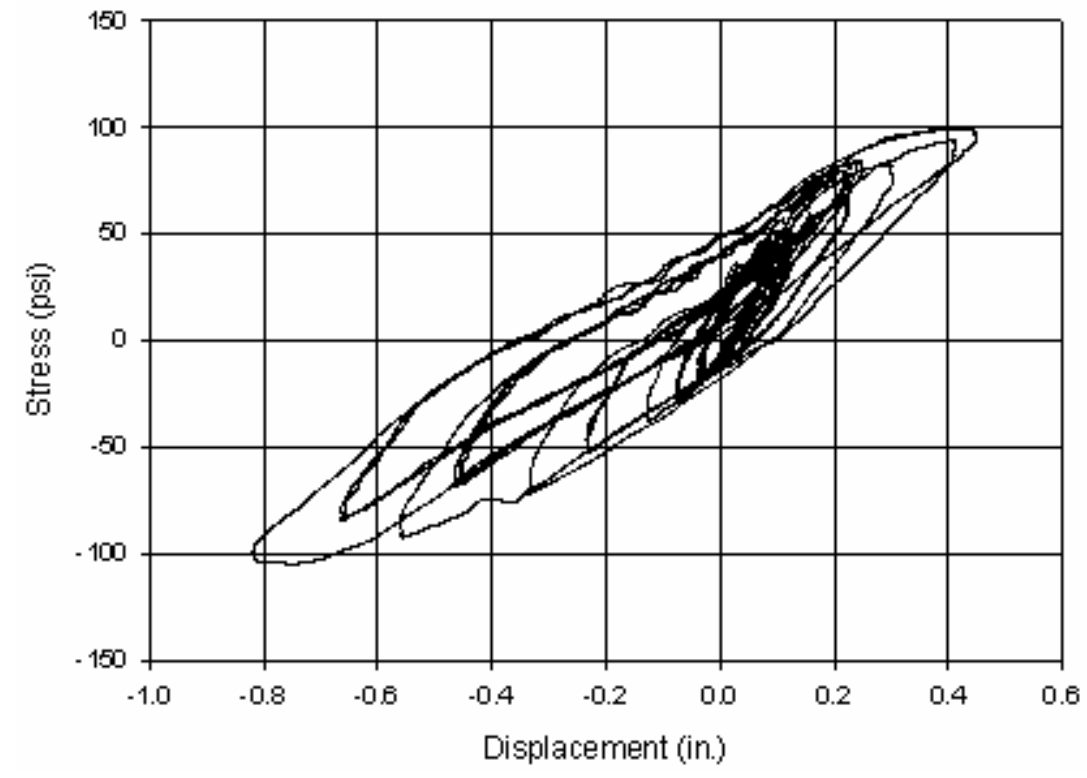

Figure 89. Hysteresis for Specimen 011 Bare Wall, 75 percent.

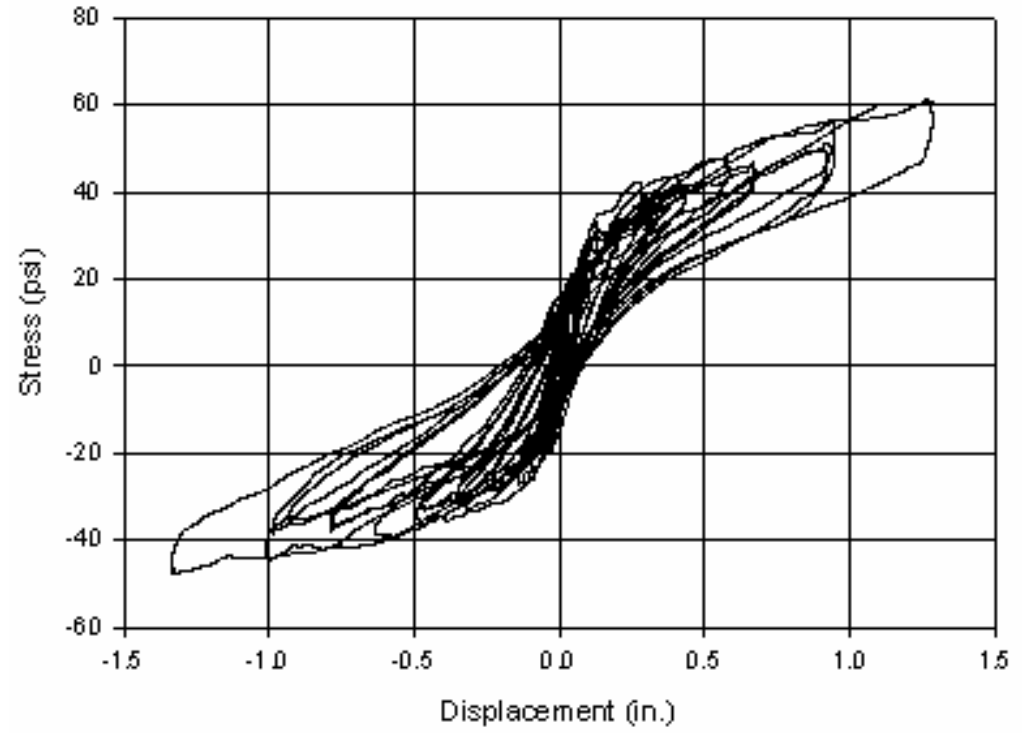

Figure 90. Hysteresis for Specimen 012 Bare Wall, 75 percent. 


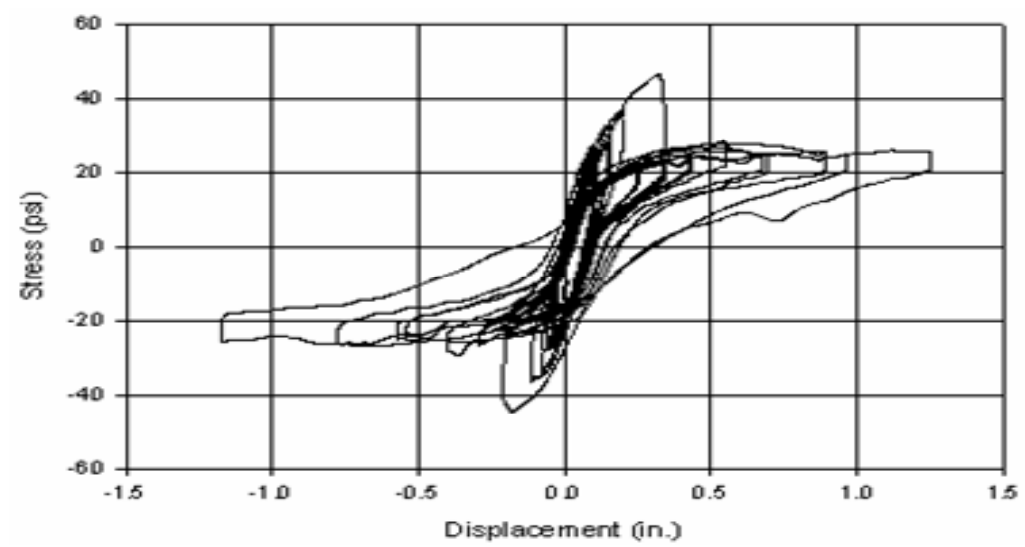

Figure 91. Hysteresis Specimen C3 Saint Gobain Glass with Cement Base FRP, 6.3 percent.

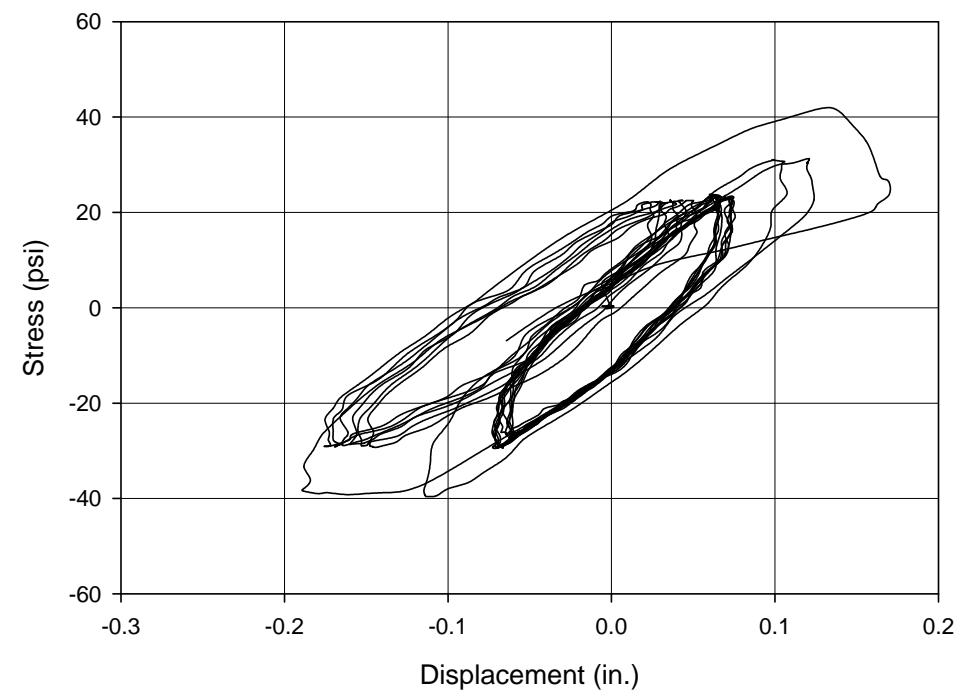

Figure 92. Hysteresis of Specimen C4 Saint Gobain Glass with Cement Base FRP, 6.3 percent. 


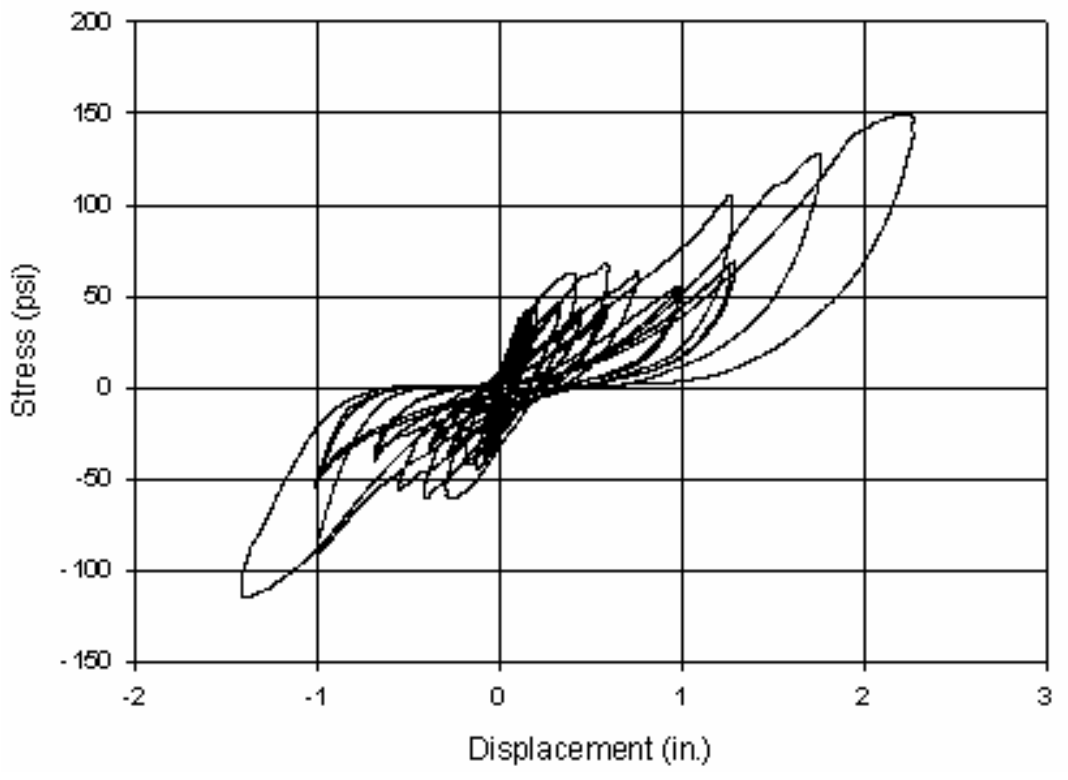

Figure 93. Hysteresis of Specimen C6 Saint Gobain Glass with Cement Base FRP, 25 percent.

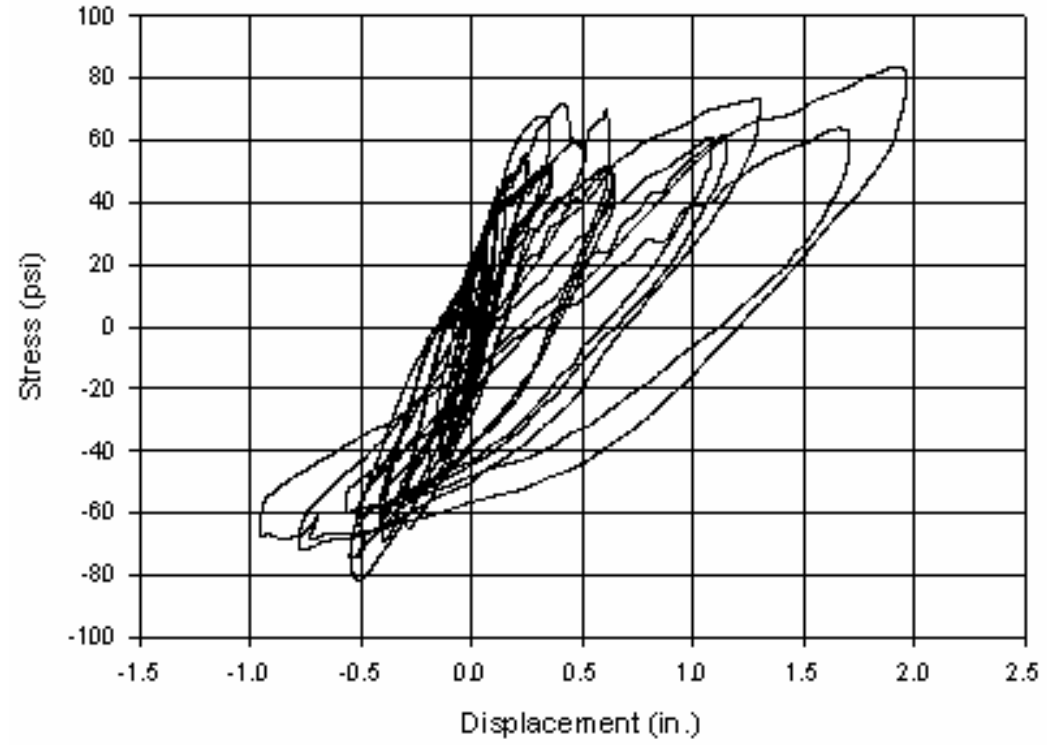

Figure 94. Hysteresis of Specimen C7 Saint Gobain Glass with Cement Base FRP, 25 percent. 


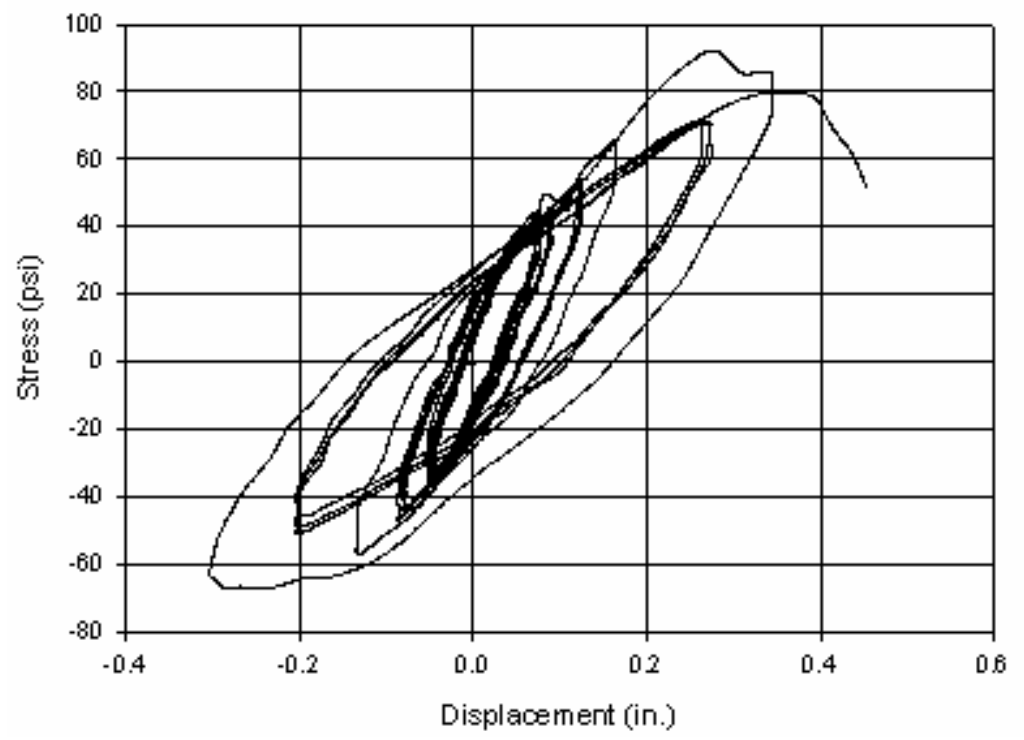

Figure 95. Hysteresis for Specimen C8 Saint Gobain Glass with Cement Base FRP, 50 percent.

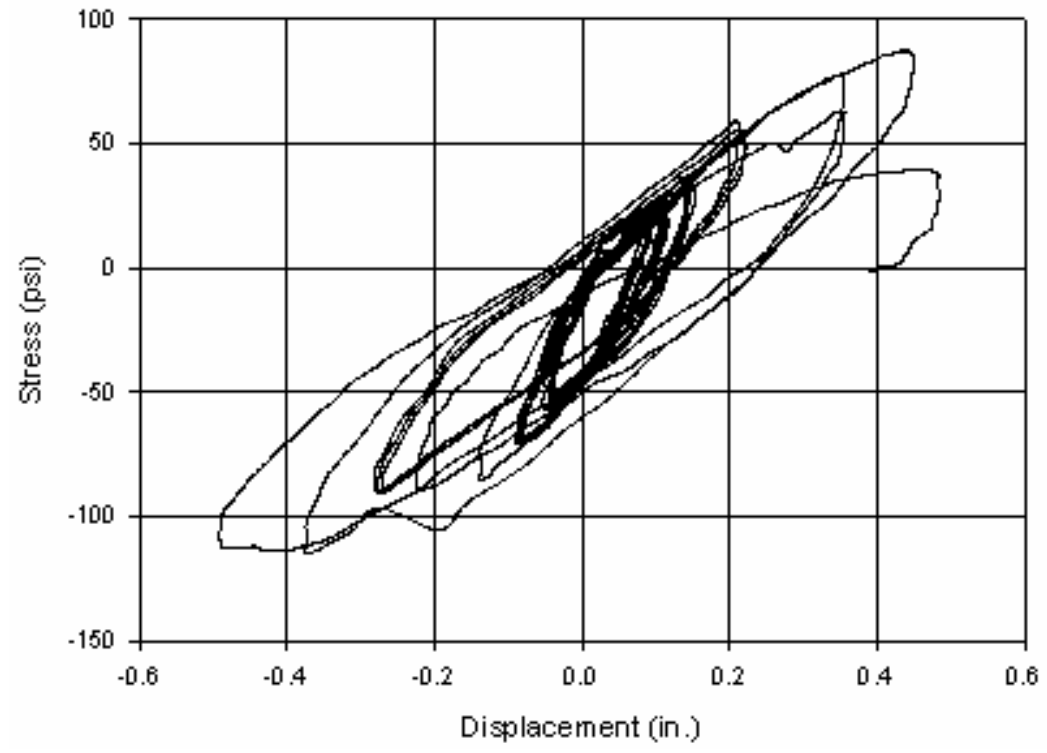

Figure 96. Hysteresis for Specimen C5 Saint Gobain Glass with Cement Base FRP, 50 percent. 


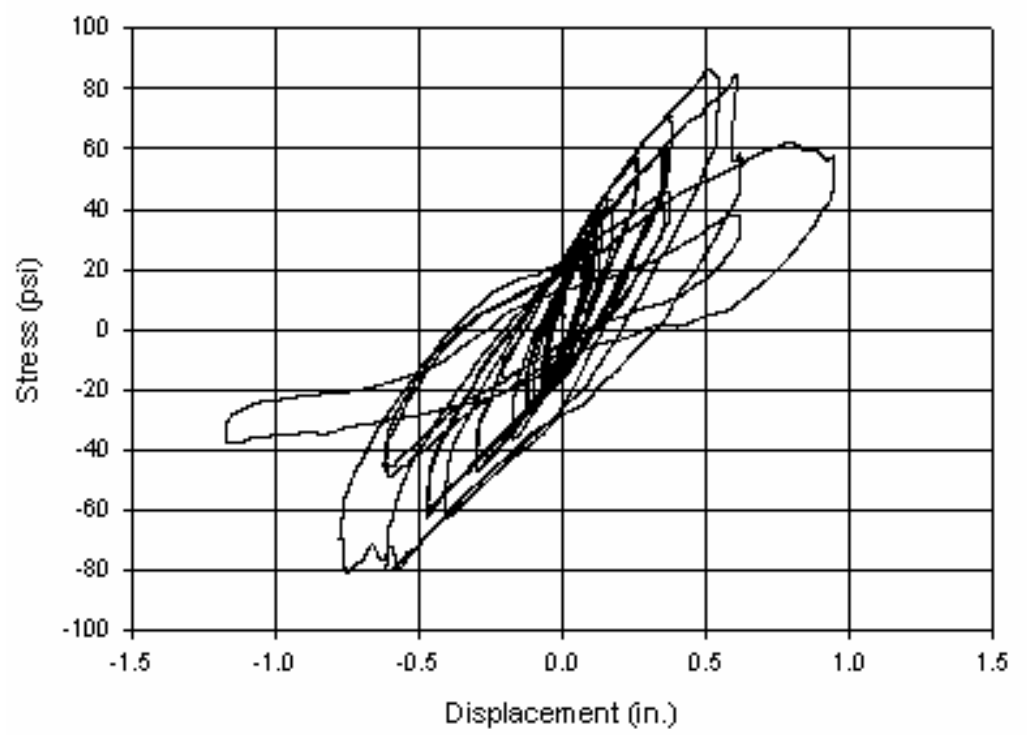

Figure 97. Hysteresis of Specimen G3 Sika FRP, 6 percent.

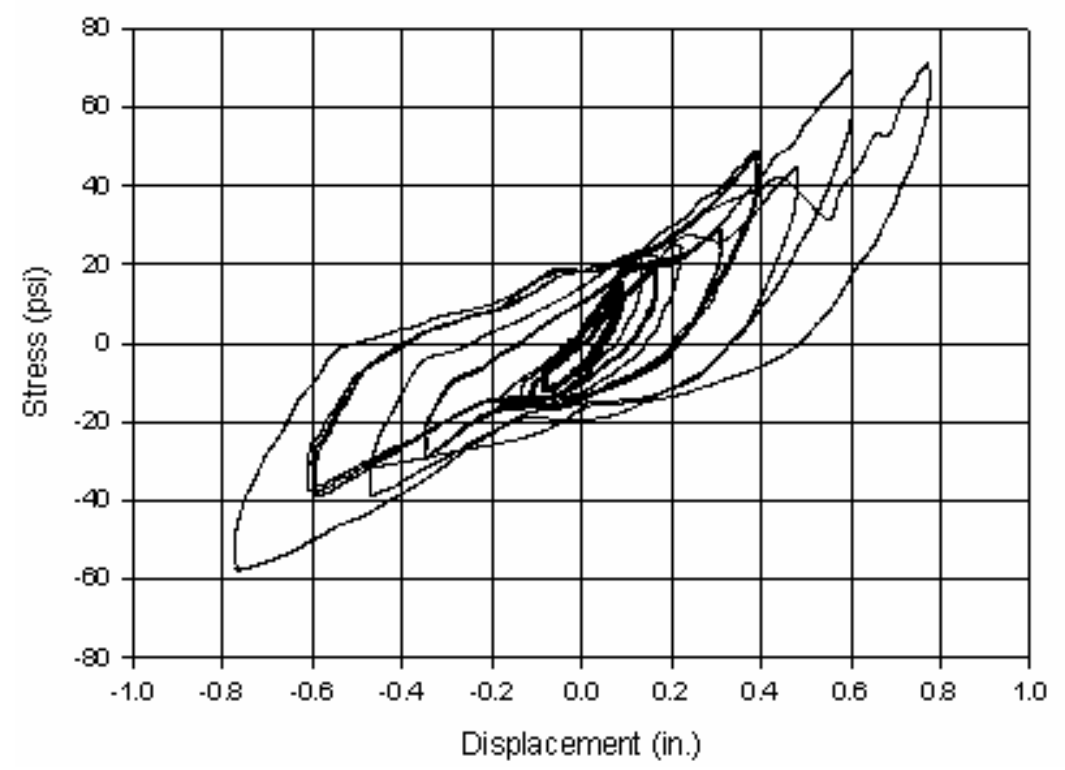

Figure 98. Hysteresis Specimen G4 Sika FRP, 6 percent. 


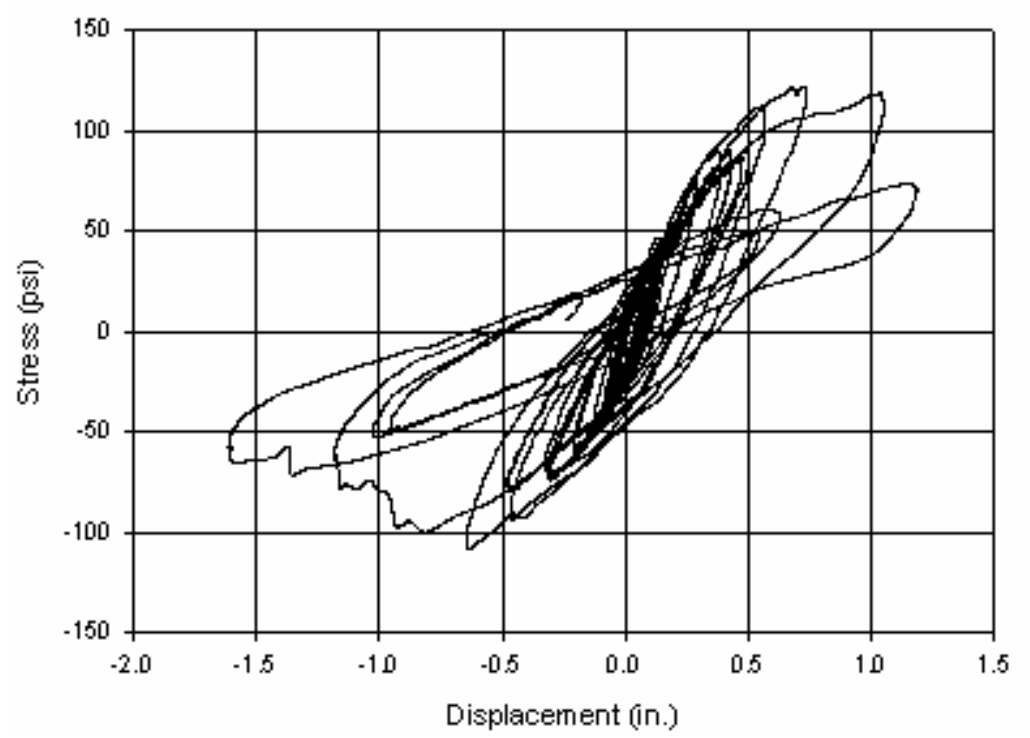

Figure 99. Hysteresis Specimen G6 Sika FRP, 25 percent.

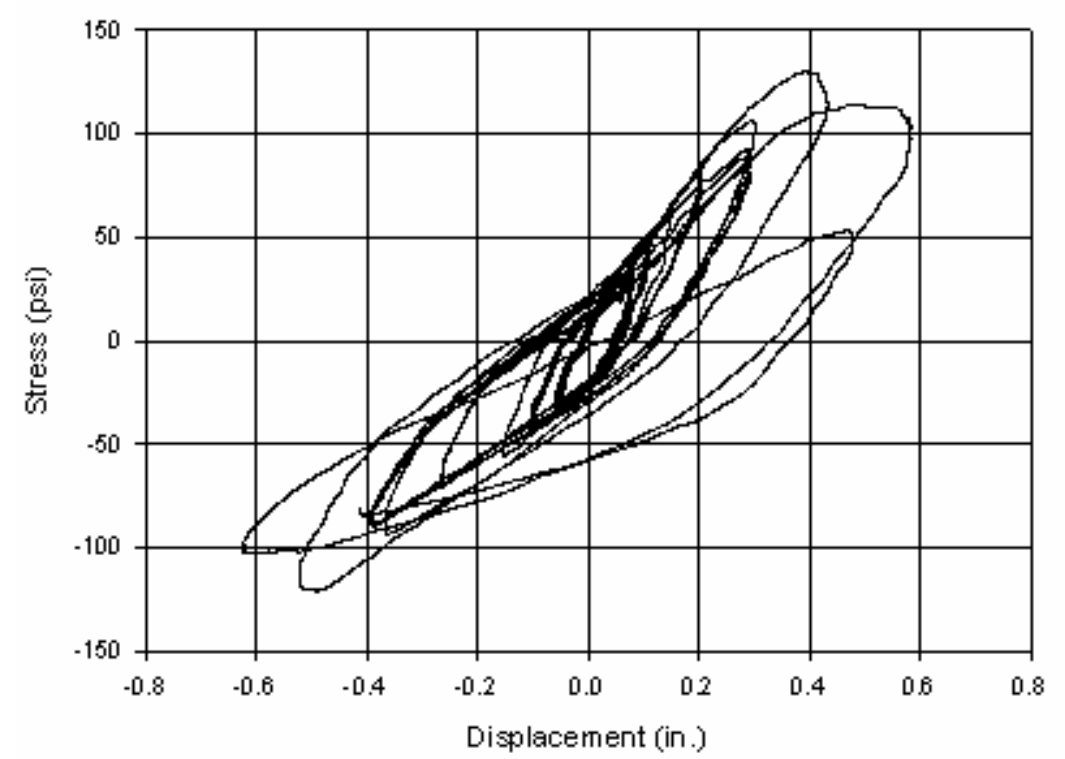

Figure 100. Hysteresis for Specimen G5 Sika FRP, 50 percent. 


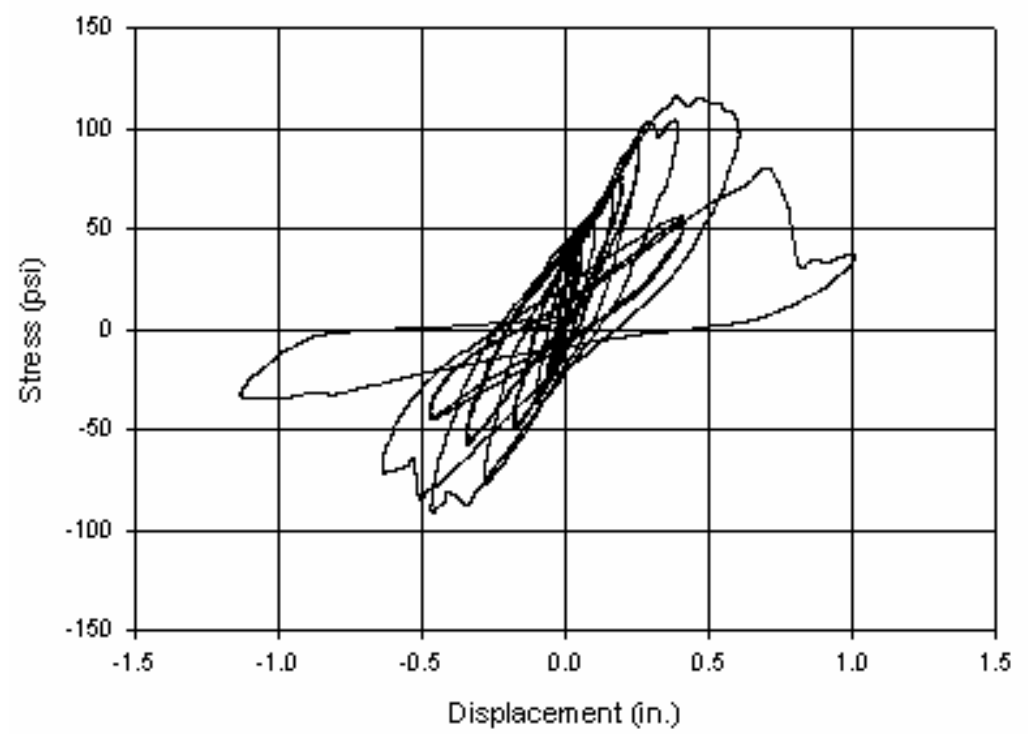

Figure 101. Hysteresis for Specimen G7 Sika FRP, 50 percent.

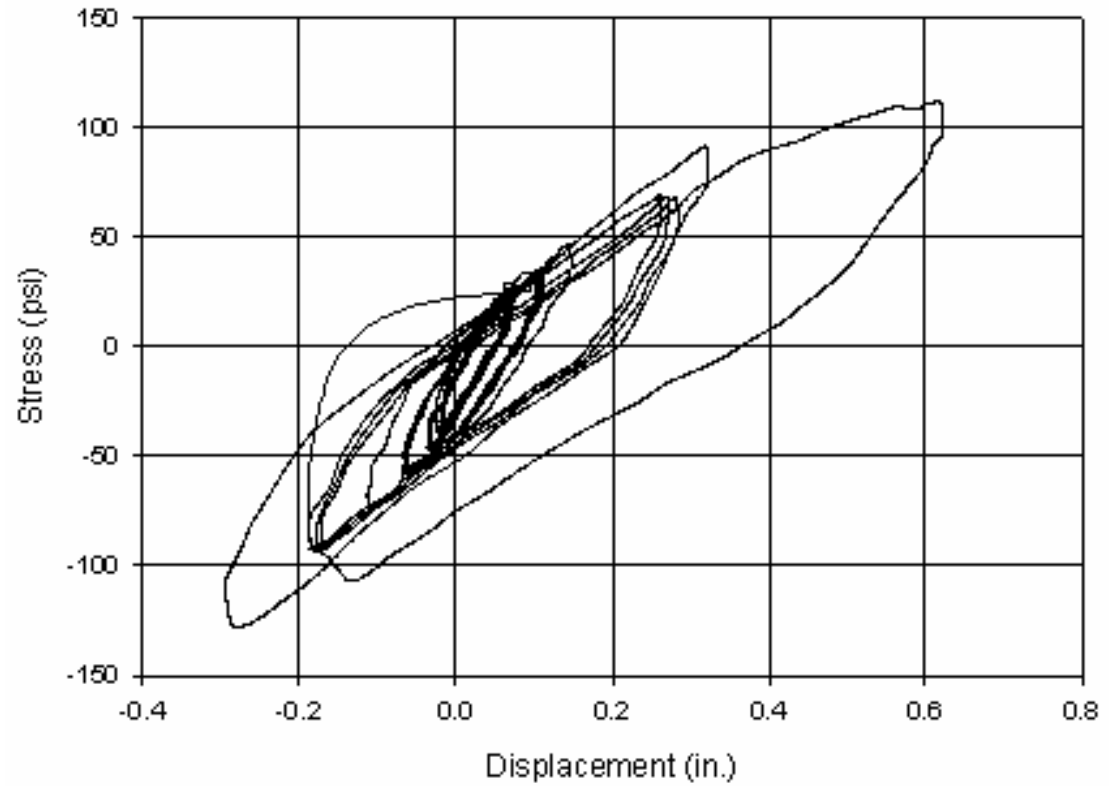

Figure 102. Hysteresis for Specimen G8 Sika FRP, 75\%. 
Table 18. Summary of the maximum stresses and their corresponding displacements and maximum displacements and their corresponding stresses for all out-of-plane tests.

\begin{tabular}{|c|c|c|c|c|c|}
\hline & $\%$ of $f^{\prime} m$ & $\begin{array}{l}\sigma_{\max } \\
(p s i)\end{array}$ & $\begin{array}{l}d_{\text {corresponding }} \\
\text { (in.) }\end{array}$ & $\begin{array}{l}d_{\max } \\
\text { (in.) }\end{array}$ & $\begin{array}{c}\sigma_{\text {corresponding }} \\
\quad(p s i)\end{array}$ \\
\hline \multicolumn{6}{|c|}{0 -series } \\
\hline 04 & $8.4 \%$ & 30.1 & 2.3 & 2.4 & 15.8 \\
\hline 06 & $8.4 \%$ & 29.9 & 2.0 & 2.0 & 25.9 \\
\hline 010 & $25 \%$ & 66.5 & 1.7 & 2.4 & 44.2 \\
\hline 07 (Stroke CTL) & $50 \%$ & 100.6 & 1.1 & 2.4 & 62.6 \\
\hline 09 & $50 \%$ & 87.0 & 0.84 & 0.86 & 86.3 \\
\hline 011 & $75 \%$ & 100.4 & 0.44 & 0.45 & 93.8 \\
\hline 012 & $75 \%$ & 61.4 & 1.27 & 1.3 & 47.0 \\
\hline \multicolumn{6}{|c|}{ C-series } \\
\hline $\mathrm{C} 3$ & $6.3 \%$ & 46.6 & 0.3 & 1.3 & 25.2 \\
\hline $\mathrm{C4}$ & $6.3 \%$ & 42.0 & 0.13 & 0.19 & 38.0 \\
\hline C6 (Stroke CTL) & $25 \%$ & 150.1 & 2.2 & 2.3 & 146.3 \\
\hline $\mathrm{C} 7$ & $25 \%$ & 83.9 & 1.9 & 2.0 & 79.2 \\
\hline $\mathrm{C} 8$ & $50 \%$ & 92.6 & 0.3 & 0.45 & 51.4 \\
\hline C5 & $75 \%$ & 114.8 & 0.4 & 0.5 & 104.7 \\
\hline \multicolumn{6}{|c|}{ G-series } \\
\hline G3 & $6 \%$ & 86.5 & 0.5 & 1.2 & 36.6 \\
\hline G4 & $6 \%$ & 71.1 & 0.77 & 0.78 & 64.7 \\
\hline G6 & $25 \%$ & 122.4 & 0.7 & 1.6 & 56.6 \\
\hline G5 & $50 \%$ & 130.1 & 0.4 & 0.6 & 100.3 \\
\hline G7 & $50 \%$ & 117.5 & 0.4 & 1.1 & 33.1 \\
\hline G8 & $75 \%$ & 127.9 & 0.3 & 0.6 & 110.6 \\
\hline
\end{tabular}

Table 18 and Figure 103 summarize the maximum shear stresses of the wall strips associated with the percent of failure load applied axially. The curves in Figure 104 were plotted assuming linear relationship between the data points. The G-series has better performance; however, the Sika Wrap's appearance may put it at a disadvantage. The maximum lateral shear stresses for the C- and G-series occurred at a vertical stress of $75 \%$ $\mathrm{f}^{\prime} \mathrm{m}$., while for the o-series the maximum lateral shear stress occurred at about $50 \%$ of $\mathrm{f}_{\mathrm{m}}$ vertical stress. In the case of the $\mathrm{C}$ - and G-series, the GFRP provided some confinement for the masonry, holding the surface together and allowing for higher compressive forces at the surface. At the expected service loads, the C-series showed a 14.3 psi shear-stress improvement, and the G-series showed a 48.8 psi shear-stress improvement compared to the bare-brick specimen. Table 19 lists maximum shear stresses for all series under various vertical loading, for comparison. 


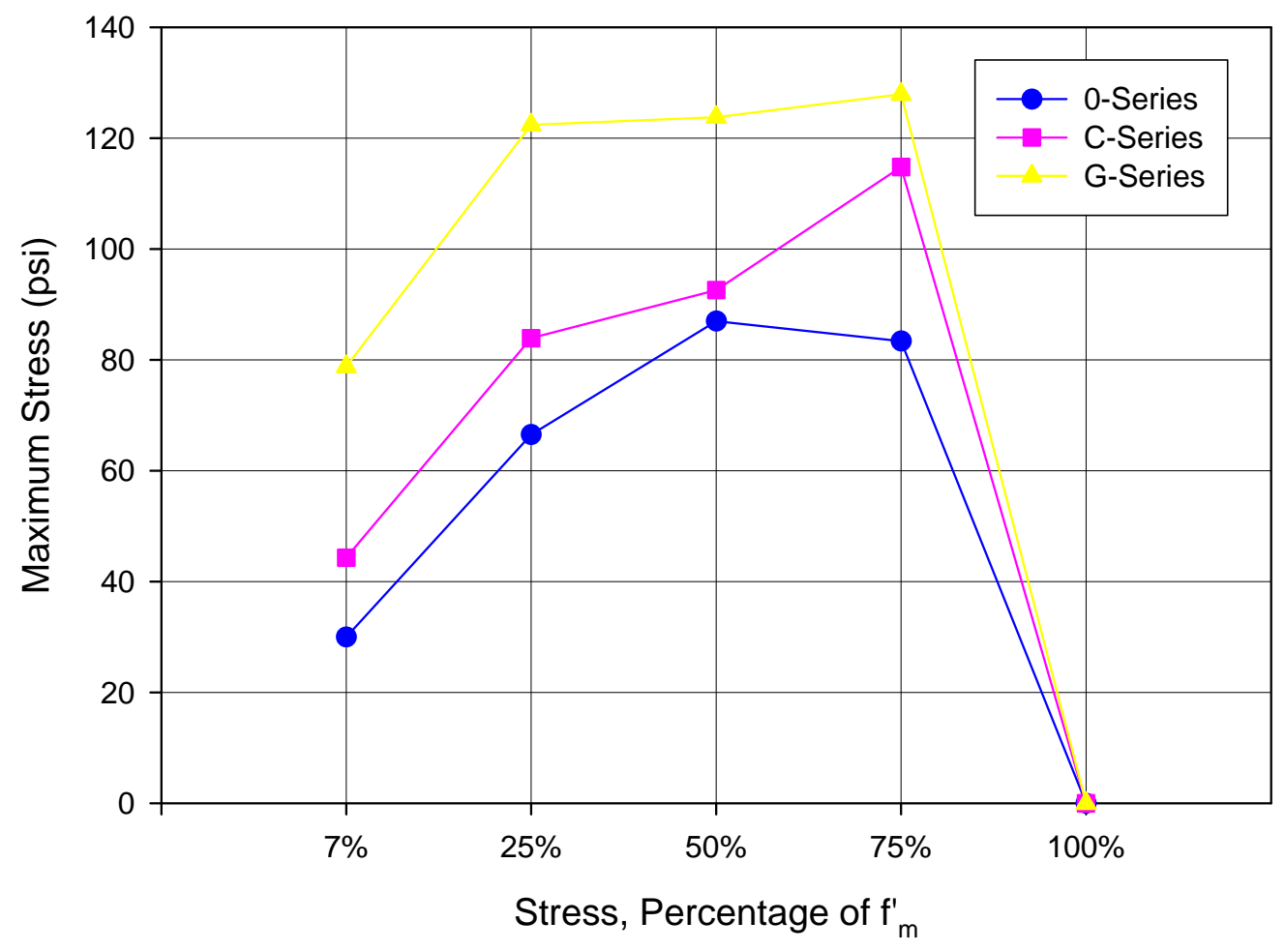

Figure 103. Axial stress v. maximum stress for each specimen type.

Table 19. Maximum shear stresses for all series under various vertical loading.

\begin{tabular}{|l|c|c|c|c|c|}
\hline \multicolumn{5}{|c|}{ Max. Shear Stress Associated With \% Axial Stress (psi) } \\
\hline & \multicolumn{5}{|c|}{ \% of Max. Compression Stress (psi) } \\
\hline Series & $\sim 7 \%$ & $25 \%$ & $50 \%$ & $75 \%$ & $100 \%$ \\
\hline 0 & 30 & 66.5 & 87 & 83.4 & 0 \\
\hline C & 44.3 & 83.9 & 92.6 & 114.8 & 0 \\
\hline G & 78.8 & 122.4 & 123.8 & 127.9 & 0 \\
\hline
\end{tabular}




\section{Summary and Conclusions}

\subsection{Summary of testing program}

1. This work conducted compression testing of brick prisms with and without two FRP overlay systems to determine compressive strength. Results are: f'm $=489$ psi, 462, and $737 \mathrm{psi}$, for the $\mathrm{o}, \mathrm{C}$ and $\mathrm{G}$ series, respectively. The Young's modulus E was $1.3 \times 106$.

2. The maximum in-plane shear capacity was determined by testing large specimens in cyclic horizontal shear with a constant in-plane vertical load. The bare wall maximum shear strength was 29.4 psi. The Saint Gobain Cementitious FRP System increased the in-plane shear strength by 36.7 percent. The SikaWrap FRP system increased the inplane shear strength by 24.1 percent (Table 20).

3. Double-wythe test specimens 11 units tall were tested in pure compression with and without the two FRP overlay systems. The maximum compressive strength for the bare wall strip was 296 psi. The Saint Gobain Cementitious FRP System increased the compressive strength by 32.4 percent. The SikaWrap FRP system increased the compressive stress by 44.4 percent (Table 21).

4. Double-wythe test specimens 11 units tall were tested in combinations of constant axial compression and increasing cyclic horizontal shear with and without the two FRP overlay systems applied to resist bending in the direction of the horizontal loading. The maximum out-ofplane shear capacity for the bare wall is 30.0 psi. The Saint Gobain Cementitious FRP System increased the in-plane shear strength by 47.7 percent. The SikaWrap FRP system increased the in-plane shear strength by 263.0 percent (Table 22).

5. The maximum out-of-plane shear capacity for the bare strip is $30 \mathrm{psi}$, and it is consistent with the maximum in-plane shear capacity of 29.4 psi under 15 kips vertical load (Table 22).

6. Initial tests of both IP-G1 and IP-C1 (in-plane) walls showed a weakness in the joint between the concrete beam and the masonry. Proper detailing to ensure load is properly transferred through the FRP is important. The test fixture was modified to apply loading to the edge of the top and bottom two courses of masonry. Figure 104 shows a recommended construction detail that combines dowels into the masonry and bonds beams continuously with the slabs to develop the strength of the composite overlays. 
7. The Saint Gobain Cementitious FRP System showed higher in-plane shear strength and lower out-of-plane shear strength than the SikaWrap FRP system. The matrix for SikaWrap is stronger in tension and therefore increased the moment resistant for the out-of-plane specimens significantly.

8. Specimens 07 and C6 were tested under vertical stroke control loads. These two specimens can be compared with specimens 09 and $\mathrm{C}_{7}$, respectively. In the vertical stroke control tests, the specimens are loaded initially to the set percentage of $\mathrm{f}^{\prime} \mathrm{m}$. There after the vertical loads increase as the specimens are restrained from vertical displacements and deform under cyclic loads. The increase in vertical load resulted in increased shear stresses by 15.6 percent for 07 specimen and 78.9 percent for the $\mathrm{C6}$ specimens.

Table 20. Summary of maximum stress and displacement

\begin{tabular}{|c|c|c|c|c|c|c|}
\hline \multirow[b]{2}{*}{ Specimen } & \multirow[b]{2}{*}{$\begin{array}{l}\sigma_{\max } \\
(p s i)\end{array}$} & \multirow[b]{2}{*}{$\begin{array}{l}d_{\text {corresponding }} \\
\text { (in.) }\end{array}$} & \multirow[b]{2}{*}{$\begin{array}{l}d_{\max } \\
\text { (in.) }\end{array}$} & \multirow[b]{2}{*}{$\begin{array}{l}\sigma_{\text {corresponding }} \\
\quad(p s i)\end{array}$} & \multicolumn{2}{|c|}{ Backbone Curves } \\
\hline & & & & & $\begin{array}{l}\sigma_{\max } \\
(\mathrm{psi})\end{array}$ & $\begin{array}{l}\mathrm{d}_{\text {corresponding }} \\
\text { (in.) }\end{array}$ \\
\hline 02 & 29.4 & 0.013 & 1.2 & 14.3 & 17.5 & 0.65 \\
\hline C1 (1st Run) & 32.1 & 0.015 & 0.64 & 4.3 & N/A & \\
\hline C1 (2 ${ }^{\text {nd }}$ Run $)$ & 40.2 & 0.38 & 0.4 & 30.5 & 23.1 & 1.4 \\
\hline C1 (3' Run) & 61.9 & 0.43 & 0.45 & 60.9 & N/A & \\
\hline G1 (1st Run) & 36.5 & 0.039 & 0.18 & 32.9 & 21.1 & 0.1 \\
\hline G1 (2 ${ }^{\text {nd }}$ Run $)$ & 72.2 & 0.22 & 0.23 & 72.0 & N/A & \\
\hline
\end{tabular}

Table 21. Summary of Pure Compression Tests Forces and Stresses:

\begin{tabular}{|c|c|c|c|}
\hline Specimen & $\begin{array}{l}\text { Max. Force } \\
\text { (kips) }\end{array}$ & $\begin{array}{c}\text { Average Forces } \\
\text { in Each Series } \\
\text { (Kips) }\end{array}$ & $\begin{array}{l}\text { Max. Stress } \\
\text { (ksi)* }\end{array}$ \\
\hline 01 & 24.884 & \multirow{2}{*}{23.963} & \multirow{2}{*}{0.296} \\
\hline 02 & 23.042 & & \\
\hline C1 & 37.265 & \multirow{2}{*}{31.746} & \multirow{2}{*}{0.392} \\
\hline $\mathrm{C} 2$ & 26.227 & & \\
\hline G1 & 35.468 & \multirow{2}{*}{34.500} & \multirow{2}{*}{0.426} \\
\hline G2 & 33.533 & & \\
\hline
\end{tabular}


Table 22. Summary of the maximum stresses and their corresponding displacements and maximum displacements and their corresponding stresses for all out-of-plane tests.

\begin{tabular}{|c|c|c|c|c|c|}
\hline & $\%$ of $f^{\prime} m$ & $\begin{array}{l}\sigma_{\max } \\
(p s i)\end{array}$ & $\begin{array}{l}d_{\text {corresponding }} \\
\text { (in.) }\end{array}$ & $\begin{array}{l}d_{\max } \\
\text { (in.) }\end{array}$ & $\begin{array}{l}\sigma_{\text {corresponding }} \\
(\mathrm{psi})\end{array}$ \\
\hline \multicolumn{6}{|c|}{ 0-series } \\
\hline 04 & $8.4 \%$ & 30.1 & 2.3 & 2.4 & 15.8 \\
\hline 06 & $8.4 \%$ & 29.9 & 2.0 & 2.0 & 25.9 \\
\hline 010 & $25 \%$ & 66.5 & 1.7 & 2.4 & 44.2 \\
\hline 07 (Stroke CTL) & $50 \%$ & 100.6 & 1.1 & 2.4 & 62.6 \\
\hline 09 & $50 \%$ & 87.0 & 0.84 & 0.86 & 86.3 \\
\hline 011 & $75 \%$ & 100.4 & 0.44 & 0.45 & 93.8 \\
\hline 012 & $75 \%$ & 61.4 & 1.27 & 1.3 & 47.0 \\
\hline \multicolumn{6}{|c|}{ C-series } \\
\hline $\mathrm{C} 3$ & $6.3 \%$ & 46.6 & 0.3 & 1.3 & 25.2 \\
\hline $\mathrm{C4}$ & $6.3 \%$ & 42.0 & 0.13 & 0.19 & 38.0 \\
\hline C6 (Stroke CTL) & $25 \%$ & 150.1 & 2.2 & 2.3 & 146.3 \\
\hline $\mathrm{C} 7$ & $25 \%$ & 83.9 & 1.9 & 2.0 & 79.2 \\
\hline $\mathrm{C8}$ & $50 \%$ & 92.6 & 0.3 & 0.45 & 51.4 \\
\hline C5 & $75 \%$ & 114.8 & 0.4 & 0.5 & 104.7 \\
\hline \multicolumn{6}{|c|}{ G-series } \\
\hline G3 & $6 \%$ & 86.5 & 0.5 & 1.2 & 36.6 \\
\hline G4 & $6 \%$ & 71.1 & 0.77 & 0.78 & 64.7 \\
\hline G6 & $25 \%$ & 122.4 & 0.7 & 1.6 & 56.6 \\
\hline G5 & $50 \%$ & 130.1 & 0.4 & 0.6 & 100.3 \\
\hline G7 & $50 \%$ & 117.5 & 0.4 & 1.1 & 33.1 \\
\hline G8 & $75 \%$ & 127.9 & 0.3 & 0.6 & 110.6 \\
\hline
\end{tabular}




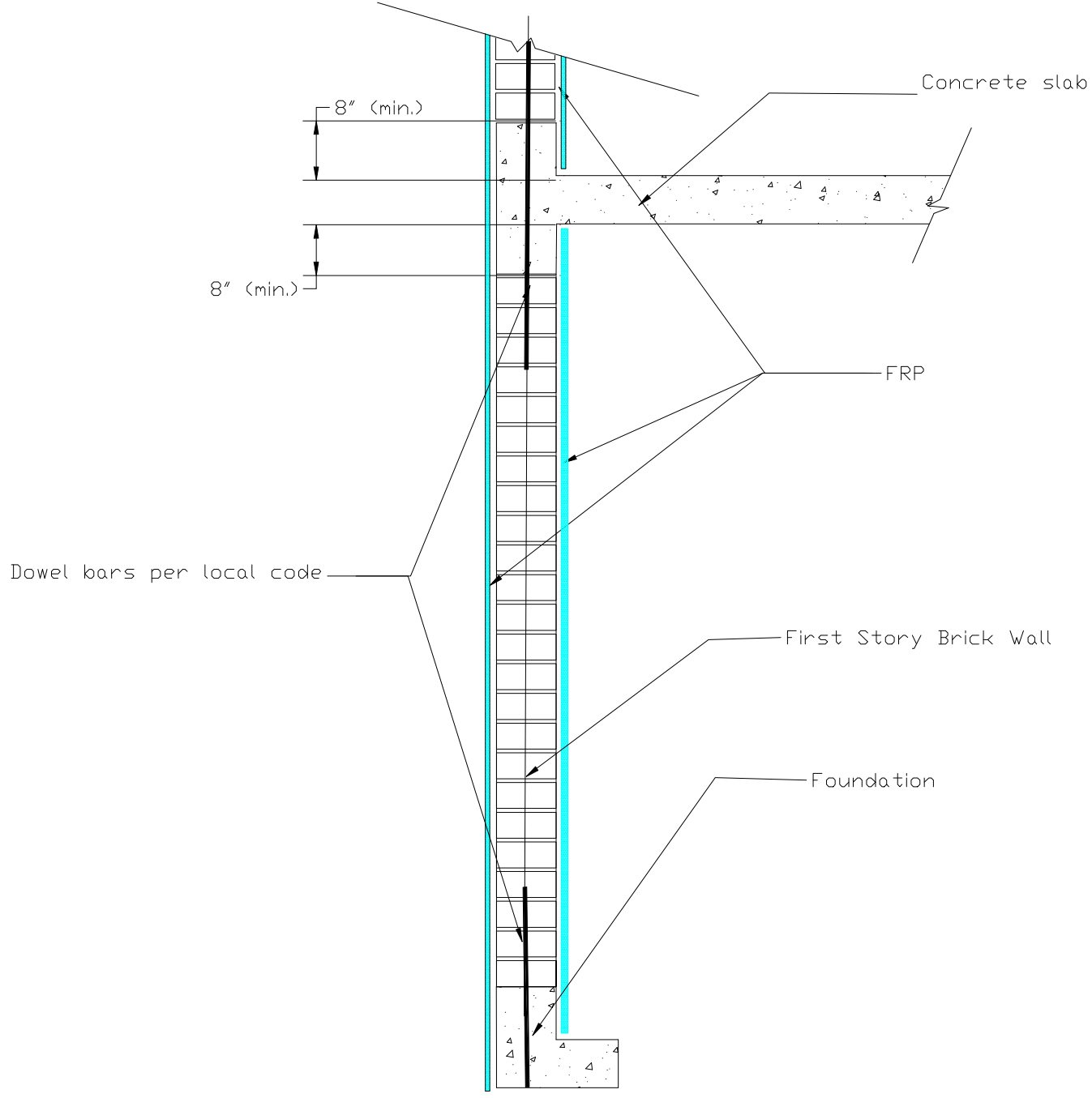

Figure 104. Proposed design section details in the construction.

\subsection{Conclusions relevant to design implications}

1. It is recommended for design purposes to use the prism compressive strength of $\mathrm{f}^{\prime} \mathrm{m}=669 \mathrm{psi}$ and Young's Modulus E=1.3 $\times 10^{6}$.

2. It is recommended for design purposes to use the in-plane strength based on ultimate strength as read by from the back bone curves. The values are: 17.5, 23.1, and $21.1 \mathrm{psi}$ for the $\mathrm{o}, \mathrm{C}$, and G-series, respectively.

3. Out-of-plane resistance to shear and bending are significantly improved using the FRP overlay systems.

4. The designer should check the International Conference of Building Officials (ICBO) reports of both FRPs used in this report to ensure that they pass the fire rating in the interior face of walls. (Flame-spread coatings must satisfy fire code requirements.) 


\section{References}

ACI ITG/T1.1. 1999. Acceptance criteria for moment frames based on structural testing (ACI ITG/T1.1-99) and Commentary (ACI ITG/T1.1R-99). Farmington Hills, MI: American Concrete Institute.

Al-Chaar, G. K., and H. A. Hasan. 2002. Dynamic response and seismic testing of CMU walls rehabilitated with composite material applied to only one side, Proceedings of the Institution of Civil Engineers, Structures and Buildings 152(2):135-146.

Applied Technology Council (ATC). 1992. ATC-24, Guidelines for cyclic seismic testing of components of steel structures, Washington, DC: Applied Technology Council.

Berman, J. B., G. K. Al-Chaar, and P. K. Dutta. 2002. Biaxial loading and failure behavior of brick triplets with fiber-reinforced polymer composite upgrades, ERDC/CERL TR-02-7. Champaign, IL: Engineer Research and Development Center, Construction Engineering Research Laboratory (ERDC- CERL).

ElGawady, Mohamed A., Pierino Lestuzzi, and Marc Badoux. 2007. Static cyclic response of masonry walls retrofitted with fiber-reinforced polymers, ASCE J ournal of Composites for Construction. January-February 2007: 50-61.

FEMA-178. 1992. A handbook for seismic evaluation of existing buildings. Redwood City, CA: Federal Emergency Management Agency.

Hamed, E. and O. Rabinovitch. 2007. Out-of-plane behavior of unreinforced masonry walls strengthened with FRP strips. Composites Science and Technology 67:489-500.

Korany, Yasser, and Robert Drysdale. 2006. Rehabilitation of masonry walls using unobtrusive FRP techniques for enhanced out-of-plane seismic resistance, ASCE J ournal of Composites for Construction, May-June 2006: 213-222.

Krawinkler, Helmut, Francisco Parisi, Luis Ibarra, Ashraf Ayoub, and Ricardo Medina. 2001. Development of a testing protocol for wood frame structures, CUREE Publication No. Wo2. Richmond, CA: CUREE.

Structural Engineers Association of Southern California (SEAOC). 1997. SAC testing programs and loading histories. In Standard Method of Cyclic (Reversed) Load Test for Shear Resistance of Framed Walls for Buildings. Whittier, CA: SEAOC.

Velazques-Dimas, J., M. R. Ehsani, and H. Saadatmanesh. 1998. Cyclic behavior of retrofitted URM walls.” In Fiber Composites in Infrastructure, Vol. 1: Proceedings of the Second International Conference on Composites in Infrastructure. 5-7 January: 328-340.

Velazquez-Dimas, Juan I., Mohammad, R. Ehsani, and Hamid Saadatmanesh. 20oo. Out-of-plane behavior of brick masonry walls strengthened with fiber composites. ACI Structural J ournal. May-June: 377-387. 


\section{Acronyms and Abbreviations}

\begin{tabular}{|c|c|}
\hline Term & Spellout \\
\hline $\mathrm{ACl}$ & American Concrete Institute \\
\hline AFRP & aramid fiber-reinforced polymer \\
\hline ASCE & American Society of Civil Engineers \\
\hline ASTM & American Society for Testing and Materials \\
\hline ATC & Applied Technology Council \\
\hline CFCC & carbon fiber composite cable \\
\hline CMU & concrete masonry unit \\
\hline DB & Displacement at bottom of specimen in inches \\
\hline DC & direct current \\
\hline $\mathrm{DH}$ & Horizontal displacement in inches \\
\hline DT & Displacement at top of specimen in inches \\
\hline DV & Vertical displacement \\
\hline ELVDT & LVDT placed on the east side of the specimen \\
\hline ERDC-CERL & $\begin{array}{l}\text { Engineer Research and Development Center, Construction Engineering Re- } \\
\text { search Laboratory }\end{array}$ \\
\hline FEMA & Federal Emergency Management Agency \\
\hline $\mathrm{FH}$ & Horizontal force in kips \\
\hline FME & first major event \\
\hline FRP & Fiber-Reinforced Polymer \\
\hline FVN & Force in the north vertical actuator in kips \\
\hline FVS & Force in the south vertical actuator in kips \\
\hline GFRP & Glass Fiber Reinforced Polymer \\
\hline ID & identification \\
\hline IP & in plane \\
\hline ITG & Innovation Task Group \\
\hline LVDT & Linear Variable Displacement Transducer \\
\hline N/A & not applicable \\
\hline $\mathrm{OP}$ & out of plane \\
\hline $\mathrm{R} / \mathrm{C}$ & reinforced-concrete \\
\hline SAC & Scientific Advisory Committee \\
\hline SEAOC & Structural Engineers Association of Southern California \\
\hline SFC & Super FibaCrete \\
\hline SRG & Strengthening Reinforcement Grid \\
\hline UBC & Uniform Building Code \\
\hline URL & Universal Resource Locator \\
\hline URM & unreinforced masonry \\
\hline WLVDT & LVDT placed on the west side of the specimen \\
\hline WWW & World Wide Web \\
\hline
\end{tabular}




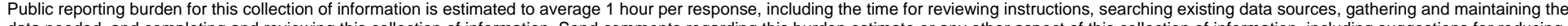

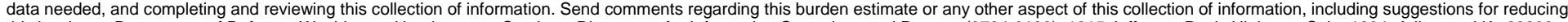

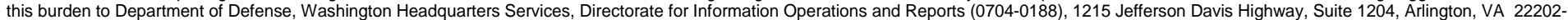

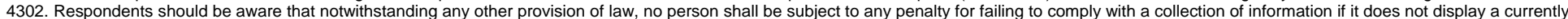
valid OMB control number. PLEASE DO NOT RETURN YOUR FORM TO THE ABOVE ADDRESS.
1. REPORT DATE (DD-MM-YYYY)

\section{REPORT TYPE}

\section{DATES COVERED (From - To)}

17-04-2008

Final

\section{TITLE AND SUBTITLE}

Pseudo Dynamic Testing and Seismic Rehabilitation of Iraqi Brick Bearing and Shear Walls

5a. CONTRACT NUMBER

5b. GRANT NUMBER

5c. PROGRAM ELEMENT

6. AUTHOR(S)

Ghassan K. Al-Chaar, Steven C. Sweeney, Jonathan C. Trovillion,

Orange S. Marshall, and Brendan Danielson

5d. PROJECT NUMBER

Reimbursable Order No.

5e. TASK NUMBER

W81EYN70935664, 53211

5f. WORK UNIT NUMBER

P2 140001

7. PERFORMING ORGANIZATION NAME(S) AND ADDRESS(ES)

U.S. Army Engineer Research and Development Center (ERDC)

Construction Engineering Research Laboratory (CERL)

PO Box 9005,

Champaign, IL 61826-9005

8. PERFORMING ORGANIZATION REPORT NUMBER

ERDC/CERL TR-o8-6

\section{SPONSORING I MONITORING AGENCY NAME(S) AND ADDRESS(ES)}

U.S. Army Corps of Engineers

Los Angeles District
10. SPONSOR/MONITOR'S ACRONYM(S)

11. SPONSOR/MONITOR'S REPORT NUMBER(S)

12. DISTRIBUTION / AVAILABILITY STATEMENT

Approved for public release; distribution is unlimited.

13. SUPPLEMENTARY NOTES

\section{ABSTRACT}

The Iraqi Village Project is a planned training center that will create a realistic training environment to simulate urban warfare in the Middle East. However, the materials, design, and construction methods typical in the Middle East do not provide adequate seismic protection. The Los Angeles District tasked the U.S. Army Engineer Research and Development Center, Construction Engineering Research Laboratory (ERDC-CERL) with developing alternative construction methods consistent with the overall project objectives and to test structural components to determine whether the alternative construction methods are adequate to withstand seismic design loads. ERDC-CERL conducted in-plane cyclic load tests on three double wythe panels and out-of-plane cyclic load tests on 24 double wythe wall strips of the same materials and construction to be used in the project. Unimproved walls and two alternative methods of strengthening were also tested. Elements to be addressed were the lack of adequate in-plane shear strength to resist lateral loads, and the lack of minimum reinforcement within the walls. Two surface applied overlay systems were considered as candidates for mitigating seismic risk. Results of the testing were analyzed and documented, and recommendations were made, including design detailing.

15. SUBJECT TERMS

Iraqui village Project

brick walls seismic testing

fiber-reinforced polymer (FRP)

\begin{tabular}{|l|l|l|}
\hline \multicolumn{2}{|l|}{ 16. SECURITY CLASSIFICATION OF: } \\
\hline $\begin{array}{c}\text { a. REPORT } \\
\text { Unclassified }\end{array}$ & $\begin{array}{c}\text { b. ABSTRACT } \\
\text { Unclassified }\end{array}$ & $\begin{array}{c}\text { c. THIS PAGE } \\
\text { Unclassified }\end{array}$ \\
\hline
\end{tabular}

NSN 7540-01-280-5500

\begin{tabular}{c|c|c}
$\begin{array}{l}\text { 17. LIMITATION } \\
\text { OF ABSTRACT }\end{array}$ & $\begin{array}{c}\text { 18. NUMBER } \\
\text { OF PAGES }\end{array}$ & 196 \\
\cline { 3 - 3 } SAR & 96 & 196 \\
\end{tabular}

Standard Form 298 (Rev. 8-98)

Prescribed by ANSI Std. 239.1 19a. NAME OF RESPONSIBLE PERSON

19b. TELEPHONE NUMBER

(include area code) 